\author{
UNIVERSIDADE DE SÃO PAULO \\ ESCOLA DE ENGENHARIA DE SÃO CARLOS \\ DEPARTAMENTO DE ENGENHARIA ELÉTRICA
}

Daniel Thomazini

CLASSIFICAÇÃO DA HIDROFOBICIDADE EM ISOLADORES

ELÉTRICOS POLIMÉRICOS DE ALTA TENSÃO 

Daniel Thomazini

TESE DE DOUTORADO

\section{CLASSIFICAÇÃO DA HIDROFOBICIDADE EM ISOLADORES ELÉTRICOS POLIMÉRICOS DE ALTA TENSÃO}

Tese apresentada à Escola de Engenharia de São Carlos da Universidade de São Paulo como requisito para obtenção do Grau de Doutor em Engenharia Elétrica.

Área de Concentração: Sistemas Elétricos de Potência

Orientador: Prof. Dr. Ruy Alberto Corrêa Altafim

São Carlos

2009 
AUTORIZO A REPRODUÇÃO E DIVULGAÇÃO TOTAL OU PARCIAL DESTE TRABALHO, POR QUALQUER MEIO CONVENCIONAL OU ELETRÔNICO, PARA FINS DE ESTUDO E PESQUISA, DESDE QUE CITADA A FONTE.

Ficha catalográfica preparada pela Seção de Tratamento da Informação do Serviço de Biblioteca - EESC/USP

Tese (Doutorado-Programa de Pós-Graduação em Engenharia Elétrica e Área de Concentração em Sistemas Elétricos de Potência) -- Escola de Engenharia de São Carlos da Universidade de São Paulo, 2009.

1. Processamento digital de imagens. 2. Isoladores elétricos. 3. Hidrofobicidade. I. Título. 
FOLHA DE JULGAMENTO

Candidato: Engenheiro DANIEL THOMAZINI

Tese defendida e julgada em 23/01/2009 perante a Comissão Julgadora:
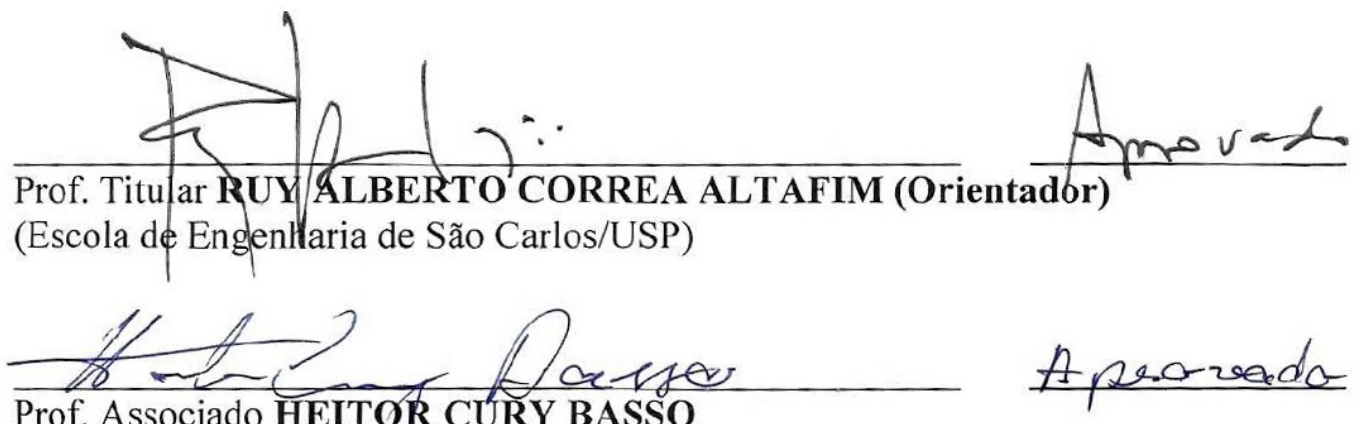

Prof. Associado HEITOR CURY BASSO

(Escola de Engenhariadde São Carlos/USP)

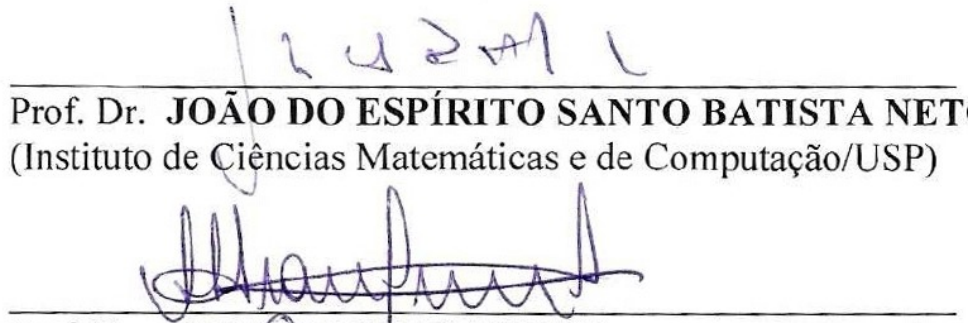

Prof. Dr. ALEXANDRE PIANTINI

(Instituto de Eletrotécnica e Energia/USP)

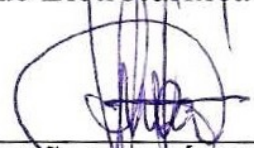

Prof. Dr. JOÃ

(Universidade Estadual de Campina/UNICAMP)
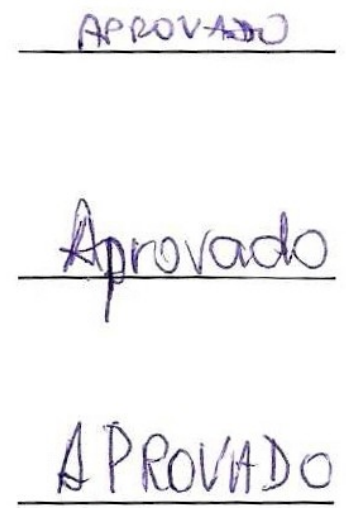

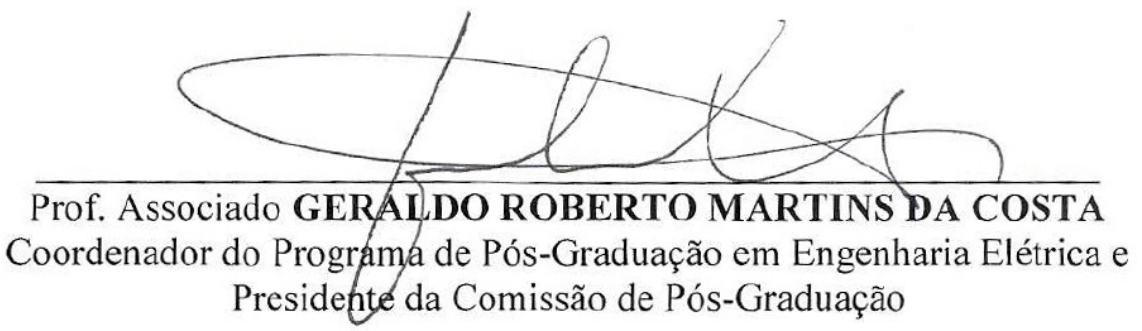


Classificação da hidrofobicidade em isoladores elétricos poliméricos de alta tensão

Vencer não é nada, se não se teve muito trabalho;

fracassar não é nada se se fez o melhor possível.

(Nadia Boulanger, pianista) 


\section{DEDICATÓRIA}

Dedico este trabalho à minha esposa Virginia e aos meus filhos Rafael e Júlia pelo infinito apoio e paciência durante a elaboração deste trabalho. 


\section{AGRADECIMENTOS}

Inicialmente gostaria de agradecer ao Prof. Altafim pelo suporte, incentivo e auxílio durante as etapas do trabalho.

Ao professor do Mestrado em Informática Aplicada da UNIFOR, Francisco Nivando Bezerra pelas aulas e discussões sobre processamento digital de imagens, através das quais foram elucidadas muitas dúvidas.

À Rebeca Gomes Feitosa, do curso de Engenharia de Controle e Automação da UNIFOR, pela ajuda na obtenção das imagens sintéticas e reais.

Ao aluno do curso de Engenharia de Controle e Automação da UNIFOR, Diogo Monte Carvalho, pela colaboração na elaboração dos aplicativos para Palmos $^{\circledR}$ e Windows Mobile ${ }^{\circledR}$

Ao Eng. Fernando Barros Sobreira pelas valiosas dicas de procedimentos de programação.

À Fundação Edson Queiroz - Universidade de Fortaleza (UNIFOR) pelo suporte e incentivo para a realização das disciplinas e pela disponibilização da infraestrutura necessária para a execução dos procedimentos realizados.

Aos Profs. Valéria C. Gelfuso e Cláudio P. Bidurin pelas sugestões para a apresentação e o suporte na produção do trabalho final.

À minha mãe e ao meu irmão (Neto) sempre torcendo por mim.

A todos os outros que direta ou indiretamente contribuíram para a realização deste trabalho. 


\section{PRODUÇÃO CIENTÍFICA}

\section{CONGRESSOS}

THOMAZINI, D.; GELFUSO, M. V.; ALTAFIM, R. A. C., Hydrophobicity Classification of Polymeric materials Based on Fractal Dimension. In: 6th Brazilian MRS Meeting, 2007, Natal. Proceedings of 6th Brazilian MRS Meeting. Rio de Janeiro : SBPMat, 2007.

THOMAZINI, D.; GELFUSO, M. V.; ALTAFIM, R. A. C., Hydrophobicity Classification of Polymer Insulator Based on Mathematical Morphology. In: 2nd Conference on Electrical Engineering, 2007, Coimbra. Proceedings of 2nd Conference on Electrical Engineering, 2007. v. único.

THOMAZINI, D. ; GELFUSO, M. V.; ALTAFIM, R. A. C. . Analyses of Entropy and Fractal Dimension Descriptors to Classify the Hydrophobicity in Polymeric Insulators. In: International Symposium on Electrical Insulating Materials, 2008, Mie, Japão. Proceedings of International Symposium on Electrical Insulating Materials. Tokio: Toshio Shimada, 2008. v. único.

THOMAZINI, D. ; GELFUSO, M. V.; ALTAFIM, R. A. C. . Análise da Hidrofobicidade de materiais isolantes auxiliada pelo processamento digital de imagens. In: $18^{\circ}$ Congresso Brasileiro de Engenharia e Ciência dos Materiais, 2008, Ipojuca - Pe. Anais do $18^{\circ}$ Congresso Brasileiro de Engenharia e Ciência dos Materiais, 2008. v. único.

\section{PERIÓDICOS}

THOMAZINI, D.; GELFUSO, M. V.; ALTAFIM, R. A. C., Hydrophobicity Classification of Polymeric Materials Based on Fractal Dimension, Materials Research, n. 4, v.11, 2008.

THOMAZINI, D.; GELFUSO, M. V.; ALTAFIM, R. A. C., Análise da Dimensão Fractal e Entropia em Imagens Digitais Para Classificação de Texturas Hidrofóbicas, Revista Tecnologia, em impressão, 2009.

\section{PATENTE DEPOSITADA}

MÉTODO DE DETERMINAÇÃO DE HIDROFOBICIDADE EM SUPERFÍCIES E MÉTODO DE AVALIAÇÃO DO ENVELHECIMENTO DE SUPERFÍCIES E SISTEMAS COMPREENDENDO TAIS MÉTODOS, Protocolo INPI nro 018080076268 em 12 de Dezembro de 2008. 


\section{RESUMO}

Este trabalho tem como objetivo propor uma metodologia para a classificação da hidrofobicidade $(\mathrm{HC})$ em isoladores elétricos poliméricos de alta tensão.

Atualmente a HC está baseada no guia da STRI (Swedish Transmission Research Institute) elaborado em 1992. Porém neste guia a hidrofobicidade das superfícies de isoladores é classificada de acordo com o ângulo de contato e/ou a quantidade de superfície molhada com água de forma subjetiva, através de um operador dependurado em uma torre de transmissão.

Desta forma, este trabalho contribuiu na classificação da hidrofobicidade de forma objetiva, onde a análise foi realizada através de processamento digital de imagens. Na metodologia proposta, a HC foi determinada utilizando a análise da textura de imagens obtidas para materiais de isoladores elétricos poliméricos. Essas análises foram avaliadas com base na morfologia matemática, dimensão fractal, entropia, energia, variância e homogeneidade.

Foram simuladas imagens (imagens sintéticas) da textura das superfícies dos isoladores utilizando uma placa de silicone e soluções de álcool isopropílico e água destilada (AIA) em proporções que variaram de 0 até $100 \%$ em volume de álcool. A partir destas soluções foram obtidas imagens de gotas sobre as superfícies, para determinação do ângulo de contato, e imagens da superfície para a obtenção dos padrões das texturas, que serviriam de base para a aplicação dos métodos estudados. 
$\mathrm{Na}$ tentativa de analisar as imagens independente do padrão de iluminação, inerente às condições ambientais, foi aplicado o equalização de histograma (EQU) e/ ou implementado um filtro do tipo White Top-Hat (WTH). Este filtro funciona como um passa-alta, reduzindo o gradiente de iluminação das imagens obtidas em condições naturais. Outro método analisado de forma a eliminar o efeito do gradiente de iluminação, foi através da segmentação usando detecção de borda.

Os cálculos da dimensão fractal das imagens em escala de cinza foram realizados através do método do box-counting, com tamanho do cubo variando de 3 até 11.

A morfologia matemática foi utilizada de forma a qualificar as formas presentes nas imagens. Foram analisadas as derivadas das curvas do volume das imagens de abertura, de forma a identificar o tamanho dos elementos presentes na imagem.

Na classificação das texturas das imagens através dos descritores de textura, os valores obtidos com a entropia apresentaram menor dispersão dentre os resultados, além de baixo tempo de processamento, se apresentando como uma metodologia apropriada para a classificação da hidrofobicidade.

Alteração nos valores de gama das imagens foi feito de forma a observar a modificação dos valores de entropia em função do efeito da iluminação das imagens. Os valores apresentaram pouca variação deste parâmetro nos resultados.

Como forma de avaliar a qualidade da imagem em termos de tamanho, aumento e resolução, diversas imagens foram geradas visando a modificação destes parâmetros e analisando sua influência nos valores de entropia. 
A partir dos resultados obtidos foi possível obter uma relação matemática entre as ferramentas aplicadas e as imagens, sendo possível definir a HC. Utilizando estas técnicas foi determinado o desvio dos resultados e o tempo de processamento, visando a aplicação em dispositivos móveis, como por exemplo celulares.

Assim, foi elaborado um aplicativo embarcado em um smartphone para analisar uma imagem em campo de um isolador, mostrando ao operador o valor da classificação da hidrofobicidade em aproximadamente um minuto.

Palavras-chave: Processamento digital de imagens, isoladores elétricos, hidrofobicidade. 


\section{ABSTRACT}

The aim of this study is to propose a new method to classify the hydrophobicity $(\mathrm{HC})$ in high voltage polymer insulators.

Currently the $\mathrm{HC}$ is based on the STRI Guide(Swedish Transmission Research Institute) published in 1992, where the hydrophobicity is classified by contact angle and/or amount of wet surface.

In the proposed method, the $\mathrm{HC}$ was analyzed by digital image processing using the textures of the images obtained from electric insulators polymeric materials. These analysis were evaluated using mathematical morphology, fractal dimension, entropy, energy, variance and homogeneity.

Simulated texture images (synthetic Images) about the surfaces of the insulators were created using a silicon plate and isopropyl alcohol and distilled water solutions in proportions from 0 to $100 \%$ in volume of alcohol (AIA). From these solutions, images of drops on the insulator surfaces were obtained to measure the contact angle; and surfaces images using the AIA solutions were obtained and then employed in the analysis of the texture patterns, which were used as basis for the analyzed methods.

To analyze the images regardless the illumination conditions, which is a serious problem in natural weather, histogram equalization (EQU) and/or a White Top-Hat filter (WTH) was applied. This filter works as a high-pass filter, reducing the illumination gradient from the images obtained in natural conditions. Another way to 
avoid the gradient illumination was the segmentation technique by edge detection.

The fractal dimension calculations in grayscale images were performed by the box-count method, with box size ranging from 3 to 11 .

Mathematical morphology was used to quantify the shapes in the images. The derivate of the volume from the opening images was analyzed to identify the elements in the image.

The classification of the image texture by the entropy revealed not only the lowest dispersion of the results, but also the shortest time processing, presenting as an appropriated method to classify the hydrophobicity.

Gama alterations in the images was done to observe the entropy values modifications as a function of the illumination effects in the images. The values shown the low influence of this parameter in the results.

To evaluate the image quality regarding to size, zoom and resolution, different images were produced to observe the modification of these parameters and analyze its influence in the entropy values.

From this study was possible to propose a mathematical function which relates the surface hidrophobicity and the texture patterns obtained by the AIA images. Hence, the hidrophobicity classification could be embedded in mobile devices, as example, cell phones, and performed in loco.

A smartphone software was then developed to analyze the surface image of an insulator, producing the hidrophobicity classification value in about one minute.

Key-words: Digital image processing, electrical insulators, hidrophobicity. 


\section{ÍNDICE DE FIGURAS}

Figura 1. Detalhe de um isolador (conjunto vertical de discos) suspendendo uma linha de $275 \mathrm{kV}$ .5

Figura 2. Vista em corte de um isolador de borracha de silicone. 6

Figura 3. Isoladores tipo pino em uma linha de

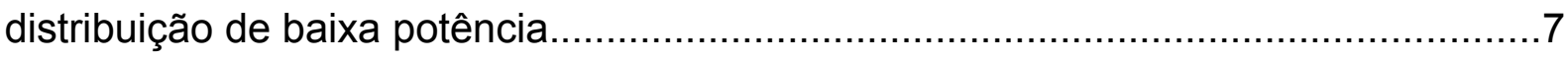

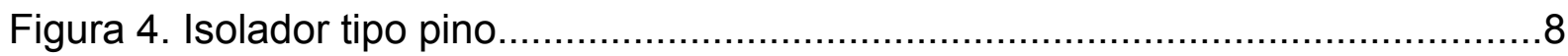

Figura 5. Exemplo da garrafa de spray de água utilizada para ensaio da HC..........14

Figura 6. Ilustração da definição dos ângulos de molhamento................................15

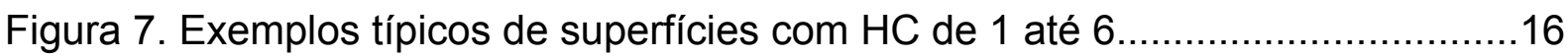

Figura 8. Média da Entropia Normalizada vs HC. Superfícies inclinadas à 10o (linha sólida) e à 35o (linha pontilhada). Adaptado de Berg35........................20

Figura 9. Método de binarização. Imagem a) original e b) binarizada $(T=98) \ldots \ldots \ldots \ldots . .25$

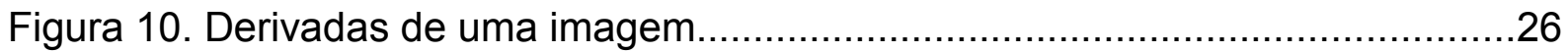

Figura 11: Processo de convolução para filtragem espacial usando uma máscara $3 \times 3$ .27

Figura 12. Processo de convolução usando a máscara Sobel, com a soma dos gradientes em $\mathrm{x}$ e y ........................................................

Figura 13. Processo de convolução usando uma máscara Laplaciano $3 \times 3 \ldots \ldots \ldots \ldots . . .31$

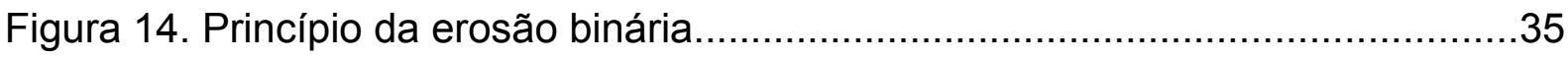

Figura 15. a) Imagem em escala de cinza e b) aplicação da erosão com um elemento estruturante quadrado $2 \times 2$ preenchido.................................................36 
Figura 16. Princípio da dilatação binária.

Figura 17. a) Imagem em escala de cinza e b) aplicação da dilatação com elemento estruturante quadrado $2 \times 2$ completamente preenchido. .38

Figura 18. a) imagem em escala de cinza e b) aplicação da abertura com um elemento estruturante quadrado $2 \times 2$ completamente preenchido. 39

Figura 19. Exemplo de uma curva granulométrica obtida por morfologia matemática. Adaptado de Prodanova43.

Figura 20. a) imagem em escala de cinza e b) aplicação do fechamento com um elemento estruturante quadrado $2 \times 2$

Figura 21. Processo de correção de iluminação. a) imagem original, b) filtro de abertura e c) a imagem final.

Figura 22. Curva do tempo de processamento em função do tamanho do elemento estruturante (B) para operação de dilatação. Para uma imagem em escala de cinza de 1024 x 1024 . O programa foi escrito em ANSI C e executado em um Intel P-II $450 \mathrm{Mhz}$. Figura adaptada de Soille47.

Figura 23. Ilustração da relação entre os pixels em uma imagem para criação da GLCM

Figura 24. Modelagem de uma imagem no R3. .53

Figura 25. Formulário de abertura das imagens a serem analisadas. 68

Figura 26. Formulário para parametrização e obtenção da imagem com correção de iluminação. .69

Figura 27. Obtenção do valor da entropia da imagem e visualização do histograma. 
Figura 28. Formulário para definição da matriz de convolução para a detecção de bordas. 70

Figura 29. Formulário de obtenção da imagem gerada por detecção de contornos..71

Figura 30. Formulário para parametrização da morfologia matemática 72

Figura 31. Formulário para exibição dos valores obtidos a partir do cálculo da dimensão fractal da imagem original. 72

Figura 32. Imagem de uma gota de água destilada sobre uma superfície plana de borracha de silicone. .73

Figura 33. Imagens obtidas através da detecção de contornos utilizando Sobel em gotas com a) $0 \%$, b) $10 \%$, c) $20 \%$, d) $30 \%$, e) $40 \%$, f) $50 \%$, g) $60 \%$, h) $70 \%$, i) $80 \%$ e j) $90 \%$ AIA sobre uma superfície horizontal. 74

Figura 34. Relação do HC em função da curva da solução AIA vs. ângulo de contato.

Figura 35. Imagens sintéticas utilizadas para validação da metodologia. a) $0 \%$, b) $10 \%$, c) $20 \%$, d) $30 \%$, e) $40 \%$, f) $50 \%$, g) $60 \%$, h) $70 \%$, i) $80 \%$, j) 90 e I) $100 \%$ vol AIA.

Figura 36. Volume e derivada do volume das imagens white top-hat em função do tamanho do elemento estruturante. 78

Figura 37. Tempo de processamento em função do tamanho do elemento estruturante .80

Figura 38. Curvas da Abertura Normalizada em função de B para imagens OR......81 Figura 39. Curvas da Abertura Normalizada em função de B para imagens EQU....82 Figura 40. Curvas da Abertura Normalizada em função de B para imagens WTH41. 
Figura 41. Curvas da Abertura Normalizada em função de B para imagens EQU+WTH41. .83

Figura 42. Curvas da Abertura Normalizada em função de B para imagens $\mathrm{EQU}+\mathrm{WTH} 41+\mathrm{EQU}$

Figura 43. Curvas da derivada da abertura normalizada em função do tamanho do elemento estruturante para as imagens OR. .84

Figura 44. Curvas da derivada da abertura normalizada em função do tamanho do elemento estruturante para as imagens EQU. .85

Figura 45. Curvas da derivada da abertura normalizada em função do tamanho do elemento estruturante para as imagens WTH41 .85

Figura 46. Curvas da derivada da abertura normalizada em função do tamanho do elemento estruturante para as imagens EQU+WTH41 .86

Figura 47. Curvas da derivada da abertura normalizada em função do tamanho do elemento estruturante para as imagens EQU+WTH41+EQU .86

Figura 48. Derivada para $B=3$ da abertura em função das imagens de AIA. 87

Figura 49. Valores da dimensão fractal das imagens com detecção de bordas em função de AIA. .89

Figura 50. Relação entre as soluções de AIA e a dimensão fractal para as imagens OR, EQU, WTH41, EQU+WTH41 e EQU+WTH41+EQU .90

Figura 51. Relação entre a entropia e as imagens de AIA e para as imagens OR, EQU, WTH41, EQU+WTH41, EQU+WTH41+EQU e SOB. .93

Figura 52. Relação entre a energia e as imagens de AIA e para OR, EQU, WTH41, 
Figura 53. Comportamento da variância em função das imagens de AIA e para OR, EQU, WTH41, EQU+WTH41, EQU+WTH41+EQU e SOB. .96

Figura 54. Homogeneidade em função das imagens de AIA para OR, EQU, WTH41, EQU+WTH41, EQU+WTH41+EQU e SOB. .98

Figura 55. Imagem 0\%AIA OR com ajuste de gama nas seguintes condições: a) 10, b) 30, c) 50 , d) 100 , e) 150 e f) 300 . 102

Figura 56. Entropia em função de imagens 0\%AIA OR contendo alterações nos valores de gama. 103

Figura 57. Imagens 0\%AIA com resoluções de a) $200 \times 200$, b) $600 \times 600$ e c) $1000 \times 1000$ 104

Figura 58. Imagens 0\%AIA OR com tamanho de a) 200x200, b) $600 \times 600$ e c) $1000 \times 1000$ 105

Figura 59. Imagens 0\%AIA OR com tamanho de 1800×1800 aumentadas a partir de imagens de a) $200 \times 200$, b) $600 \times 600$ e c) $1000 \times 1000$. 105 Figura 60. Entropia e tempo de processamento em função da resolução, do tamanho e da escala para diferentes tamanhos de imagens. 106

Figura 61. Emulador do smartphone em operação durante a análise de uma imagem. 109 


\section{LISTA DE ABREVIATURAS E SÍMBOLOS}

HC: Hydrophobic Classification;

STRI: Swedish Transmission Research Institute;

IEC: International Electrotechnical Commission;

PDA: Personal Digital Assistent;

$\theta$ : ângulo de contato (molhamento);

$\theta_{a}$ :ângulo de avanço;

$\theta_{r}$ : ângulo de retrocesso;

$\theta_{e}$ : ângulo de contato de equilíbrio;

$\theta_{0}$ : ângulo de contato intrínseco;

$\gamma$. tensão superficial;

$\gamma_{\mathrm{sL}}$ : tensão superficial entre sólido e líquido;

$\gamma_{L v}$ : tensão superficial entre líquido e vapor;

$\gamma_{\text {sv: }}$ tensão superficial entre sólido e vapor;

m: massa da gota;

$g$ : aceleração da gravidade;

$\alpha$ : ângulo de inclinação;

$a$ : área da gota;

l: comprimento da gota;

$f_{c}$ : fator circular;

$f$ : imagem; 
WTH: White Top-Hat;

$\mathrm{T}:$ threshold (limiar; ponto de corte);

$i$ : n-ésima coluna na imagem;

$j:$ n-ésima linha na imagem;

M: altura da imagem;

$N$ : largura da imagem;

$S_{x}$ : operador Sobel na direção X;

$S_{y}$ : operador Sobel na direção Y;

$B$ : elemento estruturante;

$\varepsilon$ : operação morfológica de erosão;

$\delta$ : operação morfológica de dilatação;

$\gamma$ : operação morfológica de abertura;

$\phi$ : operação morfológica de fechamento;

$R$ : conjunto dos números Real;

$d f:$ dimensão fractal;

GLCM: Matriz de co-ocorrência (do inglês Gray-Level Co-occurency Matrix); $d x$ : deslocamento na GLCM;

$\Omega$ : conjunto de valores de escala de cinza;

$\lambda$ : evento;

$p(\lambda)$ : probabilidade de ocorrência do evento $\lambda$;

$S:$ Entropia;

E: Energia; 
$\sigma_{2}:$ Variância;

$m:$ média dos valores de cinza

$H$ : Homogeneidade;

$D_{n}$ : valor associado à uma imagem fracionada $\mathrm{n}$ vezes no $R^{3}$;

$N_{n}$ : número boxes que interceptam a imagem representada;

$b$ : coeficiente angular;

$r$ : coeficiente de correlação de Pearson; 


\section{Sumário}

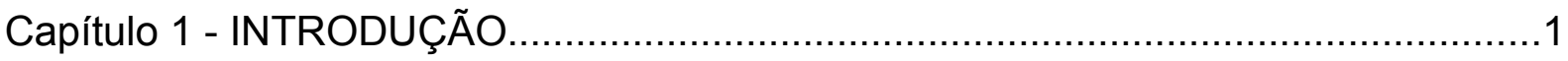

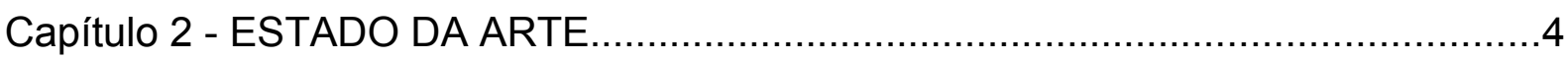

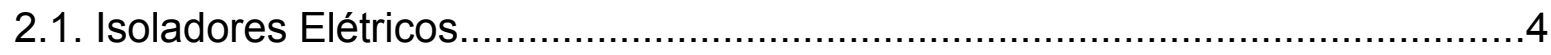

2.1.1. Envelhecimento de Isoladores Elétricos Poliméricos.................................8

2.1.2. Isoladores e a hidrofobicidade no setor elétrico.......................................10

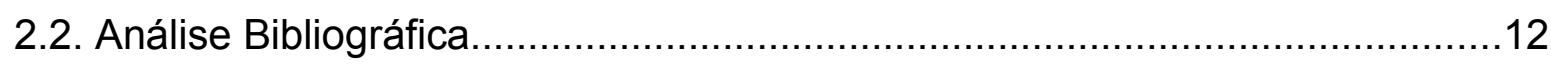

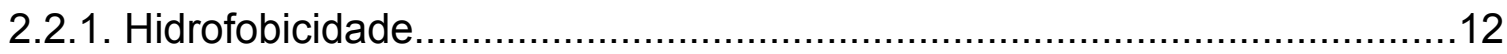

2.2.2. Classificação da hidrofobicidade em isoladores elétricos..........................13

2.2.3. Metodologia de análise da hidrofobicidade em isoladores elétricos..........13

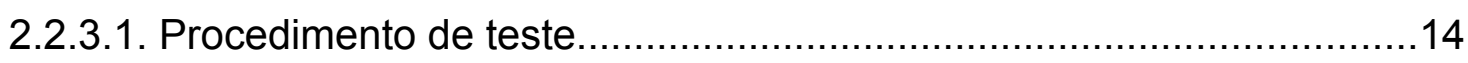

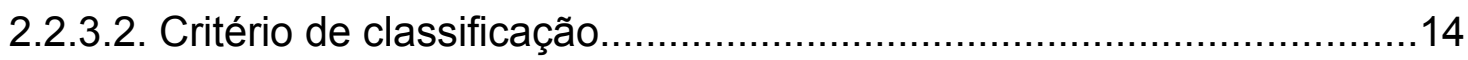

2.2.3.3. Histerese no ângulo de contato......................................................17

2.2.4. Análise de imagens na classificação da hidrofobicidade..........................19

2.2.5. Processamento Digital de Imagens.....................................................21

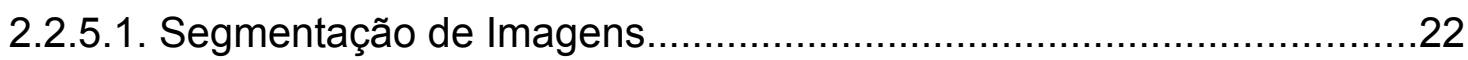

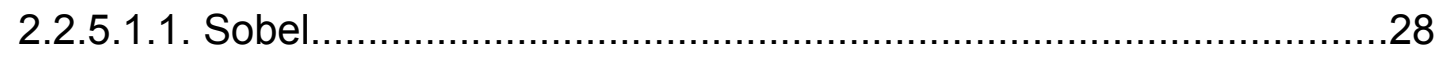

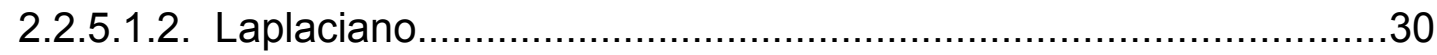

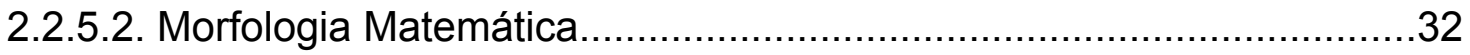

2.2.5.2.1. Comutação com as translações.......................................................33

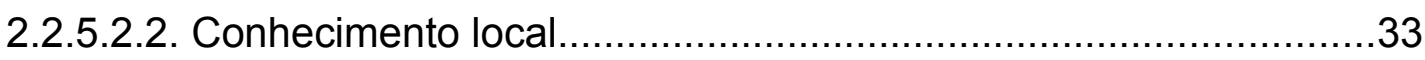

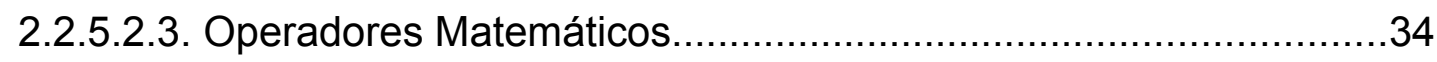




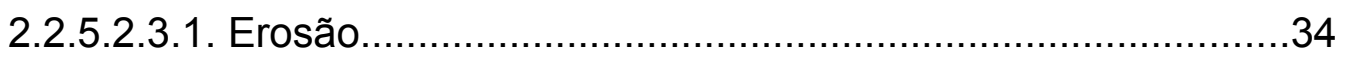

2.2.5.2.3.2. Dilatação........................................................36

2.2.5.2.3.3. Abertura......................................................... 38

2.2.5.2.3.4. Fechamento......................................................... 40

2.2.5.3. Correção de iluminação de imagens.........................................41

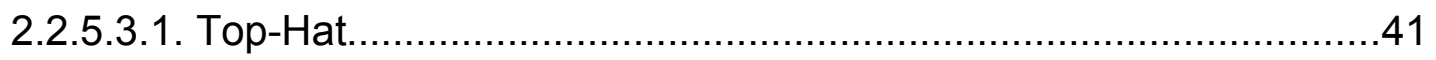

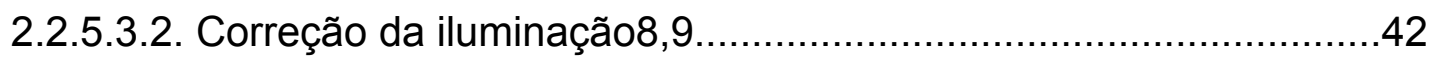

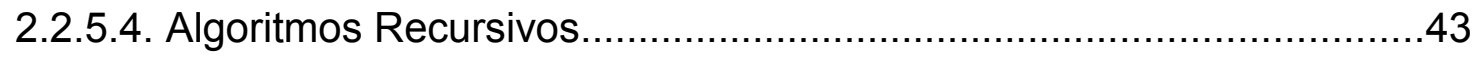

2.2.5.5. Descritores de texturas ......................................................... 45

2.2.5.5.1. Matriz de co-ocorrência em escala de cinza (GLCM).................46

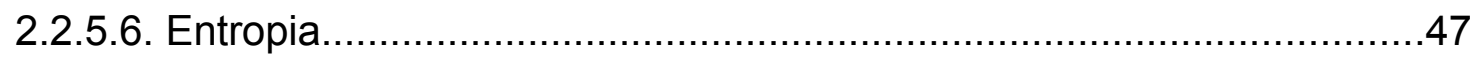

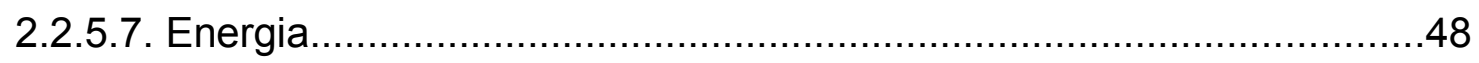

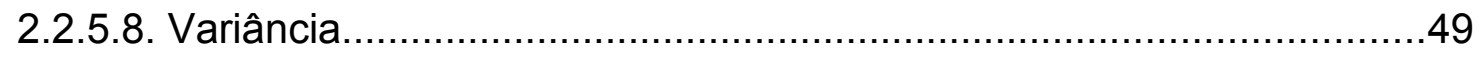

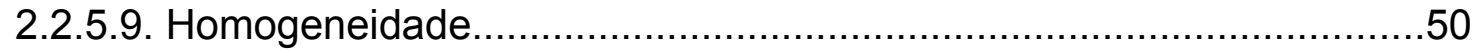

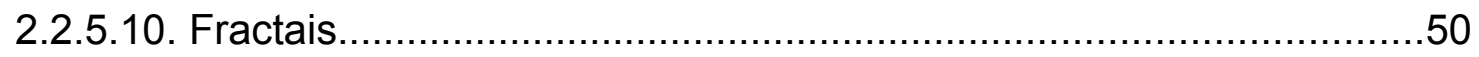

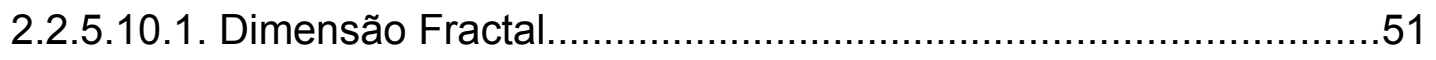

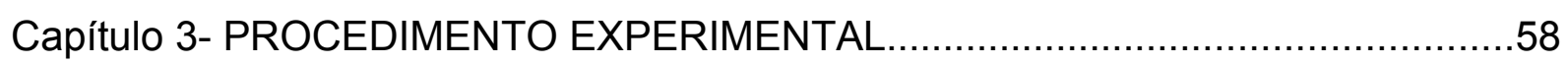

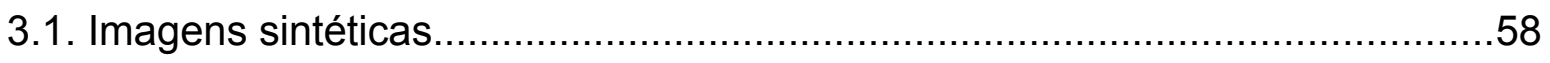

3.1.1. Metodologia para Obtenção de Imagens Sintéticas...............................58

3.1.2. Obtenção das curvas de abertura e fechamento nas imagens do guia da

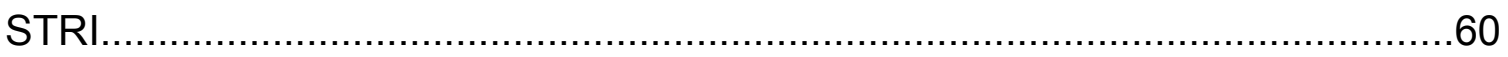

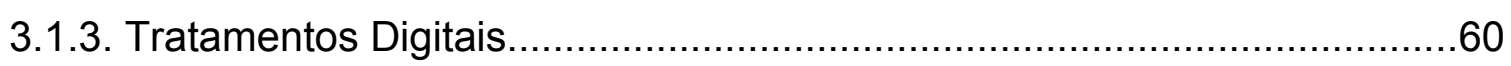

3.1.4. Análise da variação no gama das imagens.....................................61 
3.1.5. Análise de resolução, escala e tamanho das imagens.

3.2. Desenvolvimento do Aplicativo para Microcomputadores.

3.2.1. Algoritmo para detecção de bordas através de matrizes de convolução. .62

3.2.2. Algoritmo para determinação da HC utilizando binarização e morfologia matemática.

3.2.3. Algoritmo para cálculo da dimensão fractal. 64

3.2.4. Determinação da Entropia, Energia, Variância e Homogeneidade das imagens. .65

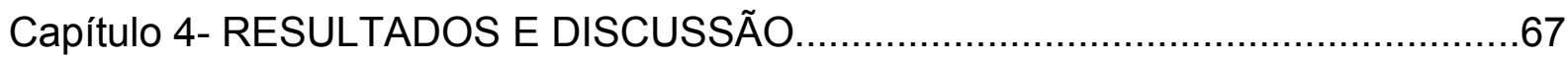

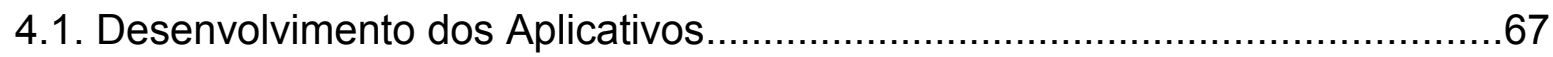

4.1.1. Aplicativo de validação no microcomputador..................................67

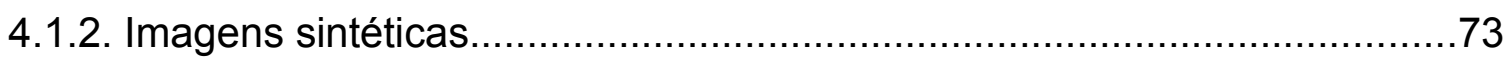

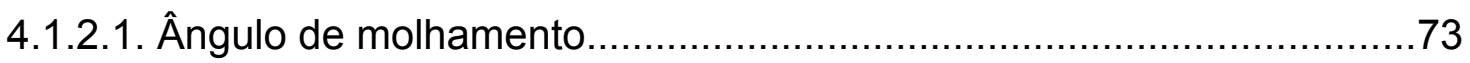

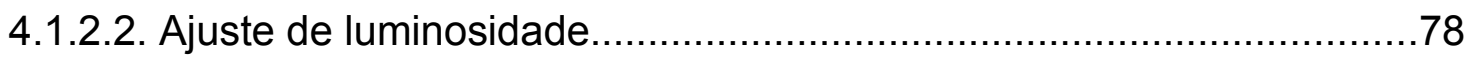

4.1.2.3. Análise por Morfologia Matemática...............................................79

4.1.2.3.1. Avaliação do tempo de processamento................................79

4.1.2.3.2. Avaliação das imagens por morfologia matemática.....................80

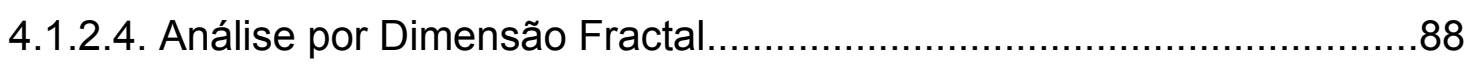

4.1.2.4.1. Imagens com detecção de bordas por Sobel..............................89

4.1.2.4.2. Imagens em escala de cinza..............................................90

4.1.2.5. Descritores de Texturas................................................... 91

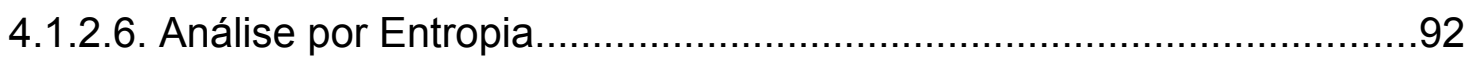

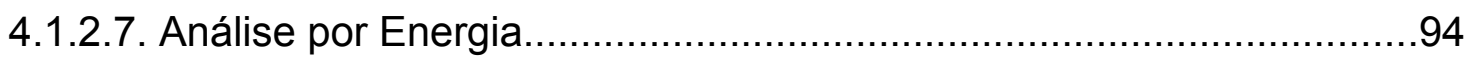


4.1.2.8. Análise por Variância.................................................................96

4.1.2.9. Análise por Homogeneidade..............................................98

4.1.2.10. Definição do método a ser utilizado para classificação da

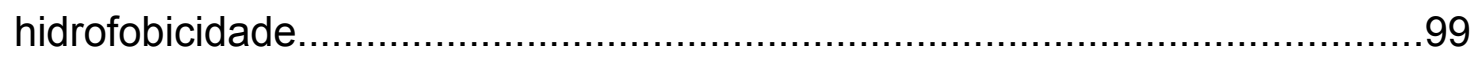

4.1.2.11. Comportamento dos valores da entropia em função da alteração da luminosidade das imagens. .101

4.1.2.12. Resultados de entropia para diferentes resoluções, escalas e tamanhos de imagens .103

4.1.2.13. Modelo para Classificação da Hidrofobicidade. 107

4.1.2.14. Aplicativo embarcado em dispositivo móvel para determinação da hidrofobicidade. 108

Capítulo 5- CONCLUSÕES. 


\section{Capítulo 1 - INTRODUÇÃO}

Nas últimas décadas alguns pesquisadores têm dado atenção à utilização de novos materiais para serem utilizados em isoladores elétricos de alta tensão ${ }^{1,2,3}$. Alguns exemplos de materiais utilizados em isoladores elétricos são porcelana, borracha de silicone, poliuretana, epóxi, mica e vidro. De maneira geral, os isolantes poliméricos têm sido empregados em diversas aplicações, em função do baixo custo de fabricação e fácil moldagem.

A poliuretana, resinas de epóxi e polímeros a base de silicone começaram a ser utilizados nas décadas de 60 em aplicações de média e alta tensão ${ }^{4}$, devido a sua estabilidade química e alta resistência às intempéries.

Estes materiais naturalmente apresentam grande repulsividade à água porque apresentam baixa energia de superfície, devido a presença de grupos metil na superfície $^{5}$, ou seja, são naturalmente hidrofóbicos. Esta propriedade é amplamente desejada na aplicação destes materiais como isoladores elétricos pois, impedem a formação de um caminho para a corrente elétrica, permitindo que o isolador possa 
ser aplicado em maiores tensões provenientes de descargas disruptivas ${ }^{6}$. Entretanto apresentam a desvantagem de serem facilmente suscetíveis ao envelhecimento por irradiação UV a qual degrada sua superfície, reduzindo sua hidrofobicidade.

A hidrofobicidade pode ser determinada de várias formas, utilizando o processamento de imagens, tendo como base o guia da STRI (Sweden Transmission Research Institute). Porém, este guia aborda a classificação de uma forma parcialmente empírica, não sendo observado, até então, um modelamento desta propriedade.

Em contrapartida existem procedimentos para emulação das diferentes classes de hidrofobicidade a partir da norma IEC $60507^{7}$, que regulamenta testes de poluição artificial em isoladores de alta tensão para serem utilizados em sistemas de corrente alternada (AC). Porém, o método de classificação proposto pela STRI é amplamente utilizado pela facilidade de execução em campo.

Desta forma, a partir deste trabalho foi proposta uma metodologia de classificação da hidrofobicidade $(\mathrm{HC})$ baseada em texturas geradas através do borrifamento de soluções compostas pela mistura de álcool isopropílico e água (AIA), sobre a superfície de borracha de silicone. Neste estudo, a análise da textura das imagens foi feita com a utilização dos recursos fornecidos pela morfologia matemática, dimensão fractal e descritores de texturas, como entropia, energia, variância e homogeneidade, utilizando matriz de co-ocorrência. Estas ferramentas foram selecionadas pois estes métodos são clássicos na literatura e fornecem parâmetros quantitativos na avaliação da textura de imagens ${ }^{8,9}$. Assim, são propostos modelos matemáticos para classificar a hidrofobicidade, que podem ser 
relacionados aos critérios expostos pela STRI.

Portanto, o objetivo deste trabalho foi desenvolver uma ferramenta baseada no processamento digital de imagens para avaliação da hidrofobicidade de isoladores elétricos poliméricos de alta tensão.

Com a finalidade de disponibilizar uma ferramenta para avaliação da $\mathrm{HC}$, foi desenvolvido um aplicativo para microcomputador. A partir dos melhores resultados, com relação à correlação e tempo de processamento, um aplicativo para dispositivo móvel foi desenvolvido visando a aplicação desta ferramenta in-loco, ou seja, no campo. Assim, será possível obter a imagem e o resultado da avaliação da HC, evitando a avaliação subjetiva do operador.

No capítulo 2 são descritos os conhecimentos relacionados aos isoladores elétricos, hidrofobicidade e as ferramentas computacionais para o processamento digital de imagens. No capítulo 3 são abordados os procedimentos experimentais realizados para execução do trabalho. Os resultados são mostrados e discutidos no capítulo 4 . O capítulo 5 apresenta as conclusões e finalmente são apresentadas as referências bibliográficas. 


\section{Capítulo 2 - ESTADO DA ARTE}

Neste capítulo será realizada uma revisão sobre os tipos de isoladores elétricos e os conceitos associados a eles como envelhecimento, hidrofobicidade e métodos de classificação no setor elétrico. Serão mostrados alguns resultados e procedimentos experimentados por outros pesquisadores, para classificar a hidrofobicidade em isoladores elétricos. Como este trabalho está baseado na análise da textura de imagens, os conceitos fundamentais sobre ferramentas computacionais como morfologia matemática, fractal, entropia, energia, variância e homogeneidade serão abordados.

\subsection{Isoladores Elétricos}

Um isolador elétrico é um dispositivo utilizado para garantir o isolamento elétrico de fios ou cabos energizados, entre seus pontos de sustentação adjacentes. Exige-se, portanto, que o isolador possua uma grande capacidade de se opor à passagem de corrente elétrica, além de elevada resistência mecânica ${ }^{10}$. 
Isoladores de alta tensão, usados para transmissão de altas potências, podem ser feitos de vidro, porcelana ou materiais compósitos poliméricos. Isoladores de porcelana são feitos de argila, quartzo e feldspato. Alumina e feldspato são utilizados para formar um vidrado que recobre o isolador, facilitando o espalhamento da sujeira. Isoladores de porcelana ricos em alumina são utilizados onde a alta resistência mecânica é necessária. Isoladores de vidro são usados para suspender linhas elétricas de alta potência. Alguns fabricantes de isoladores pararam de fabricar isoladores de vidros na década de 60, substituindo-os por materiais cerâmicos, e mais recentemente por materiais compósitos. A Figura 1 mostra um isolador em uma torre, suportando uma linha de transmissão de energia elétrica.

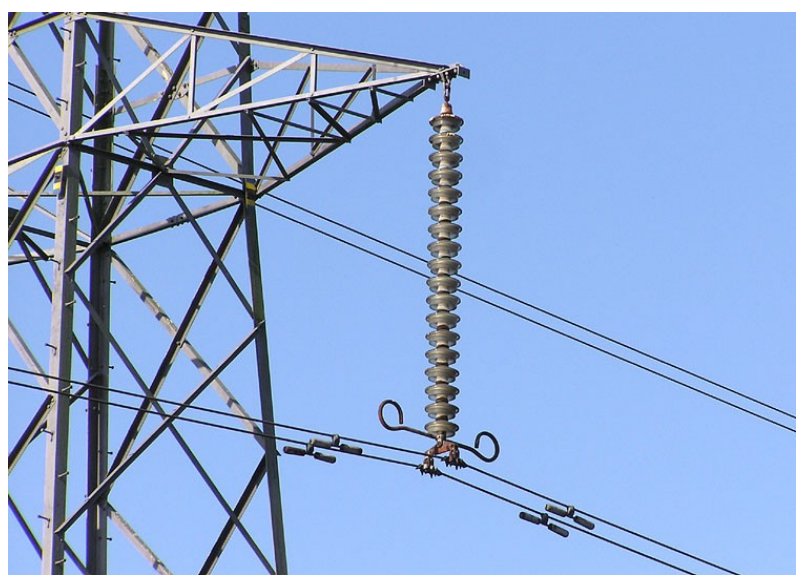

Figura 1. Detalhe de um isolador (conjunto vertical de discos) suspendendo uma linha de $275 \mathrm{kV}$.

Recentemente, alguns dispositivos elétricos passaram a ser confeccionados a base de compósitos, constituídos em alguns casos de um tubo central de plástico reforçado com fibras e um revestimento externo resistente às intempéries feito de borracha de silicone ou EPDM (Ethylene Propilene Diene Monomer). Isoladores 
compósitos são mais baratos, leves e têm excelente capacidade hidrofóbica. Esta combinação os tornam ideais para serviços em áreas poluídas. Contudo, estes materiais ainda não têm um vida útil tão longa quanto os vidros e porcelanas, pois sofrem degradação pelas condições climáticas. A figura 2 ilustra o aspecto construtivo de um isolador de borracha de silicone.

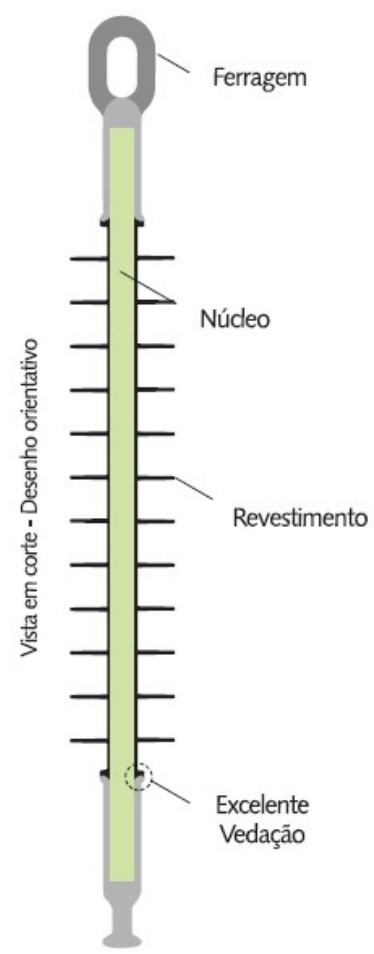

Figura 2. Vista em corte de um isolador de borracha de silicone.

Isoladores de porcelanas com vinte discos, ou saias, pesam aproximadamente $40 \mathrm{~kg}^{11}$, de vidro $92 \mathrm{~kg}^{12}$, enquanto que um isolador de borracha de silicone pesa $2,9 \mathrm{~kg}^{13}$. Assim, a aplicação de isoladores poliméricos tem sido implementada pois, além que requerer estruturas de sustentação menos robustas, facilitam a exaustiva manutenção por substituição. 
Os primeiros isoladores de vidro usados comercialmente em larga escala, tinham um furo não tratado, ou seja, a conexão entre o vidro e o parafuso sofre um processo de selamento para evitar a entrada de umidade, reduzindo as quebras dos isoladores. Estas peças de vidro eram posicionadas sobre um pino de madeira, na cruzeta do poste (comumente apenas dois isoladores para um pólo). A expansão e retração natural das dimensões dos fios, amarrados a estes isoladores resultavam em peças desencaixadas dos seus pinos, sendo necessária manutenções periódicas. A figura 3 mostra os isoladores de pinos atualmente utilizados apenas em linhas de distribuição de baixa potência.

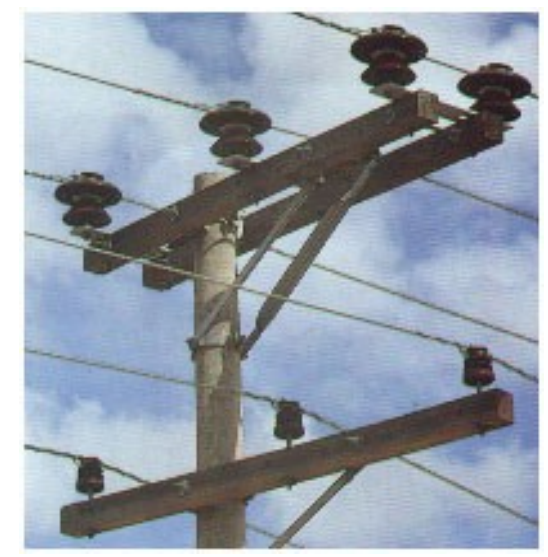

Figura 3. Isoladores tipo pino em uma linha de distribuição de baixa potência.

As primeiras companhias a produzirem isoladores cerâmicos no Reino Unido foram a Stiff and Doulton, utilizando cerâmica sanitária nos meados da década de 1840; Joseph Bourne, na década de 1860 e a Buller, em 1868 com a patente 48906 de 25 de julho de 1865, para a fabricação de um isolador com o furo tratado. Atualmente, os isoladores ainda têm os furos tratados. 
Posteriormente, com a invenção dos isoladores suspensos, foi possível fazer a transmissão de altas tensões, enquanto que os isoladores de pino, visto na figura 4, não são favoráveis para tensões acima de 40.000 volts.

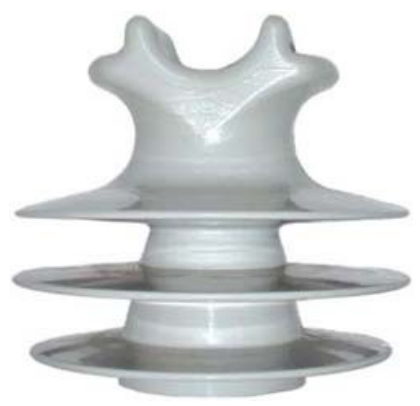

Figura 4. Isolador tipo pino.

\subsubsection{Envelhecimento de Isoladores Elétricos Poliméricos}

Fotodegradação e intempéries sobre materiais poliméricos causam bilhões de dólares em danos nos produtos e em sistemas de potência a cada ano ${ }^{14}$. Danos em isoladores incluem mudanças de cor, perda de resistência mecânica, fraturas, riscos, erosão e abertura de arcos elétricos.

Para definir o tipo de isolador adequado é necessário conhecer o processo de corrosão do isolador sob as condições de campo. A degradação é mais intensa quando há mudanças abruptas de temperaturas diárias, chuvas, insolação e maresia.

O estado do Ceará, localizado abaixo da linha do Equador, se encontra em pleno desenvolvimento industrial. É banhado por aproximadamente $600 \mathrm{~km}$ de extensão de mar e, conseqüentemente, sofre influências causadas pela maresia, poluição industrial, alta umidade relativa do ar elevada intensidade de radiação solar. 
Assim sendo, está submetido a distintos microclimas.

Em 2003 foi realizado um estudo ${ }^{15}$ abordando a corrosão e degradação atmosférica de materiais elétricos. Foi realizada a instalação de 18 Estações de Corrosão Atmosférica para a elaboração de um mapa de classificação da agressividade atmosférica do Ceará, em relação ao comportamento de diversos tipos de materiais, metálicos e não metálicos, utilizados no sistema elétrico. Este trabalho gerou a formação do centro de excelência de corrosão e tratamentos anticorrosivos, contando com infra-estrutura física e profissionais capacitados para estudar os problemas, gerando conhecimentos aplicados às condições específicas do Nordeste. A partir deste estudo foi observado que a degradação dos isoladores poliméricos não teve forte influência da ação dos agentes presentes na atmosfera do Ceará, em comparação aos estudos realizados em outros estados brasileiros.

Em um outro estudo ${ }^{16}$, isoladores poliméricos de $15 \mathrm{kV}$, de vários tipos, foram submetidos ao envelhecimento acelerado em névoa salina por 1000 horas. As propriedades superficiais dos isoladores foram avaliadas através da caracterização dos materiais antes e depois do envelhecimento. Foram feitas inspeções visuais, medidas do ângulo de contato, microscopia eletrônica de varredura e espectroscopia de infravermelho. Os resultados mostraram que nestes ensaios de duração relativamente curta não ocorrem erosão ou trilhamento visíveis. Contudo, em nível microscópico ocorre um processo de erosão (microerosão) que pode comprometer o desempenho do material em campo. 


\subsubsection{Isoladores e a hidrofobicidade no setor elétrico}

Diante da crescente demanda no consumo de energia elétrica, se faz necessária a ampliação do sistema de geração, transmissão e distribuição de energia elétrica mundial. Em função do maior número de linhas de fornecimento, a possibilidade da interrupção se torna cada vez maior, o que faz com que as companhias de energia elétrica busquem medidas para reduzir estas inconveniências. Um dos fatores que contribuem para a interrupção no fornecimento de energia elétrica é a falha no isolamento das linhas de transmissão, que pode ser causada pela diminuição da hidrofobicidade nos isoladores elétricos.

A hidrofobicidade é definida como repulsão de um filme de água sobre uma superfície. Quando uma superfície hidrofóbica é molhada, a água tende a formar gotas discretas, não se espalhando pela superfície. Quando uma superfície hidrofílica é molhada, a água não é repelida por ela sendo formado um filme que a recobre. No caso de um dispositivo elétrico, deseja-se uma superfície hidrofóbica, para que a água não seja um caminho de baixa resistência elétrica que provoque a ocorrência de descargas disruptivas ${ }^{17}$.

A hidrofobicidade dos polímeros confere aos isoladores maiores níveis de suportabilidade. Assim podem ser produzidos dispositivos mais compactos e mais baratos, ao contrário de isolantes confeccionados com materiais hidrofilicos como vidro ou porcelana. Através do guia para classificação de hidrofobicidade $(\mathrm{HC})$ da STRI ${ }^{18}$, pode ser observada a diferença de $30 \%$ na tensão de flashover (descarga elétrica sobre ou ao redor do isolador entre dois ou mais condutores adjacentes) sob chuva e $60 \%$ sob névoa limpa em isoladores de mesma geometria, diferindo apenas 
no material polimérico de recobrimento.

Desta forma os polímeros têm sido a solução de maior interesse em isoladores elétricos de alta tensão para ambientes externos. No Japão, onde importantes linhas de transmissão estão localizadas na costa, isoladores poliméricos estão sendo aplicados ${ }^{6}$.

Apesar destas vantagens, os materiais poliméricos são susceptíveis ao envelhecimento causado pelas influências climáticas ${ }^{19}$, ao contrário do vidro e da porcelana. Ainda que os isoladores apresentem superfície hidrofóbica, ao decorrer do tempo esta propriedade se altera parcialmente ou totalmente ${ }^{3,20,21}$. Assim, os isoladores são projetados para aplicações em casos extremos ${ }^{1}$. Isso mostra que as vantagens do uso de isoladores poliméricos, ao contrário dos de vidro e porcelana, ainda não estão bem explorados. Por essa razão, existem alguns estudos que propõem novas técnicas para o sensoriamento remoto de isoladores quanto ao seu estado superficial ${ }^{22,23,24}$.

Pode-se dizer que o envelhecimento em isoladores elétricos causa problemas operacionais em subestações que operam em altas tensões. Pelo aspecto econômico é necessário que se mantenha um sistema operando sem interrupções pois, com o crescimento do sistema elétrico, ele se torna vulnerável à falhas ${ }^{14}$. No caso específico de linhas de transmissão, a severidade das condições de sobretensões a que são submetidas em serviço é intensificada por fatores externos como chuva, névoa, poeira, maresia, e isso pode provocar a interrupção do fornecimento de energia elétrica ${ }^{1}$. O conjunto destes fatores, associado à redução dos níveis de hidrofobicidade, causam o aumento do risco de ocorrências de 
interrupção no abastecimento de energia pela ruptura do isolamento. Assim, uma técnica eficiente capaz de avaliar a hidrofobicidade nestes isoladores deve ser utilizada para investigar ou prever estas ocorrências.

\subsection{Análise Bibliográfica}

Neste item será apresentada a revisão bibliográfica de trabalhos realizados até o momento sobre hidrofobicidade, classificação da hidrofobicidade em isoladores poliméricos, metodologia de análise da hidrofobicidade em isoladores elétricos e análise de imagens na classificação da hidrofobicidade. Também são mostradas as ferramentas computacionais utilizadas para a análise de textura de imagens, objeto de estudo deste trabalho.

\subsubsection{Hidrofobicidade}

A hidrofobicidade é uma propriedade físico-química utilizada em diferentes áreas da química, medicina e farmacologia. É um indicador importante do transporte e permeabilidade através de membranas, interações com receptores biológicos e enzimas, toxicidade e potencial biológico ${ }^{25,26}$. Nas ciências do ambiente, a hidrofobicidade é freqüentemente usada para prever a solubilidade, o fator de bioconcentração e o coeficiente de absorção ${ }^{27}$.

No caso dos isoladores elétricos, compósitos ou recobertos, é desejável um alto índice de hidrofobicidade nas suas superfícies para melhorar resultados de desempenho. Porém, esta propriedade pode ser alterada devido à exposição da 
superfície ao ambiente externo e às descargas elétricas (efeito corona) ${ }^{2}$.

\subsubsection{Classificação da hidrofobicidade em isoladores elétricos}

Atualmente as pesquisas na área de hidrofobicidade em isoladores elétricos utilizam a classificação da STRI como referência em seus estudos. Esta classificação é feita em sete divisões (HC1-7), onde $\mathrm{HC} 1$ corresponde à completa hidrofobicidade, ou seja, a superfície não é molhada pela água, e HC7 corresponde à completa hidrofilicidade, ou seja, a superfície é totalmente molhada pela água. Esta metodologia fornece valores discretos para o estado de molhamento das superfícies dos isoladores, sendo de verificação rápida e fácil dos isoladores em campo, porém depende da avaliação subjetivo do operador.

\subsubsection{Metodologia de análise da hidrofobicidade em isoladores elétricos}

O único equipamento de teste necessário para a realização do ensaio da classificação da hidrofobicidade é uma garrafa de borrifamento de líquidos (figura 5), a qual pode produzir uma fina névoa de água destilada. Para complementar o julgamento da classificação, caso necessário, se faz o uso de uma lupa, lâmpada e uma fita de medida. 


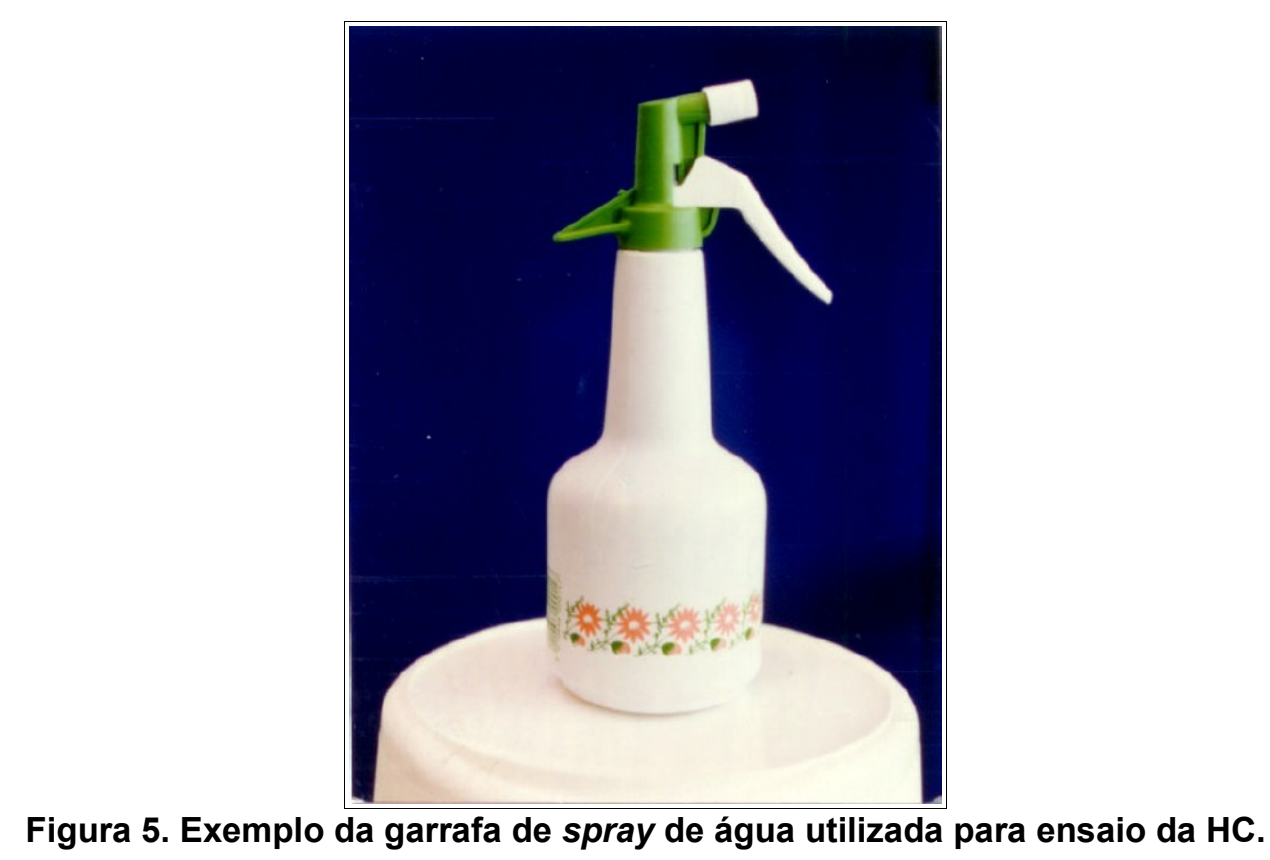

\subsubsection{Procedimento de teste}

A área testada deve ser de 50 até $100 \mathrm{~cm}^{2}$. O spray deve ser aplicado ou uma ou duas vezes por segundo a uma distância de $25 \pm 10 \mathrm{~cm}$. A névoa deve continuar por 20 a 30 segundos. A classificação da hidrofobicidade deve ser feita 10 segundos após a névoa ter sido dispersada.

\subsubsection{Critério de classificação}

O método usualmente utilizado na classificação da hidrofobicidade é o método da gota séssil. Neste método, o ângulo de contato $(\theta)$ entre a gota de água e a superfície, deve ser levado em consideração. Existem dois diferentes ângulos de contato, o de avanço $\left(\theta_{a}\right)$ e o de retrocesso $\left(\theta_{r}\right)$. As gotas exibem estes ângulos 
quando estão sobre uma superfície inclinada, conforme ilustrado na figura 6 . 0 ângulo de retrocesso é o mais importante quando se procura as propriedades de molhamento de um isolador. Na tabela 1 estão descritos os critérios para a classificação da hidrofobicidade.

Tabela 1: Critério para Classificação da Hidrofobicidade (HC).

\begin{tabular}{|c|l|}
\hline HC & \multicolumn{1}{|c|}{ Descrição } \\
\hline \hline 1 & $\begin{array}{l}\text { Formação de gotas discretas. } \\
\theta_{r} \cong 80^{\circ} \text { ou maior para a maioria das gotas. }\end{array}$ \\
\hline 2 & $\begin{array}{l}\text { Formação de gotas discretas. } \\
50<\theta_{r}<80^{\circ} \text { para a maioria das gotas. }\end{array}$ \\
\hline 3 & $\begin{array}{l}\text { Formação de gotas discretas. } \\
20<\theta_{r}<50^{\circ} \text { para a maioria das gotas. Normalmente não } \\
\text { apresentam mais o formato circular. }\end{array}$ \\
\hline 4 & $\begin{array}{l}\text { Formação de gotas discretas e traços de água }\left(\theta_{r} \cong 0^{\circ}\right) . \\
\text { Áreas completamente molhadas }<2 \mathrm{~cm}^{2} . \text { Área total molhada }< \\
9 \mathrm{~cm}^{2} .\end{array}$ \\
\hline 5 & $\begin{array}{l}\text { Algumas áreas completamente molhadas }>2 \mathrm{~cm}^{2}, \text { recobrindo } \\
90 \% \text { da área testada. }\end{array}$ \\
\hline 6 & $\begin{array}{l}\text { Áreas molhadas recobrem }>90 \% \text { da área testada, ou seja, } \\
\text { pequenas áreas não molhadas são observadas. }\end{array}$ \\
\hline 7 & Filme de água contínuo sobre toda a área testada. \\
\hline
\end{tabular}

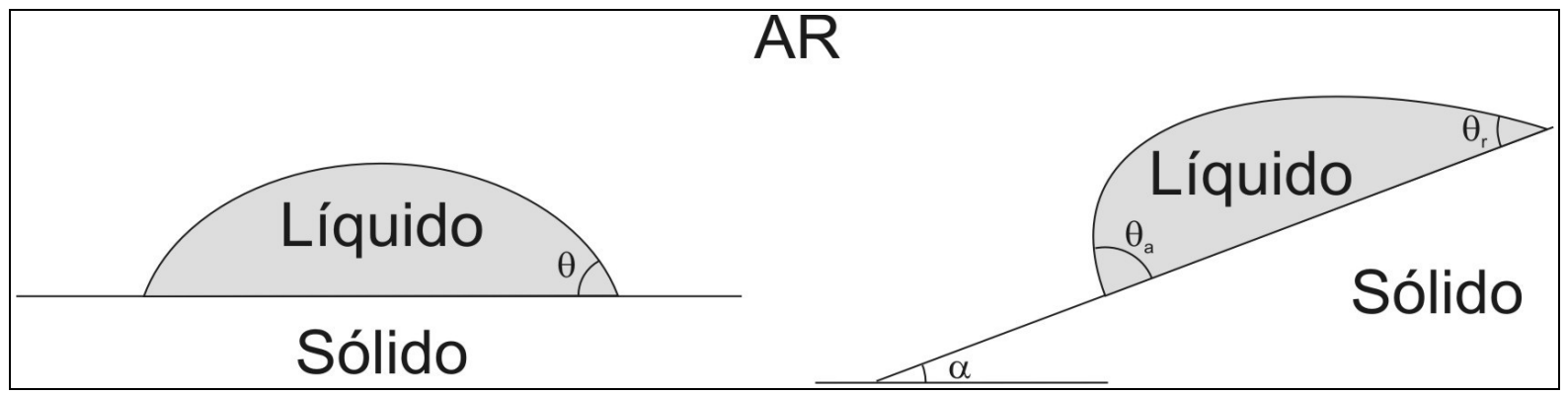

Figura 6. llustração da definição dos ângulos de molhamento.

A aparência de molhamento do isolador deve ser identificada dentre uma das sete classes de hidrofobicidade, que compõem o guia da STRI, mostradas na figura 7. 


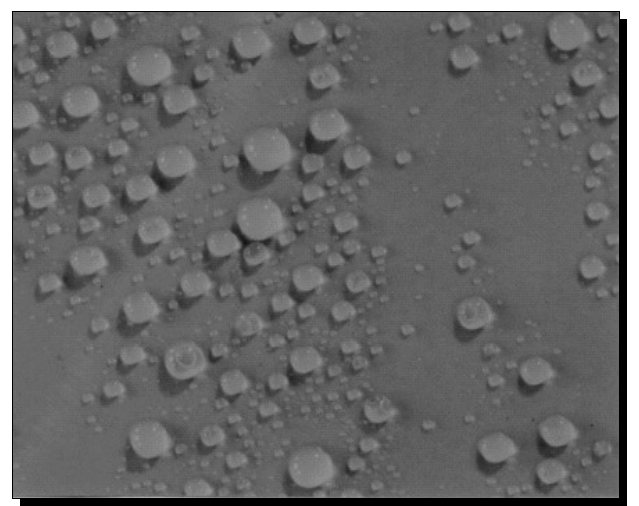

$\mathrm{HC} 1$

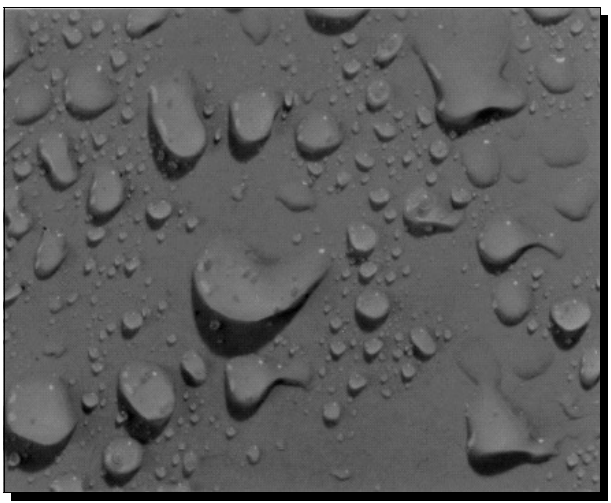

$\mathrm{HC} 3$

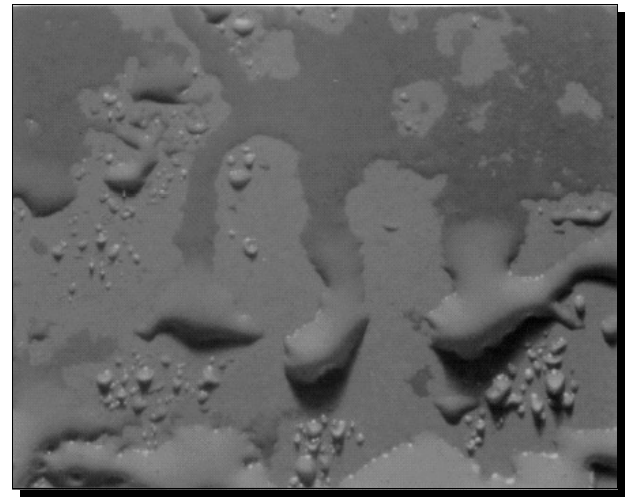

$\mathrm{HC} 5$

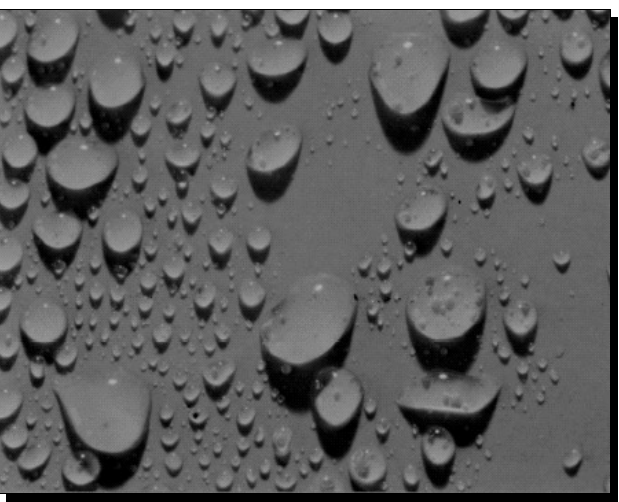

$\mathrm{HC} 2$

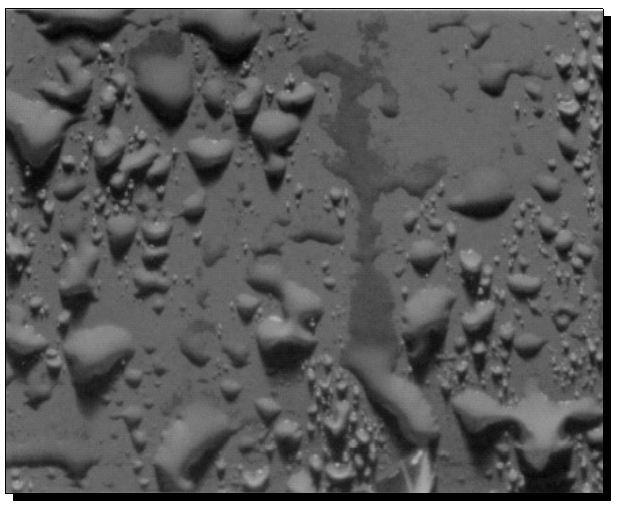

$\mathrm{HC} 4$

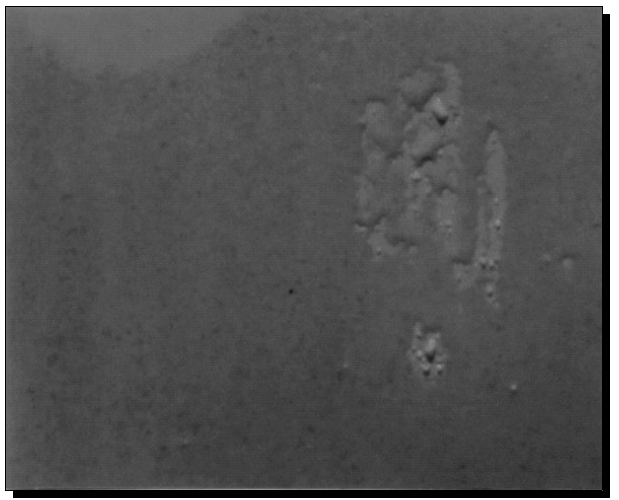

HC6

Figura 7. Exemplos típicos de superfícies com HC de 1 até 6.

A norma internacional IEC 62073 TS Ed. 1.0 (Guia para medida da molhabilidade da superfície de isoladores elétricos) determina três métodos para a 
determinação da HC: Método A - ângulo de contato; Método B - tensão superficial; e Método C - spray.

\subsubsection{Histerese no ângulo de contato ${ }^{28}$}

Uma gota de líquido depositada sobre uma superfície pode apresentar um estado de equilíbrio estável (menor estado de energia), ou metaestável (energia separando vizinhanças por barreiras de energia). O ângulo de contato de equilíbrio $\left(\theta_{e}\right)$ é observado quando um sistema se encontra no menor estado de energia. Considerando uma superfície idealmente lisa e de composição homogênea, o ângulo de contato é o ângulo de contato intrínseco $\left(\theta_{0}\right)$. O $\theta_{0}$ é determinado através das várias tensões interfaciais determinado pela equação de Young (eq. 1):

$$
\gamma_{\mathrm{LV}} \cos \theta_{0}=\gamma_{\mathrm{sv}}-\gamma_{\mathrm{sL}}
$$

eq. 1

onde $\gamma_{\mathrm{Lv}}$ é a tensão superficial de um líquido em equilíbrio com o vapor saturado, $\gamma_{\mathbf{s v}}$ é tensão superficial entre a superfície e o vapor saturado e $\gamma_{\text {sL }}$ é a tensão superficial entre o sólido e o líquido. Uma superfície real é naturalmente rugosa e de composição heterogênea. O ângulo de contato de equilíbrio sobre esta superfície normalmente não é observado experimentalmente. Ao contrário disso, o sistema permanece em estado metaestável, exibindo um ângulo de contato metaestável. Neste caso, os ângulos de avanço e retrocesso são diferentes, isto é conhecido como histerese. A diferença entre os ângulos é a extensão da histerese. O ângulo 
de contato de histerese aumenta com o aumento da rugosidade e da heterogeneidade da superfície. Considerando uma gota de líquido, com um ângulo de contato estável sobre um plano horizontal, e uma superfície idealmente lisa e homogênea. Adicionando uma pequena quantidade de líquido à gota ocorre o avanço desta gota e o mesmo ângulo de contato será mantido. Da mesma forma, retirando-se uma pequena quantidade de líquido da gota, haverá a retração da gota mas, o mesmo ângulo de contato será estabelecido.

Por outro lado, se a superfície é rugosa ou heterogênea, com a adição de líquido, a gota irá crescer sem modificar sua periferia, aumentando o ângulo de contato, neste caso, o ângulo de avanço. Quando uma quantidade de líquido suficiente é adicionada, a gota repentinamente avança com um impulso, atingindo o máximo ângulo de contato. A remoção de líquido faz a gota murchar sem o movimento de sua periferia, e o ângulo de contato se torna menor, neste caso, o ângulo de retrocesso. Quando muito líquido é removido, a gota irá se retrair subitamente e o ângulo no início da súbita retração é o mínimo ângulo de contato de retrocesso. Em laboratório, a hidrofobicidade pode ser investigada pela adição e subtração de líquido de uma gota repousada em uma superfície horizontal, medindose o máximo ângulo de avanço e o mínimo ângulo de retrocesso.

Os ângulos de contato estão relacionados com o ângulo de inclinação conforme a eq. 2.

$$
m g \sin \alpha=L \gamma\left(\cos \theta_{a}-\cos \theta_{r}\right)
$$


onde $\boldsymbol{m}$ é a massa da gota, $g$ é a aceleração da gravidade, $\alpha$ é o ângulo de inclinação da superfície, $L$ é o comprimento da gota e $\gamma$ é a tensão superficial do líquido. Os ângulos $\theta_{a}$ e $\theta_{r}$ no qual a gota começa a descer na superfície inclinada são os ângulos de máximo avanço e mínimo retrocesso, respectivamente. Contudo, se não há histerese, a gota irá descer mais rapidamente na superfície inclinada.

\subsubsection{Análise de imagens na classificação da hidrofobicidade}

Alguns estudos relatam métodos de determinação da classe de hidrofobicidade utilizando análise de imagens obtidas com o molhamento de isoladores elétricos.

Os métodos mais utilizados para classificar a hidrofobicidade são pela análise do tamanho das gotas e do fator circular $\left(f_{c}\right)^{29,30}$. Normalmente estes métodos são complementados por medidas das propriedades dielétricas ${ }^{30,31}$ ou energia de superfície ${ }^{32}$.

Altafim e colaboradores $^{33,34}$ desenvolveram uma metodologia para avaliar a HC através de medidas goniométricas. Nesta técnica, a avaliação do ângulo de contato é realizada por processamento digital de imagem utilizando transformada de Hough.

Berg e colaboradores ${ }^{35,36}$ propuseram uma metodologia para classificar a hidrofobicidade de isolantes de borracha de silicone através da análise de imagens digitais. Eles realizaram a análise das imagens através do MatLab 5.3 com toolbox v.2.2. Nesta metodologia eles analisam os histogramas, utilizam técnica de segmentação por convolução e o desvio padrão devido as diferenças entre os níveis 
de cinza das imagens, entropia escalonada, fração de pequenas diferenças, entropia normalizada e média das entropias normalizadas para superfícies à 10 e $35^{\circ}$. Eles obtiveram os melhores resultados para a média das entropias normalizadas (figura 8).

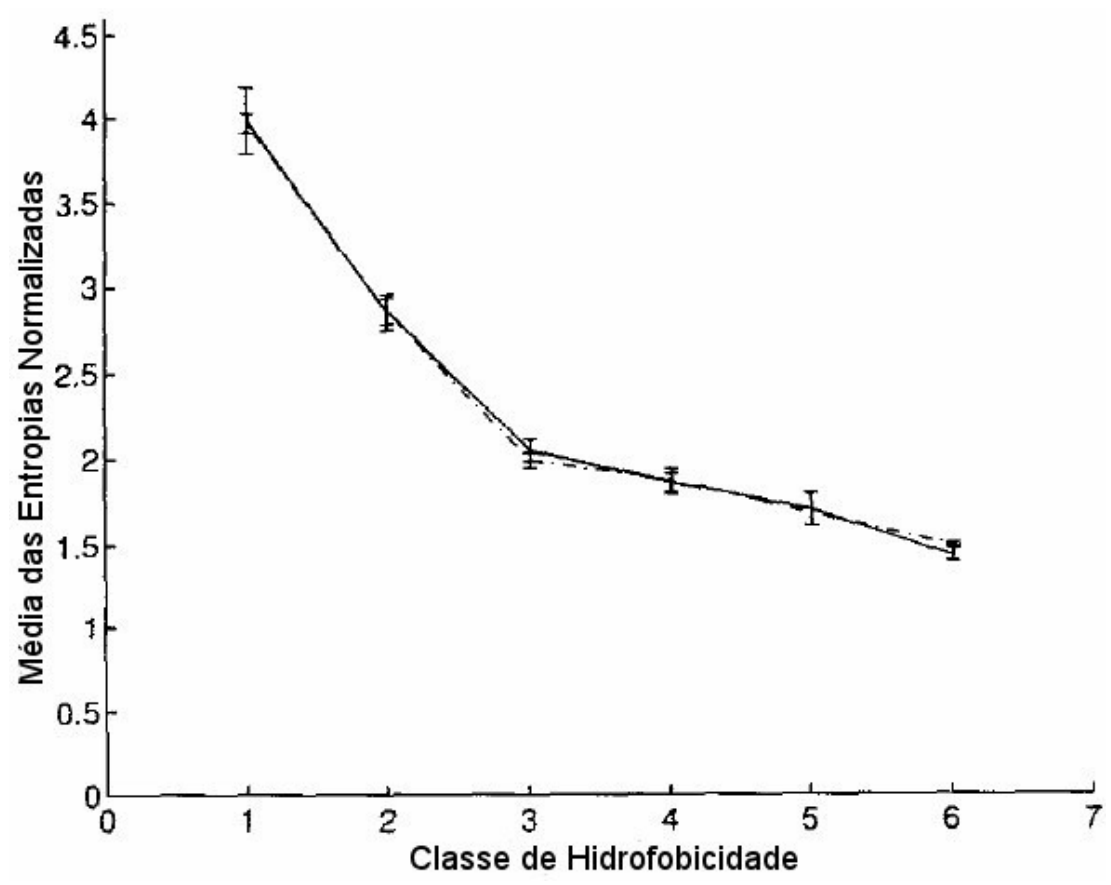

Figura 8. Média da Entropia Normalizada vs HC. Superfícies inclinadas à $10^{\circ}$ (linha sólida) e à $35^{\circ}$ (linha pontilhada). Adaptado de Berg ${ }^{35}$.

Na figura 8 pode ser observado que não houve diferenças na classificação da hidrofobicidade em função da inclinação da superfície, indicando a validade do método empregado. Neste estudo pode ser observado que a inclinação do isolador não interfere na análise da textura por este método, sendo um importante indicativo para o uso do processamento digital de imagens para esta finalidade.

Tokoro $^{29}$ e colaboradores utilizaram método geométrico para classificar a hidrofobicidade nos isoladores elétricos. Eles propuseram a medida do fator médio 
circular que usa o valor da área e da circunferência das gotas, através da seguinte equação:

$$
f_{c}=\frac{4 \pi a}{l^{2}}
$$

onde $a$ é a área da gota e $l$ é o comprimento da borda da gota. Quando a gota apresenta grande deformação, o valor de $f_{c}$ tende a ser pequeno. Baseado nesta observação o autor afirma que o valor do HC pode ser determinado.

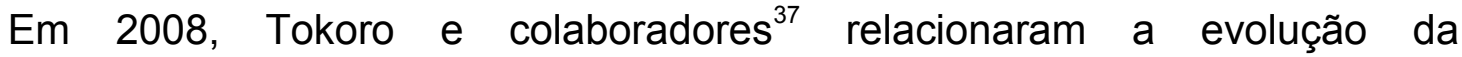
hidrofobicidade com a condição de degradação da borracha de silicone, a partir de imagens digitalizadas e do teste da gota séssil. Neste trabalho foi demonstrado a relação entre o tamanho das gotas e a rugosidade superficial das amostras.

\subsubsection{Processamento Digital de Imagens}

Atualmente o processamento digital de imagens tem sido utilizado em diversas áreas de pesquisa, como análise de vegetação, investigação clínica, fraturas em materiais, análise de texturas, dentre outras. Existem algumas etapas de processamento como a segmentação e binarização, e ferramentas de análise como a morfologia matemática e os descritores de textura. Alguns destes processamentos e ferramentas serão descritos a seguir por serem as usualmente empregadas na análise de padrões de imagens.

Métodos para caracterizar uma região de uma imagem, podem ser baseados na quantificação de sua textura ${ }^{8}$, através de seus descritores ${ }^{38}$. Embora não exista uma definição formal, intuitivamente estes descritores provêem a medida de 
propriedades tais como suavidade, refinamento e regularidade. As três principais formas de abordagem usadas para descrever a textura de uma imagem são: estatística, estrutural e espectral. A abordagem estatística recai na caracterização da suavidade, refinamento, e etc. As técnicas estruturais tratam com o arranjo das imagens primitivas, tais como a textura baseada na regularidade de linhas espaçadas paralelamente. As técnicas espectrais estão baseadas em propriedades do espectro de Fourier e são usadas primariamente para detectar a periodicidade em uma imagem pela identificação de alta-energia e picos estreitos no espectro.

A seguir serão apresentadas as técnicas de processamento de imagens estudadas e implementadas para a análise da $\mathrm{HC}$, no desenvolvimento deste trabalho.

\subsubsection{Segmentação de Imagens}

Existem muitos métodos para segmentação objetivando a análise de imagens $^{8,39}$. Os mais usuais envolvem binarização ou limiarização (thresholding) e detecção de contorno (edge detection). Existem ainda as técnicas baseadas em regiões (region based segmentation) e por textura (texture segmentation). O objetivo principal do uso destes métodos é identificar partes semelhantes das imagens digitalizadas. Algoritmos de segmentação para imagens monocromáticas geralmente são baseados nas similaridades e descontinuidades dos níveis de cinza da imagem. No primeiro caso, o foco principal é o nível de cinza de cada pixel individualmente. 
Esse nível, depois de ser comparado com um valor definido, é então modificado. No segundo caso, a segmentação é baseada em variações abruptas nos níveis de cinza. Por isto, são usados os pixels de uma vizinhança e o resultado é a detecção de pontos isolados, linhas ou contornos da imagem. De acordo com a característica que se deseja extrair da imagem, determinadas técnicas podem ser aplicadas e outras não.

O método mais rápido e simples de segmentação de imagens é a limiarização (binarização). Resumidamente consiste em separar uma imagem, originalmente em tons de cinza (ou em tons de diversas cores, em imagens coloridas), em pixels pretos e brancos (ou em outras cores pré-definidas). A decisão da nova cor que terá o pixel de imagens, em tons de cinza, é feita de acordo com a escolha do ponto de corte $T$ ou threshold. Qualquer pixel com intensidade maior que o ponto de corte passa a ser branco (ou preto), caso contrário, ou seja, se o pixel tem intensidade menor ou igual que o ponto de corte, o pixel passa a ter a cor preta (ou branca, de acordo com o que foi convencionado). Como uma imagem digitalizada pode ser descrita como uma função $f(x, y)$, a resposta de uma binarização é;

$$
g(x, y)=\left\{\begin{array}{l}
R_{1} \operatorname{sef}(x, y) \leqslant T \\
R_{2} \operatorname{sef}(x, y)>T
\end{array}\right\}
$$

onde $R_{1}$ e $R_{2}$ são os valores estipulados para os dois níveis de cinza da imagem binarizada, no caso utiliza-se 0 e 255, ou seja, preto e branco. Alguns autores se referem ao método de binarização como um método para separar os objetos do fundo (background) da imagem. Um ponto fundamental no uso deste método é a 
escolha do ponto de corte $T$. Uma ferramenta auxiliar usual para determinação deste ponto é o uso do histograma da imagem. O histograma indica o número de pixels da imagem associado a cada nível de cinza. A observação deste gráfico permite a localização do melhor valor de $T$ para a imagem. Esta localização é tão mais fácil quanto mais bimodal for o histograma. Quando a imagem tem, por exemplo, dois objetos com níveis de cinzas diferentes em um background mais escuro pode ser usada a técnica de binarização multi-nível (multilevel thresholding). Nesta técnica é mais difícil estabelecer os pontos de corte que isolam as regiões de interesse. Existem métodos automáticos para a escolha e ajuste do ponto de corte ${ }^{40}$ que usam a imagem como referência. Métodos que comparam conhecimentos prévios sobre os parâmetros da imagem e obtêm vários pontos de corte também são conhecidos ${ }^{41}$. Estes métodos têm eficiência para o propósito no qual foram desenvolvidos. Neste estudo a escolha do ponto de corte é feita pelo usuário que, processando inicialmente algumas imagens, pode facilmente determinar qual o valor de nível de cinza para o qual o método funcionará. $\mathrm{Na}$ figura 9 , gerada pelo algoritmo implementado, tem-se um exemplo da aplicação do método de binarização à imagem. Do lado direito observa-se a imagem original e do lado esquerdo a mesma imagem binarizada (com $T=98$ ) onde se pode observar que as gotas ficam mais visíveis. 
a)

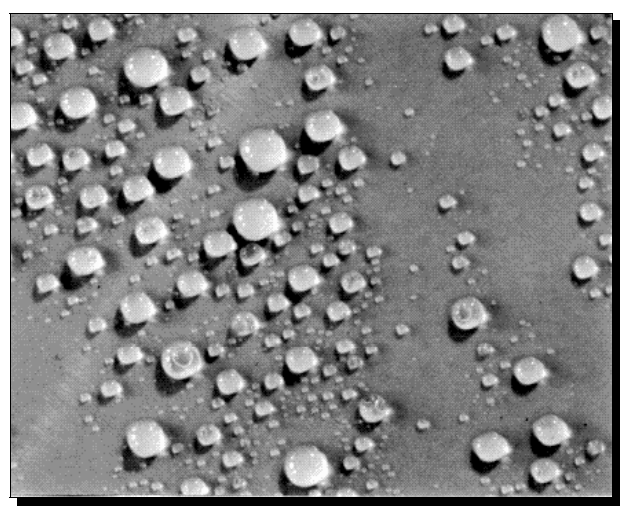

b)

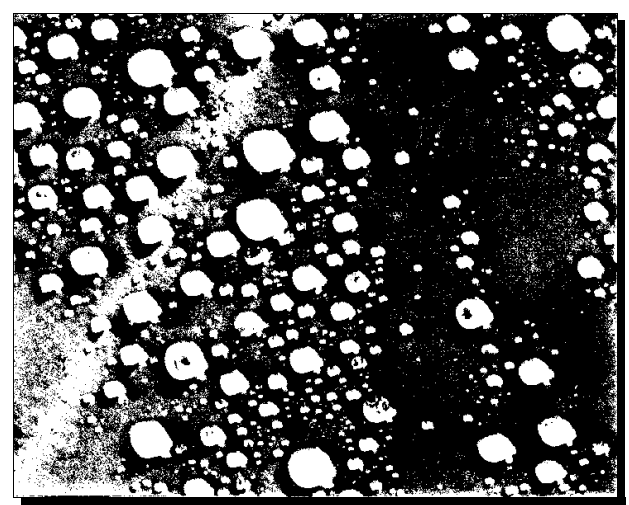

Figura 9. Método de binarização. Imagem a) original e b) binarizada ( $T=98)$.

Uma outra gama de técnicas de segmentação é agrupada com o nome de "Detecção de Contorno" (Edge Detection). Um contorno, nesse contexto, é o limite entre duas regiões com uma diferença relevante entre os níveis de cinza. Os métodos para detecção de contornos têm como objetivo detectar descontinuidades na imagem que podem representar pontos, linhas e contornos de figuras. Estes métodos são fundamentais quando se deseja fazer o reconhecimento de objetos. Um grupo de técnicas de detecção de contornos utiliza o conceito de derivada de uma imagem. Estas técnicas assumem que as regiões a serem segmentadas são suficientemente homogêneas, de forma que a transição entre elas signifique descontinuidade nos tons de cinza. A figura 10 ilustra o conceito de primeira e segunda derivada de imagens, mostrando as imagens originais, uma com uma faixa clara no fundo mais escuro (a), e a outra com uma faixa mais escura no fundo mais claro (b). Observando-se que a primeira derivada é nula em áreas onde o nível de cinza permanece constante, logo a magnitude da primeira derivada pode ser usada para detectar descontinuidades nos níveis de cinza (contorno). A segunda derivada muda de sinal no ponto médio da transição dos níveis de cinza, logo, a localização 
desta mudança de sinal também representa uma ferramenta para a localização de contornos.

A primeira derivada da função $f(x, y)$ é representativa da imagem em qualquer ponto $(x, y)$ e é obtida usando o valor do gradiente deste ponto. A segunda derivada é obtida usando o Laplaciano. O gradiente de uma função $f(x, y)$, no ponto $f(x, y)$ é definido como o vetor;

$$
\nabla f=\left|\begin{array}{l}
G_{x} \\
G_{y}
\end{array}\right|=\left|\begin{array}{l}
\frac{\partial f}{\partial x} \\
\frac{\partial f}{\partial y}
\end{array}\right| \text {, onde }|\nabla f|=\sqrt{G_{x}^{2}+G_{y}^{2}}
$$
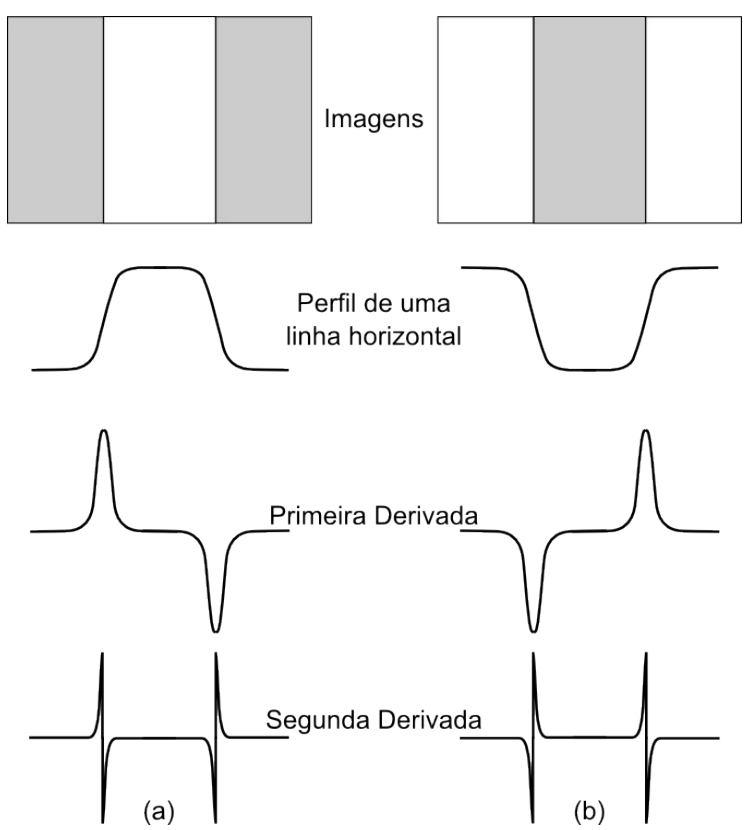

Figura 10. Derivadas de uma imagem.

Para detecção de contorno, a quantidade mais importante é o módulo do gradiente. Esta quantidade é igual a taxa máxima de crescimento de $f(x, y)$ por unidade de distância na direção do gradiente. Uma prática comum é aproximar o 
gradiente pela soma dos valores absolutos, conforme equação eq. 6 ,

$$
\nabla f \approx|G x|+|G y|
$$

eq. 6

por ser de mais simples implementação. A direção do vetor gradiente também é uma propriedade importante para determinadas aplicações. O cálculo do gradiente de uma imagem é baseado nas derivadas parciais da função $f(x, y)$, que representa a imagem em cada ponto $(x, y)$. As derivadas parciais podem ser implementadas de várias maneiras. Um dos métodos para detecção de contorno usando filtragem linear parte da distribuição espacial dos níveis de cinza da imagem. Esta filtragem é feita geralmente por convolução da imagem digitalizada com um kernel ou "máscara" (mask). O processo de convolução calcula um novo valor de intensidade, para cada pixel da imagem, tendo como base para o cálculo os tons de cinza dos pixels da vizinhança. Cada pixel contribui com uma porcentagem do seu valor, para o cálculo do nível de cinza do novo pixel. Um esquema do processo pode ser visto na figura 11.

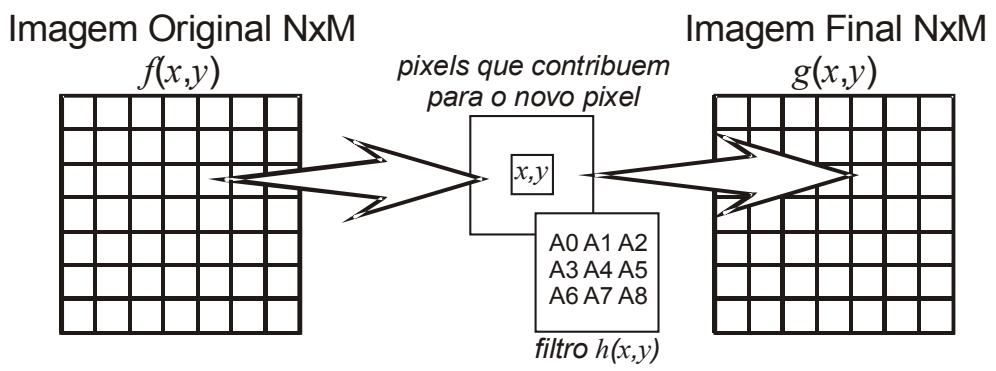

Figura 11: Processo de convolução para filtragem espacial usando uma máscara $3 \times 3$.

Usando a representação de uma imagem digitalizada como uma função $f(x, y)$ tem-se como resultado da convolução: 


$$
g(x, y)=\sum_{i, j \in h} \sum f(x-i, y-j) * h(x, y)
$$

onde $0 \leq x-i \leq N$ e $0 \leq y-j \leq M$

Os valores dos elementos da máscara $h(x, y)$ são fundamentais na determinação das formas básicas que podem ser detectadas. Para o cálculo de cada pixel da imagem final, $g(x, y)$, (equação 7) soma-se o valor na imagem original, $f(x, y)$, com os valores vizinhos multiplicados pelo peso definido na máscara $h(x, y)$. Existem algumas máscaras para detecção de pontos, retas horizontais, verticais ou inclinadas, quando o objetivo é selecionar estas formas. Pontos isolados e linhas com direção bem definida são pouco freqüentes em aplicações em controle de qualidade.

Existem vários operadores utilizados nos processos de convolução, os mais usados são: Sobel, baseado na filtragem direcional; e Laplaciano, um operador derivativo que utiliza as descontinuidades dos níveis de cinza de uma imagem, suprimindo regiões com baixa variação de níveis de cinza.

\subsection{Sobel}

As técnicas mais usuais para controle de qualidade são as que usam o conceito de contorno como o limite entre duas regiões. Dentre estas estão os conhecidos operadores Sobel. Se $I$ representa uma parte da imagem original $(3 \times 3$ pixels), os operadores Sobel $S_{x}$ e $S_{y}$ são: 


$$
I=\left|\begin{array}{lll}
p_{1} & p_{2} & p_{3} \\
p_{4} & p_{5} & p_{6} \\
p_{7} & p_{8} & p_{9}
\end{array}\right| \text {, onde } S_{x}=\left|\begin{array}{lll}
-1 & 0 & 1 \\
-2 & 0 & 2 \\
-1 & 0 & 1
\end{array}\right| \quad \text { e } \quad S_{y}=\left|\begin{array}{ccc}
-1 & -2 & -1 \\
0 & 0 & 0 \\
1 & 2 & 1
\end{array}\right|
$$

os valores de $G_{x}$ e $G_{y}$ da eq. 6 são calculados como;

$$
\begin{gathered}
G_{x}=I \mathbf{x} S_{x} \text { e } G_{y}=I \mathbf{X} S_{y}, \text { ou seja } \\
G_{x}=\left(p_{7}+2 p_{8}+p_{9}\right)-\left(p_{1}+2 p_{2}+p_{3}\right) \mathrm{e} \\
G_{y}=\left(p_{3}+2 p_{6}+p_{9}\right)-\left(p_{1}+2 p_{4}+p_{7}\right)
\end{gathered}
$$

onde $\mathbf{x}$ representa multiplicação de matrizes e $p_{s}(s=1, \ldots, 9)$ são os valores dos níveis de cinza da imagem. O módulo do gradiente da imagem no ponto central $p_{5}$ é então dado pela eq. 6. Dependendo do valor do gradiente, o ponto é considerado como sendo de contorno ou não. Para esta distinção, cada valor calculado é comparado com um valor de referência, análogo ao ponto de corte no método de limiarização. $\mathrm{Na}$ figura 12 pode ser observada a aplicação do filtro Sobel para a imagem apresentada na figura $9 a$. 


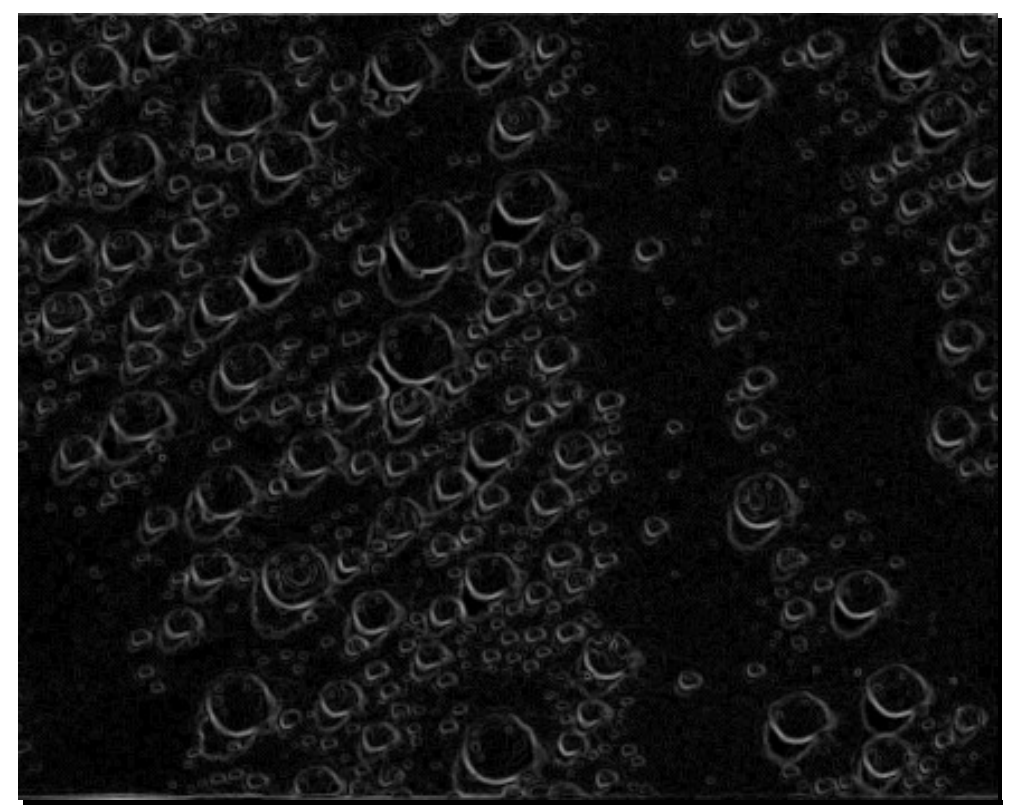

Figura 12. Processo de convolução usando a máscara Sobel, com a soma dos gradientes em $x$ e y.

\subsection{Laplaciano}

Usando a segunda derivada da imagem, para detecção de contorno, tem-se que o laplaciano de uma função $f(x, y)$ é,

$$
\nabla^{2} f=\frac{\partial^{2} f}{\partial x^{2}}+\frac{\partial^{2} f}{\partial y^{2}}
$$

onde $\frac{\partial^{2} f}{\partial x^{2}}$ e $\frac{\partial^{2} f}{\partial y^{2}}$ são as segundas derivadas parciais em relação a $x$ e a $y$ respectivamente.

Para funções discretas (como são as imagens digitalizadas), suas segundas derivadas parciais podem ser aproximadas usando

$$
\frac{\partial^{2} f}{\partial x^{2}} \simeq f(x+1)-2 f(x)+f(x-1)
$$




$$
\frac{\partial^{2} f}{\partial y^{2}} \simeq f(y+1)-2 f(y)+f(y-1)
$$

onde os $x$ 's e y's são os valores das coordenadas dos pixels na imagem. O cálculo apresentado na Eq. 10 é equivalente a convoluir a imagem com a máscara $L$, definida como;

$$
L=\left|\begin{array}{ccc}
0 & -1 & 0 \\
-1 & 4 & -1 \\
0 & -1 & 0
\end{array}\right|
$$

Na figura 13 observa-se o resultado da aplicação do Laplaciano definido na eq. 12, a partir da figura 9a.

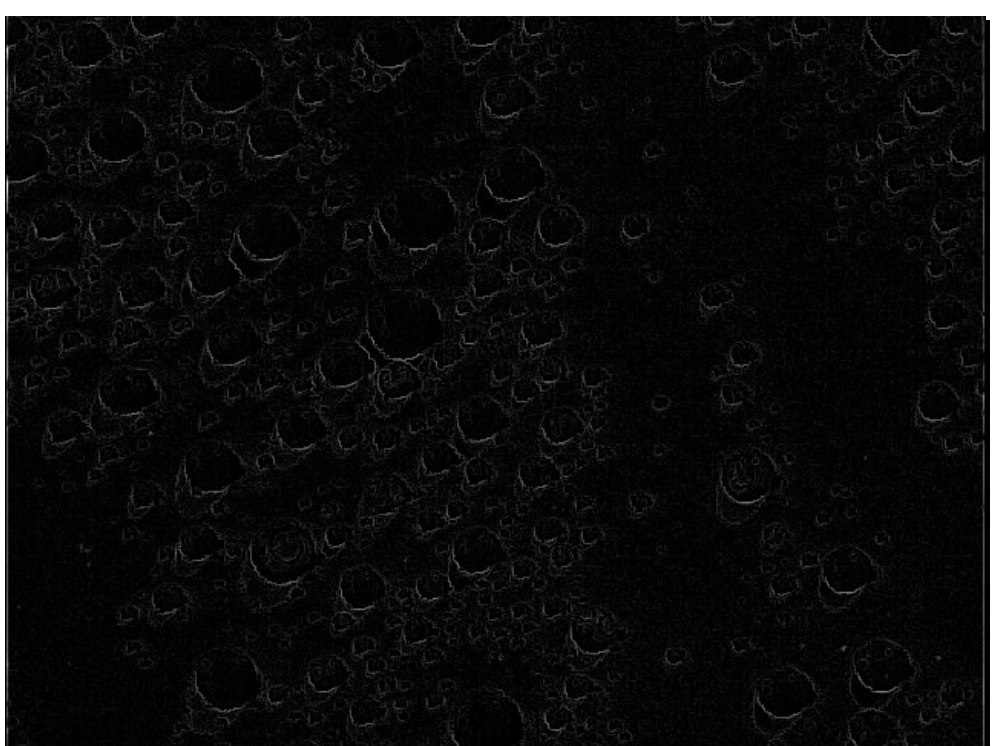

Figura 13. Processo de convolução usando uma máscara Laplaciano $3 \times 3$.

Como forma de melhorar a qualidade da imagem original, a imagem gerada pela aplicação do Laplaciano deve ser operada com ela da seguinte forma:

$$
g(x, y)=\left\{\begin{array}{l}
f(x, y)-\nabla^{2} f(x, y) \text { se centro da máscara }<0 \\
f(x, y)+\nabla^{2} f(x, y) \text { se centro da máscara }>0
\end{array}\right\}
$$




\subsubsection{Morfologia Matemática}

A morfologia matemática visa operar sobre o objeto em análise através de um outro de forma conhecida, chamado de elemento estruturante $(B)^{42}$. Cada elemento estruturante fornece uma aparência nova do objeto, assim, o formato do elemento estruturante tem grande importância. A morfologia utiliza operações sobre conjuntos que podem ser classificados em duas categorias: as operações clássicas (união, interseção); e as transformações de tudo ou nada (hit-or-miss).

As transformações morfológicas utilizam a imagem para estudar as relações entre pontos de um conjunto $X$. Elas fornecem um novo conjunto e são geralmente seguidas da medida de um ou vários parâmetros caracterizando a estrutura $X$.

A informação estrutural é dada pela transformação da imagem e não pela medida. Para aplicar uma transformação tudo ou nada, é necessário escolher um elemento estruturante $B$ de geometria conhecida que vai "deslizar" de modo que a origem passe por todas as posições do espaço. Para cada posição coloca-se uma pergunta relativa à união, à intersecção ou à inclusão de $B \operatorname{com} X$. A resposta será positiva ou negativa, de onde o nome da transformação tudo ou nada. O conjunto de pontos correspondentes às respostas positivas cria um novo conjunto chamado imagem transformada.

Toda operação morfológica compõe-se de uma transformação $\phi$ de um conjunto em um outro conjunto e de uma medida $\mu$. $\phi(X)$ é um conjunto e $\mu(\phi(X))$ é um número. Esses operadores não são simplesmente matemáticos. Os seus efeitos 
não podem variar a realidade física que eles representam. $\phi$ e $\mu$ devem respeitar as condições de contorno impostas pelas leis da percepção visual:

- a invariância à translação;

- a invariância à homotetia;

- o conhecimento local;

- e a continuidade.

\subsubsection{Comutação com as translações}

Uma transformação $\phi$ sobre um conjunto $X$ comuta com uma translação $h$ se

$$
\phi\left(X_{h}\right)=[\phi(X)] h
$$

o que traduz-se pela independência com a origem das coordenadas.

\subsection{Conhecimento local}

Não se tem acesso a todo o conjunto de $X$, mas a uma parte desse conjunto que denomina-se de $Z$. Conhece-se na realidade uma parte de $B$ e $X \cap B$. As transformações usuais são aquelas que fornecem um resultado $\phi(X)$ que é calculado utilizando uma máscara restrita $Z^{\prime}$ a qual provém de uma zona restrita $B$ onde $X$ é conhecido. A máscara $Z^{\prime}$ depende somente de $B$ e $X \cap Z$. Esse ponto chama-se de conhecimento local.

A transformação $\phi$ satisfaz a propriedade de conhecimento local se para cada conjunto restrito $Z^{\prime}$, no qual $X$ é conhecido, pode-se encontrar um conjunto restrito $B$, 
dependente de $Z^{\prime}$ e de $\phi$ mas não de $X$, no qual é conhecido $\phi(X)$ de forma que se $\forall Z^{\prime}$ restrito e $\exists B$ restrito:

$$
[\phi(X \cap B)] \cap Z^{\prime}=\phi(X) \cap B
$$

eq. 15

onde $B$ é o elemento estruturante.

\subsubsection{Operadores Matemáticos}

$B_{h}$ é o conjunto obtido de $B$ pela translação do vetor $h$.

$$
\begin{gathered}
y \in B \rightarrow y+h \in B_{h} . \\
B_{0}=B \\
\left(B_{h}\right)_{k}=\mathrm{B}_{h+k}=\left(\mathrm{B}_{k}\right)_{h}
\end{gathered}
$$

$\tilde{B}$ é o conjunto deduzido de $B$ por simetria centrada em O.

$$
\begin{aligned}
& y \in B \rightarrow-y \in \tilde{B} \\
& B_{h}=B_{h+k}=(\tilde{B})_{-h}
\end{aligned}
$$

Nas diferentes transformações, utilizamos a notação $B$ ou $B_{x}$ para um elemento estruturante centrado em $x$.

\subsection{Erosão}

A primeira questão que deve ser feita quando se deseja testar um conjunto com um elemento estruturante é: o elemento estruturante se ajusta ao conjunto ? O 
conjunto erodido é o local de pontos onde a resposta para esta questão é afirmativa. Um conjunto sob estudo representa um objeto de uma imagem binária ou o resultado de uma imagem em escala de cinza.

A erosão de um conjunto $X$ por um elemento estruturante $B$ é denotado por $\varepsilon_{B}(X)$ e é definido como o local de pontos de $\mathbf{x}$ tal que $B$ está incluído em $X$ quando sua origem é colocada em $\mathbf{x}$ :

$$
\mathcal{E}_{B}(X)=\left\{\mathbf{x} \mid x: B_{x} \subseteq X\right\}
$$

Isso pode ser ilustrado na figura 14 para um conjunto 2D. A eq. 21 pode ser reescrita em termos da interseção do conjunto de translações sendo determinadas pelo elemento estruturante $B$ :

$$
\varepsilon_{b}(X)=b \in B \cap X_{-b}
$$

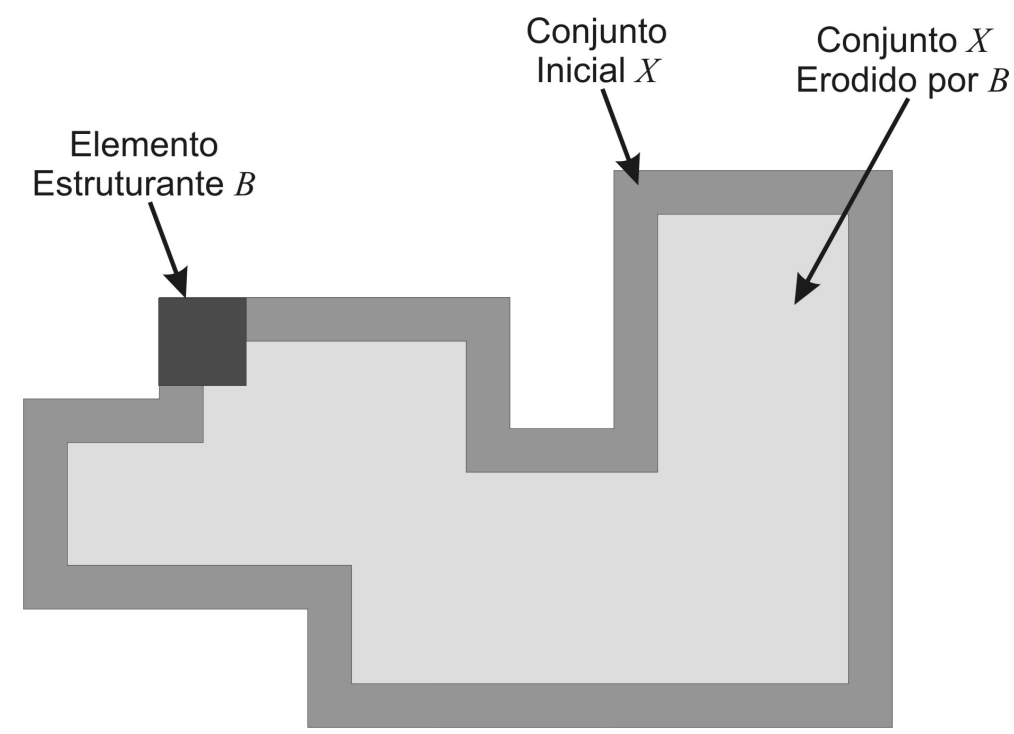

Figura 14. Princípio da erosão binária. 
Esta definição pode ser diretamente estendida para imagens binárias ou escalas de cinza: a erosão de uma imagem $f$ por um elemento estruturante $B$, quando $B$ é totalmente preenchido, pode ser definida como $\varepsilon_{B}(f)$ e é definida como o mínimo de translações de $f$ pelo vetor $-b$ de $B$ :

$$
\varepsilon_{B}(f)=\wedge_{b \in B}^{\wedge} f_{-b}
$$

Assim, o valor erodido para um pixel $\boldsymbol{x}$ é o mínimo valor para a imagem na janela definida pelo elemento estruturante quando a origem é $\boldsymbol{x}$ :

$$
\left[\varepsilon_{B}(f)\right](\mathbf{x})=\min _{b \in B} f(x+b)
$$

A figura 15 ilustra o resultado do processo de erosão (b) de uma imagem em escala de cinza (a).

a)

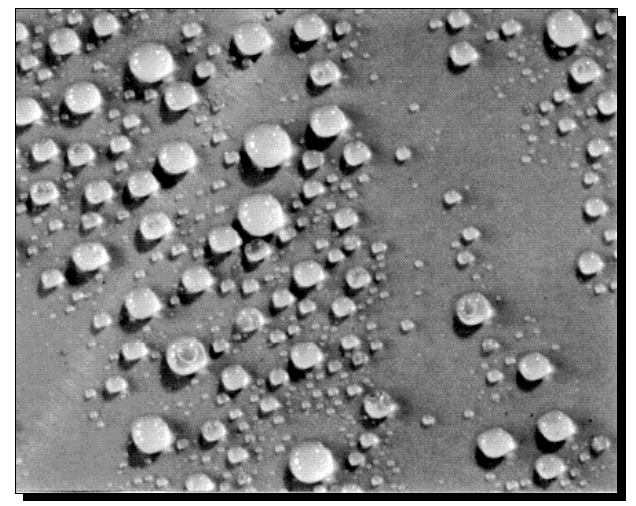

Figura 15. a) Imagem em escala de cinza e b) aplicação da erosão com um elemento estruturante quadrado $2 \times 2$ preenchido.

\subsection{Dilatação}

A dilatação é o operador dual da erosão e está baseado na questão: 0 elemento estruturante cabe no conjunto ? O conjunto dilatado é o local onde a 
resposta para esta questão é afirmativa.

A dilatação de um conjunto $X$ por um elemento estruturante $B$ é nomeada por $\delta_{B}(X)$ e é definida como o local de pontos $\mathbf{x}$ tais que $B$ cabe em $X$ quando sua origem coincide com $\mathbf{x}$ :

$$
\delta_{B}(X)=\left\{\mathbf{x} \mid B_{x} \cap X \neq \varnothing\right\}
$$

Esta definição está ilustrada na figura 16 para a dilatação de um conjunto pelo elemento estruturante $B$.

A eq. 25 pode ser reescrita em termos da união do conjunto de translações, onde as translações podem ser definidas pelo elemento estruturante:

$$
\delta_{B}(X)=b \in B \cap X_{-b}
$$

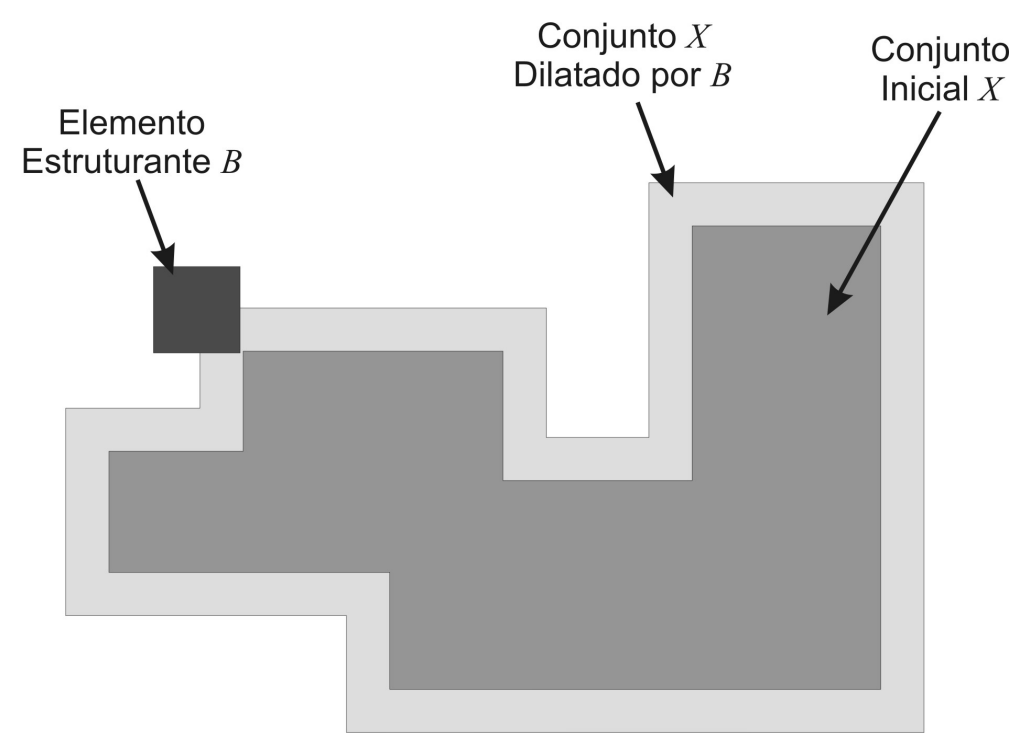

Figura 16. Princípio da dilatação binária.

Assim esta definição pode ser diretamente estendida para uma imagem binária ou em escala de cinza: a dilatação de uma imagem $f$ por um elemento 
estruturante $B$ é nomeada por $\delta_{B}(X)$ e é definida pelo máximo das translações de $f$ pelo vetor $-b$ de $B$ :

$$
\delta_{B}(f)=\underset{b \in B}{\vee} f_{-b}
$$

Em outras palavras, o valor da dilatação para um determinado pixel $\boldsymbol{x}$ é o máximo valor da imagem na janela definida pelo elemento estruturante quando a origem está em $\boldsymbol{x}$ :

$$
\left[\delta_{B}(f)\right](\mathbf{x})=\max _{b \in B} f(x+b)
$$

A Figura 17 ilustra o resultado do processo de dilatação (b) de uma imagem escala de cinza (a).

a)

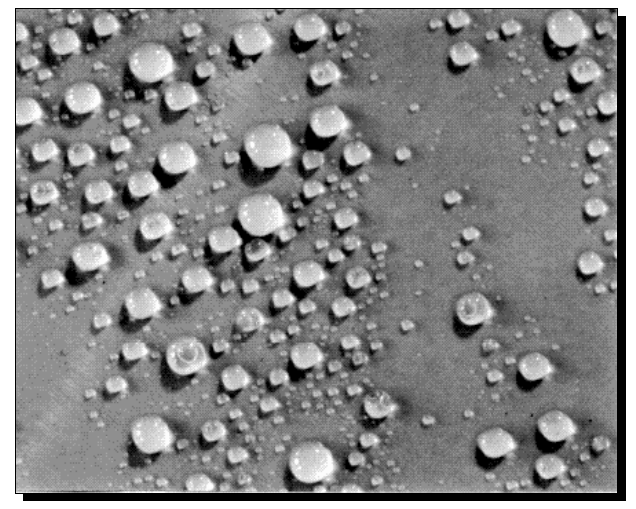

b)

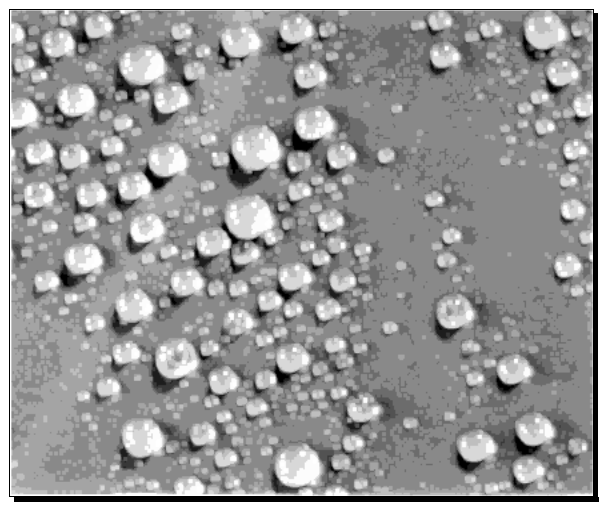

Figura 17. a) Imagem em escala de cinza e b) aplicação da dilatação com elemento estruturante quadrado $2 \times 2$ completamente preenchido.

\subsection{Abertura}

Uma vez que uma imagem foi erodida, em geral não existe transformação inversa para recuperar a imagem original. A idéia da operação morfológica de abertura é dilatar uma imagem erodida para recuperar, o que for possível, da imagem original. 
A abertura $(\gamma)$ de uma imagem $f$ por elemento estruturante $B$ é denotada como $\gamma_{B}(f)$ e é definida como a erosão de $f$ por $B$ seguida da dilatação.

$$
\gamma_{B}(f)=\delta_{B}\left[\varepsilon_{B}(f)\right]
$$

A figura 18 ilustra o resultado do processo de abertura (b) de uma imagem em escala de cinza (a).

a)

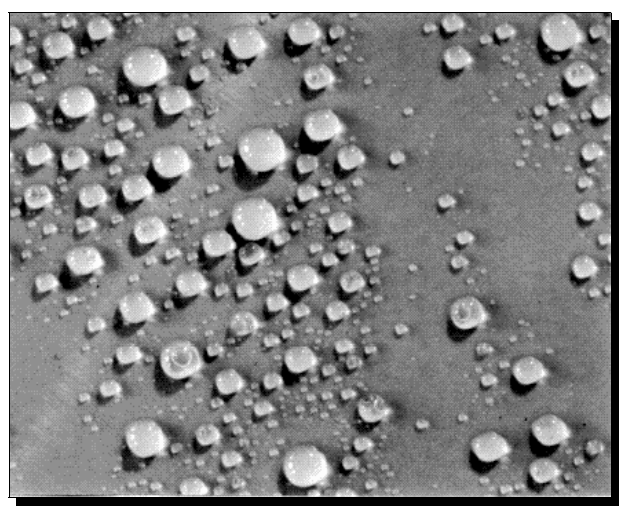

b)

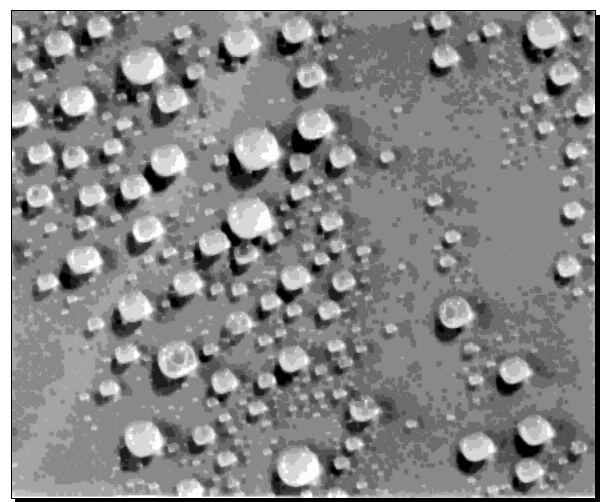

Figura 18. a) imagem em escala de cinza e b) aplicação da abertura com um elemento estruturante quadrado $2 \times 2$ completamente preenchido.

Desta forma, este processamento pode ser utilizado para analisar a granulometria, ou direção preferencial, de uma imagem, ou seja, pode ser aplicado para a classificação de textura de uma imagem.

Uma curva granulométrica, por exemplo é a soma dos valores dos pixels (ou seja, volume) de uma imagem versus o tamanho do elemento estruturante. Mas em termos práticos, as curvas granulométricas são analisadas pela sua derivada, ou seja, a perda de volume entre duas sucessivas aberturas versus o tamanho da abertura. A curva resultante mostra valores máximos e mínimos que indicam a prevalência de tamanhos das estrutura na imagem. A figura 19 ilustra uma curva 
granulométrica obtida a partir do uso deste método para a determinação do tamanho de estruturas celulares ${ }^{43}$, onde $\mathbf{G}(\mathbf{d})$ é a densidade do tamanho granulométrico e $\mathbf{d}$ o tamanho do elemento estruturante.

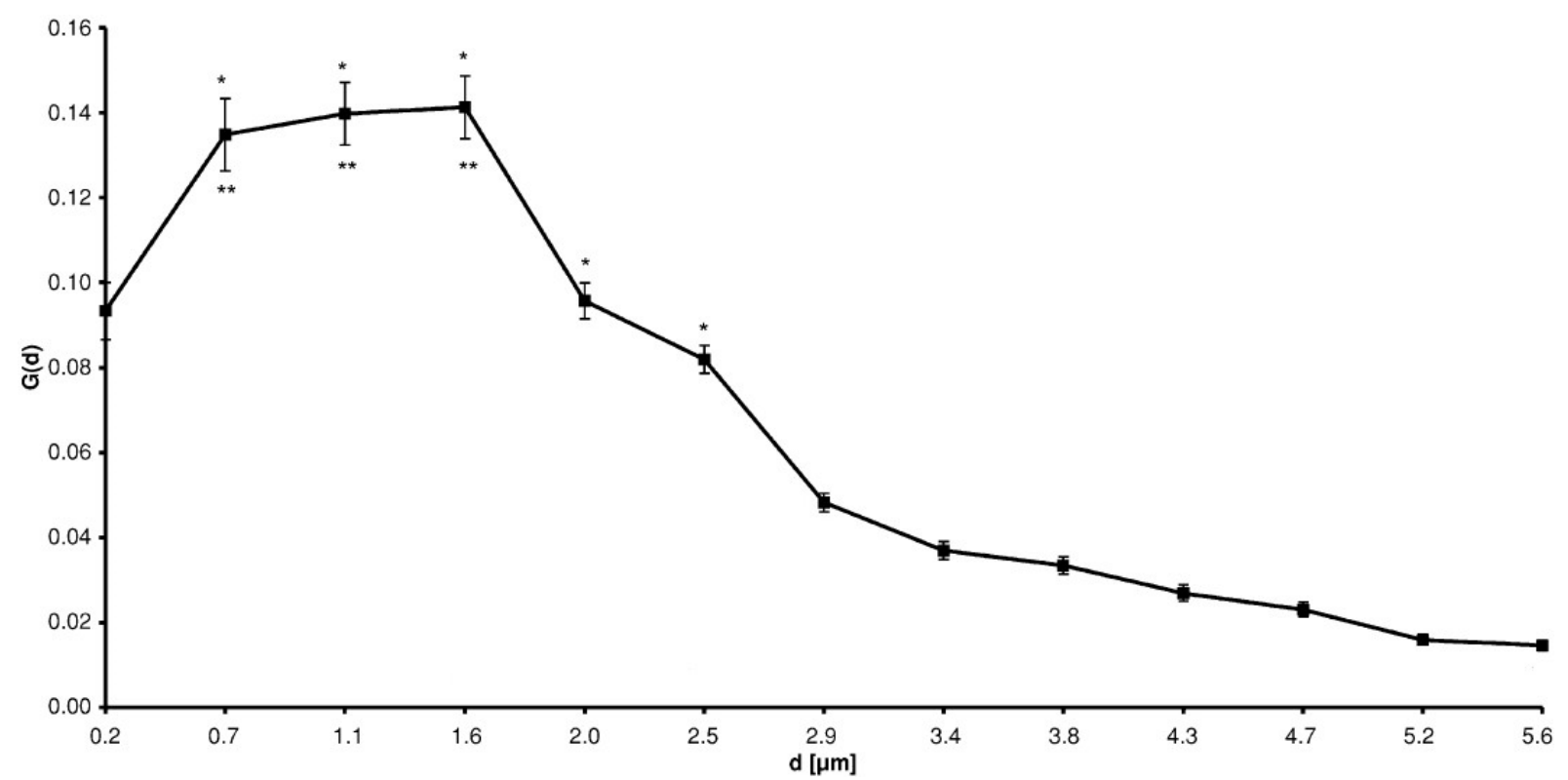

Figura 19. Exemplo de uma curva granulométrica obtida por morfologia matemática. Adaptado de Prodanova ${ }^{43}$.

\subsection{Fechamento}

A idéia do fechamento é construir um operador tendendo a recuperar o formato inicial de uma imagem com estruturas que foram dilatadas. Isso pode ser feito pela erosão de uma imagem dilatada.

O fechamento de uma imagem $f$ por um elemento estruturante $B$ é denotado por $\phi_{B}(f)$ e é definido como a dilatação de $f$ com um elemento estruturante $B$ seguido por uma erosão:

$$
\phi_{B}(f)=\varepsilon_{B}\left[\delta_{B}(f)\right]
$$


A figura 20 ilustra o resultado do processo de fechamento (b) de uma imagem em escala de cinza (a).

a)

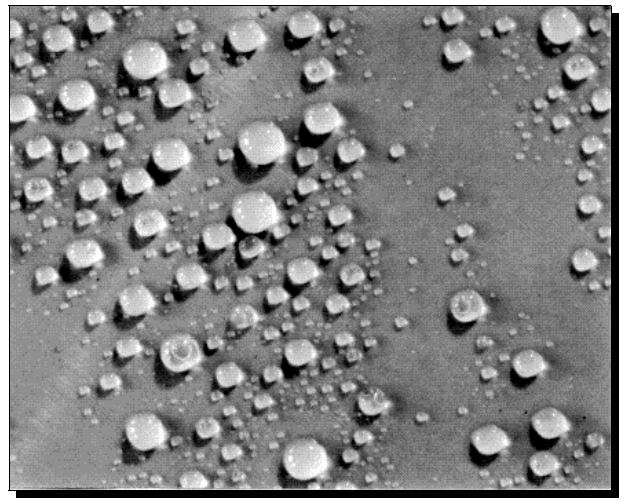

b)

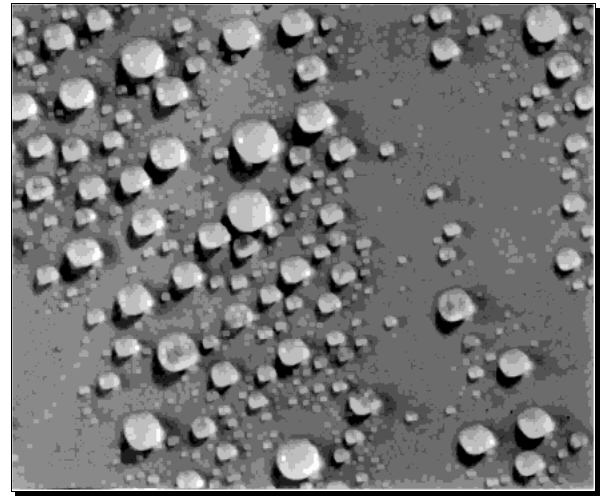

Figura 20. a) imagem em escala de cinza e b) aplicação do fechamento com um elemento estruturante quadrado $2 \times 2$.

\subsubsection{Correção de iluminação de imagens}

Para realizar o procedimento de ajuste de iluminação de uma imagem é necessário introduzir o conceito de top-hat.

\subsubsection{Top-Hat}

Um white top-hat (WTH), ou top-hat por abertura, é definido como a diferença entre a imagem original $(f)$ e sua abertura $(\gamma)$.

$$
\mathrm{WTH}(f)=f-\gamma_{B}(f)
$$

Uma vez que a abertura é uma transformação anti-extensiva da imagem, os valores da escala de cinza do white top-hat sempre serão maiores ou iguais a zero. 


\subsection{Correção da iluminação $o^{8,9}$}

Um gradiente de iluminação ocorre quando uma cena é iluminada desigualmente. Desta forma é necessária a correção deste efeito pois medidas em imagens em escala de cinza e técnicas de binarização global não podem ser aplicadas para imagens iluminadas desigualmente. A melhor solução é otimizar o sistema de iluminação, pois capturar imagens igualmente iluminadas é impossível em muitas situações práticas. Por exemplo, a iluminação de fundo para uma imagem de raios-X de uma peça metálica de espessura desigual: quanto mais larga, mais escura é a saída do nível de sinal. Se toda a imagem tem o mesmo contraste local, ou seja, se tudo é mais claro ou mais escuro que o fundo, as transformações top-hat com elementos estruturante grandes e isotrópicos, atuam como um filtro passa-alta. Como o gradiente da iluminação encontra-se dentro das freqüências baixas da imagem, isso pode ser removido pelo top-hat. White Top-hats são usados em fundos escuros e black top-hats são usados em fundos claros.

$\mathrm{Na}$ figura 21 pode ser observado um exemplo deste processo, onde a) é a imagem original sem correção de histograma, b) representa o filtro através da aplicação da abertura, utilizando um elemento estruturante de $41 \times 41$ e c) representa a imagem gerada após a aplicação do filtro. 
a)

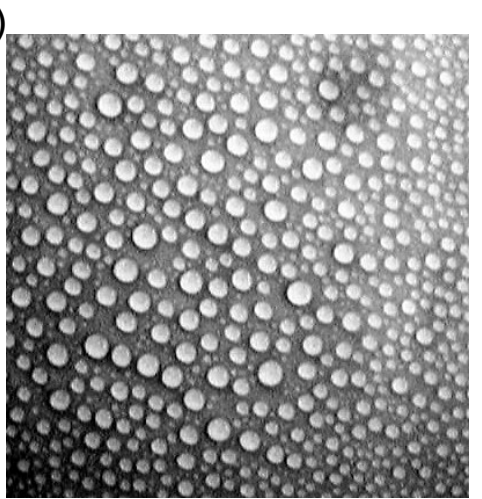

b)

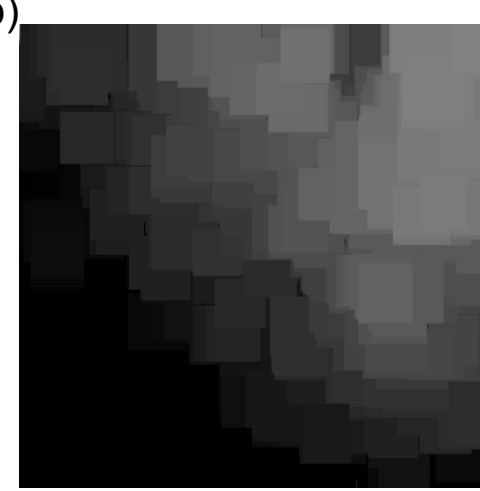

c)

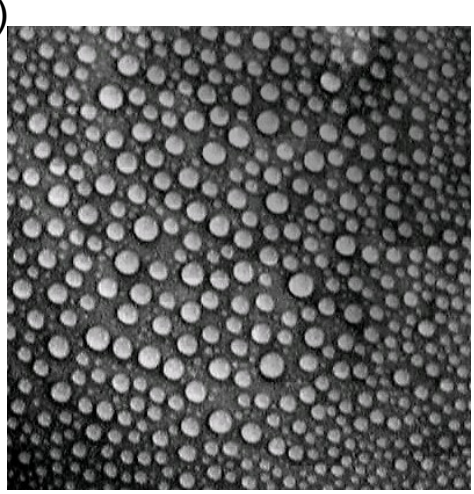

Figura 21. Processo de correção de iluminação. a) imagem original, b) filtro de abertura e c) a imagem final.

A binarização global da imagem falha para extrair a máscara da imagem de, por exemplo, anéis e cruzes. Uma abertura da imagem original com um elemento estruturante grande e quadrado remove todas as estruturas relevantes da imagem, preservando a função da iluminação. O white top-hat da imagem original, ou subtração da função de iluminação da imagem original, gera uma imagem com uma iluminação homogênea. A binarização global da imagem white top-hat mostra a extração dos elementos relevantes na imagem, comprovando a viabilidade do processo.

\subsubsection{Algoritmos Recursivos}

Recursão tem como definição ${ }^{44}$ “...uma técnica de programação em computação que envolve o uso de uma sub-rotina, função ou algoritmo que se chama uma ou mais vezes até que uma condição específica seja satisfeita, no que o resto de cada repetição é processado do fim invocando a primeira...", ou seja é o ato de recorrer. Mas recorrer é uma palavra de vários significados que se confunde 
com iteração ${ }^{45}$ “...uma ação ou um processo de iteração ou repetição é um procedimento no qual a repetição de uma seqüência de operações onde os resultados se aproximam de um resultado desejado, ou uma repetição de uma seqüência de instruções de cálculo para um número específico de vezes ou antes que uma condição seja satisfeita...".

Pode-se dizer que o "ato de recorrer" está no fato da definição, descrição ou implementação recorrer a si própria para formalizar alguma coisa. A recursão é uma ótima ferramenta nas mãos de um programador. As pessoas usam intuitivamente recursão, e por isto é geralmente mais fácil resolver um grande problema usando recursão do que usando iteração.

Um algoritmo recursivo ${ }^{46}$ é aquele com valores de entrada menores ou mais simples, que obtém resultados aplicando operações mais simples, retornando os mesmos resultados que um algoritmo convencional.

Se um conjunto ou uma função é definida recursivamente, então um algoritmo recursivo deve ser utilizado para calcular estes membros. Os passos iniciais para um algoritmo recursivo corresponde a base da definição da recursividade, identificando os elementos básicos. Eles são seguidos por passos correspondentes à cláusula indutiva, a qual reduz o cálculo para um elemento de uma geração para os elementos de geração imediatamente precedente.

Em geral, aplicativos de cálculo recursivo requerem mais memória e cálculos quando comparados com algoritmos iterativos, mas eles são mais simples e para muitos casos uma forma natural de pensar sobre um problema.

Este recurso foi utilizado por Soille e Talbot $^{47}$ para determinar a orientação de 
estruturas em imagens. Neste caso foi elaborado um algoritmo recursivo para determinação do ângulo de inclinação de estruturas presentes em uma imagem, a partir de linhas de referência. A figura 22 mostra a redução no tempo de processamento obtida com a utilização deste método. Chaudhuri ${ }^{48}$ relaciona o algoritmo recursivo principalmente com relação a precisão no cálculo e complexidade computacionais.

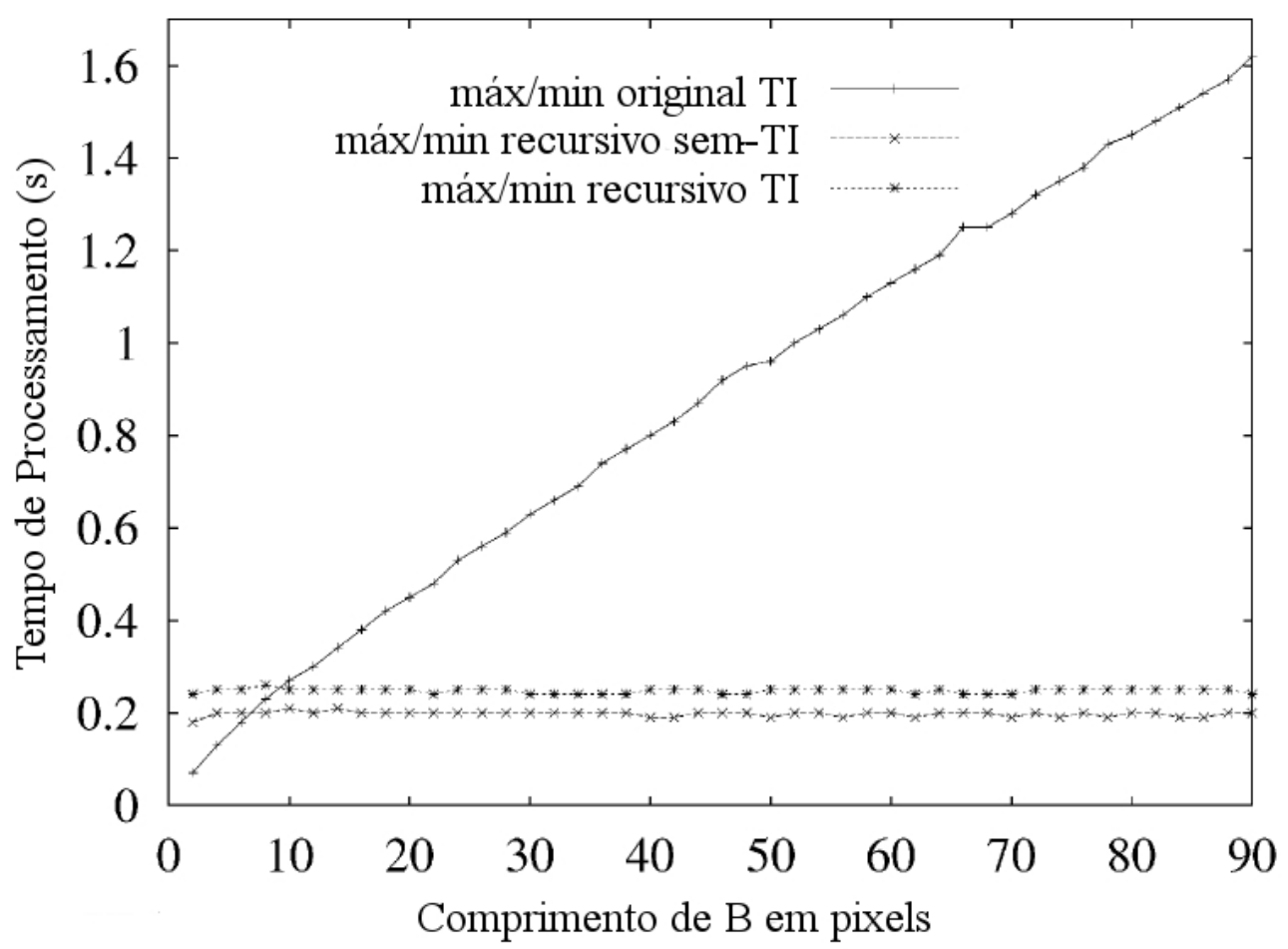

Figura 22. Curva do tempo de processamento em função do tamanho do elemento estruturante (B) para operação de dilatação. Para uma imagem em escala de cinza de $1024 \times 1024$. 0 programa foi escrito em ANSI C e executado em um Intel P-Il 450 Mhz. Figura adaptada de Soille $e^{47}$.

\subsubsection{Descritores de texturas}

Uma perspectiva inicial de textura e tom está baseada no conceito de que textura e tom estão intimamente ligados. Tom e textura estão sempre presentes em 
uma imagem embora um possa dominar o outro às vezes. A intuitiva percepção básica entre tom e textura é a seguinte: quando uma pequena área em uma imagem tem uma pequena variação, isto é, uma variação nas características dominantes dos discretos tons de cinza de uma área, isso é tom; quando uma pequena área tem uma variação ampla nas suas características nos discretos tons de cinza, a propriedade dominante é textura.

O precedente da descrição de texturas é uma simplificação grosseira e idealização do que ocorre em uma imagem. Assim, a extração de características discretas pode ser confusa no que elas realmente representam. Desta forma, a aplicação de descritores de textura como forma de analisar uma textura está intuitivamente baseada nas próprias características da textura.

As informações das texturas estão especificadas por um conjunto de matrizes em escala de cinza com dependência espacial, as quais são obtidas para várias relações e distâncias angulares entre seus vizinhos em uma imagem. Neste trabalho, os descritores de textura estão baseados nestas matrizes, atualmente conhecidas como Matrizes de Co-Ocorrência (GLCM).

\subsubsection{Matriz de co-ocorrência em escala de cinza (GLCM)}

Um método estatístico para examinar a textura de uma imagem que considera a relação espacial entre os pixels é a matriz de co-ocorrência em escala de cinza $(\mathrm{GLCM})^{38}$, também conhecida como matriz de dependência espacial em escala de cinza. As funções da GLCM caracteriza a textura de uma imagem pelo cálculo da 
freqüência de aparecimento de pares de pixels com valores específicos e em uma relação espacial específica em uma imagem, criando a GLCM, e então extraindo medidas estatísticas desta matriz.

A figura 23 ilustra a relação espacial entre os pixels que são definidos na matriz de deslocamentos, ou seja, a definição dos pares de pixels de interesse, onde deve ser definido um vetor que indica a direção e distância dos pares.

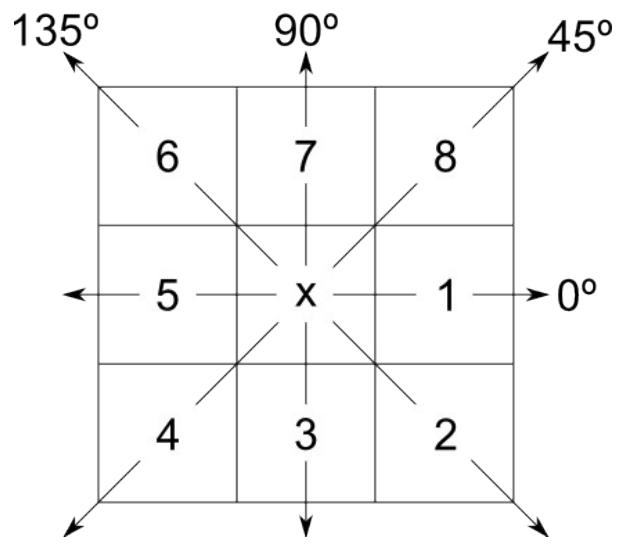

Figura 23. llustração da relação entre os pixels em uma imagem para criação da GLCM.

Após a criação da GLCM, podem ser derivados vários parâmetros estatísticos. Estes parâmetros estatísticos fornecem informações sobre a textura de uma imagem, dentre as quais: segundo momento angular (Entropia), Energia, Variância, Homogeneidade, dentre outros.

\subsubsection{Entropia}

De acordo com a definição clássica, entropia ${ }^{49,50}$ em um conjunto é a probabilidade de ocorrência de um evento neste conjunto, ou seja: 


$$
S=-\sum_{\lambda \in \Omega} p(\lambda) \log p(\lambda)
$$

onde $\Omega$ é o conjunto de valores. No processamento de imagens, $\Omega$ é o conjunto representado pela GLCM, e $p(\lambda)$ é a probabilidade de ocorrência do evento $\lambda$ na GLCM, usualmente estimada pela curva do histograma normalizada da imagem em análise.

A determinação do valor da entropia é um dos descritores de textura que pode caracterizar uma imagem, podendo ser utilizada como forma de discriminação da textura de imagens ${ }^{51}$.

Para o uso em processamento de imagens, Haralick ${ }^{38}$ descreveu a entropia com a análise da suavidade da textura da imagem, que pode ser calculada como:

$$
S=-\sum_{i} \sum_{j} p(i, j) \times \log p(i, j)
$$

onde $p(i, j)$ é a matriz de co-ocorrência obtida para um deslocamento $d x=1$ (GLCM), após normalização descrita por Gonzalez ${ }^{8}$.

\subsubsection{Energia}

A determinação da energia de uma textura indica a uniformidade atribuída a essa imagem. De acordo com Haralick ${ }^{\text {Erro: Origem da referência não encontrado }}$, a energia de uma imagem pode ser calculada da seguinte forma: 


$$
E=-\sum_{i} \sum_{j} p(i, j)^{2}
$$

eq. 34

onde $p(i, j)$ é a GLCM obtida a partir da imagem sob análise.

\subsubsection{Variância}

Uma das mais simples abordagens para descrever texturas é o uso de momentos estatísticos em escala de cinza de uma imagem ou região. Considerando $z$ uma variável aleatória denotando os valores de cinza e $p\left(z_{i}\right)$, onde $i=0,1,2, \ldots, L-1$ seja o histograma correspondente, onde $L$ é o número dos distintos níveis de cinza. O $n$-ésimo momento de $z$ sobre a média é:

$$
\mu_{n}(z)=\sum_{i=0}^{L-1}\left(z_{i}-m\right)^{n} \times p\left(z_{i}\right)
$$

onde $m$ é a média dos valores de $z$, ou seja:

$$
m=\sum_{i=0}^{L-1} z_{i} p\left(z_{i}\right)
$$

A partir da eq. 35 nota-se que $\mu_{0}=1$ e $\mu_{1}=0$. O segundo momento $\left[\sigma_{2}(z)=\mu_{2}(z)\right]$ é de particular importância na descrição de texturas. Esta é uma medida do contraste do nível de cinza, que pode ser usado para estabelecer descritores de relativa suavidade. A eq. 37 descreve a equação utilizada na determinação da variância.

$$
\sigma_{2}=-\sum_{i} \sum_{j}(i-m)^{2} \times p(i, j)
$$




\subsubsection{Homogeneidade}

A Homogeneidade revela a proximidade de distribuição dos elementos de uma GLCM, com a sua diagonal. Seu valor está entre zero e um, e seu valor é um quando a diagonal da GLCM apresenta o mesmo valor.

A Homogeneidade é calculada da seguinte forma:

$$
H=\sum_{i} \sum_{j} \frac{p(i, j)}{1+|i-j|}
$$

\subsubsection{Fractais ${ }^{52}$}

Muitos dos objetos no mundo real são tão complexos e irregulares na natureza que não podem ser descritos através da geometria clássica. A descrição de formas complexas em termos da própria similaridade foi inicialmente introduzida por Mandelbrot ${ }^{53}$. A dimensão topológica de um conjunto é sempre um inteiro, enquanto que a dimensão de Hausdorff, ou dimensão fractal, pode ser uma fração. Contudo, a dimensão de Hausdorff apresenta um tratamento matemático elegante. Ao lado da definição teórica, uma das mais populares definições é a box dimension, que é uma evolução na dimensão de Hausdorff ${ }^{53,54}$. A box dimension algumas vezes é referenciada como sendo uma dimensão de similaridade, é o conceito de fração da escolha para uma ciência experimental desde que isso seja computacionalmente mais gerenciado do que a dimensão Hausdorff. Em geral, a dimensão Hausdorff e a box dimension apresentam o mesmo valor numérico. Como um valor muito útil do conjunto fractal, o resultado do cálculo da dimensão fractal se torna uma importante referência. 


\subsection{Dimensão Fractal}

No século passado, matemáticos tais como; Von Koch, Peano, Hausdorff, Besicovitch, entre outros, criaram figuras que foram chamadas de "monstros" ou "patológicas" pelos matemáticos tradicionais ${ }^{55}$. Um novo conceito de dimensão foi proposto, no qual os objetos não têm mais dimensão inteira (como na geometria Euclideana) e sim fracionária. Surgia a Geometria Fractal cujo nome foi introduzido por Mandelbrot e é relacionada com fractus, do latim, que significa segmentos irregulares. O campo de aplicação da geometria fractal cada vez mais se amplia. $\mathrm{O}$ uso mais divulgado da geometria fractal é a criação de imagens e paisagens sintéticas fascinantes ${ }^{56}$ através da definição de modelos para objetos naturais como nuvens, montanhas, lagoas, etc. A geometria fractal também é usada para caracterizar o comportamento de sistemas caóticos ${ }^{57}$ (como por exemplo em escoamento turbulento de fluidos), para desenvolver novas modelagens matemáticas $^{54,58}$.

Recentemente a geometria fractal tem sido aplicada na área de processamento e análise de imagens; desenvolvendo técnicas de compressão de arquivos de imagens ${ }^{59}$, técnicas para segmentação de imagens $^{60,61,62,71}$, caracterização da rugosidade de superfícies visando aplicações em mecânica da fratura $^{63,64}$, estudos de desgaste e erosão de superfícies ${ }^{65}$, corrosão de superfícies $^{66}$ e outras ${ }^{67,68,69}$. 
A maioria das aplicações da geometria fractal depende da determinação da dimensão fractal $(d f)$, principalmente quando se trata de sistemas caóticos e análise de imagens. Dimensão fractal é um número, associado aos fractais, que busca quantificar a densidade destas figuras no espaço métrico em que são definidas e serve como parâmetro de comparação entre elas. Pode-se verificar se duas figuras fractais são "semelhantes" a partir do cálculo da dimensão fractal de ambas. O cálculo da dimensão fractal de uma imagem caracteriza o grau de complexidade da imagem. Dimensão fractal é um parâmetro importante, pois pode ser medida através de experimentos.

Os métodos para avaliar a dimensão de figuras podem ser separados em métodos teóricos e experimentais. Os métodos teóricos usam fundamentos matemáticos tais como: espaço métrico, conjuntos, subconjuntos, etc. Estes métodos têm como base definições e teoremas ${ }^{54}$. A determinação experimental da dimensão fractal de conjuntos dos números reais $(R)$ é feita modelando estes como subconjuntos do $R^{2}$ ou $R^{3}$, usando geralmente a métrica Euclideana. Esta modelagem pode ser feita visando a aplicação dos conceitos teóricos, definições e teoremas. Um dos precursores em estudos experimentais para o cálculo de dimensão fractal de figuras foi Mandelbrot ${ }^{53}$. No método apresentado por Proença e Conci $^{70,71}$ uma imagem é modelada no espaço $R^{3}$. As coordenadas $(x, y)$ representam a posição (em $R^{2}$ ) e a terceira coordenada $(z)$ representa a intensidade de níveis de cinzas. Uma imagem é modelada então, como um relevo, onde as alturas representam os tons de cinza. Para o cálculo da dimensão fractal de imagens foi tomado como base o teorema de contagem de box (ou cubos). O espaço, onde está 
a imagem modelada, é subdividido em cubos de lados $S \times S \times S$, onde $S$ é um múltiplo do tamanho do pixel em $(x, y)$ e $S^{\prime}$ é múltiplo do nível de cinza unitário na direção $z$. Uma imagem com tamanho MxM pixels é dividida, no plano $x, y$, em grids de $\boldsymbol{S} \times \boldsymbol{S}$ pixels onde, $1 \leq S \leq M / 2$ e $S$ é um inteiro e em cada grid há uma coluna de boxes $S \times S \times S$ '. Por exemplo, na figura 24 tem-se a modelagem de parte de uma imagem no espaço, representada pela superfície externa (níveis de cinza da imagem). Nesta figura, a superfície da imagem foi representada usando uma geometria simples para facilitar a apresentação do método. Na realidade haverá a superfície de uma imagem digitalizada que em geral é mais "acidentada". Na figura 24 tem-se os valores; $M=15$ (imagem com 15x15 pixels), $S=3$ (grid de $3 \times 3$ pixels) e $S^{\prime}=3$.

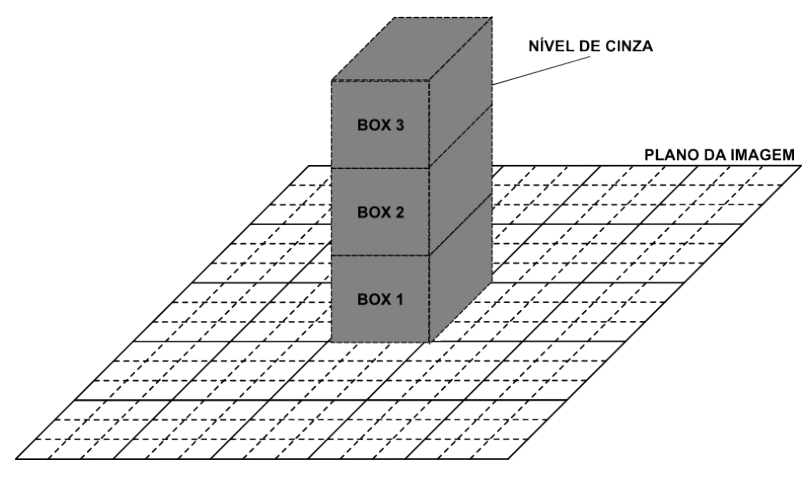

Figura 24. Modelagem de uma imagem no $R^{3}$.

A equação utilizada foi :

$$
D_{n}=\frac{\log \left(N_{n}\right)}{\log \left(2^{n}\right)}
$$

onde $D_{n}$ representa uma valor para a imagem fracionada $n$ vezes, $N_{n}$ é o número boxes (ou cubos) que interceptam a imagem representada. 
O cálculo de $N_{n}$ é feito com base nos tons de cinza dos pixels do grid $(i, j)$ da seguinte forma: sejam $\operatorname{Cinza}_{\max }(i, j)$ e $\operatorname{Cinza}_{\min }(\mathrm{i}, \mathrm{j})$ os valores máximo e mínimo dos valores de cinza da imagem no grid $x, y$.

$$
\begin{gathered}
N_{n}=\sum n_{n}(i, j) \text {, onde } \\
n_{n}(i, j)=\operatorname{inteiro}\left(\frac{\operatorname{Cinz}_{\text {max }}(i, j)-\operatorname{Cinza}_{\text {min }}(i, j)}{S^{\prime}}\right)+1
\end{gathered}
$$

$N_{n}$ é tomado para os diferentes valores de $n$, isto é, para diferentes tamanhos de grids. Esta forma de contagem de $N_{n}$ fornece uma melhor aproximação dos boxes que interceptam a superfície dos níveis de cinza da imagem. A dimensão fractal $(d f)$ da imagem é estimada por média entre os $D_{n}$, ou ainda pelo coeficiente angular da reta obtida a partir de um gráfico log-log de $n$ vs. $D_{n}$, pelo método dos mínimos quadrados $^{72}$, como mostrado na equação 42.

$$
d f=\frac{\sum(\bar{x} * \bar{y})-\sum \bar{x} * \sum \bar{y}}{\left(\sum \bar{x}^{2}\right)-\left(\sum \bar{x}\right)^{2}}
$$

As parcelas Cinza_max e Cinza_min, no algoritmo implementado, correspondem às duas matrizes que armazenam as informações de tons máximo e mínimo da imagem à medida que cada pequeno grid de $2 \times 2$ é "lido". Visando principalmente a eficiência computacional, uma imagem só é "lida" uma única vez e então são armazenadas as matrizes Cinza_max e Cinza_min. Para uma imagem com tamanho $M \times M$ são armazenadas inicialmente duas matrizes $M / 2 \times M / 2$. As intensidades de cinza da imagem não precisam ser "lidas" novamente, armazenadas 
em matrizes $M \times M$ ou conservadas durante os cálculos. Esta implementação é particularmente importante em um processamento automático. O valor de $\mathrm{M}$ utilizado é 256, logo as imagens processadas têm 256x256 e 256 níveis de cinza. Caso alguma imagem tenha tamanho $(x, y)$ maior que 256, ela é subdividida em 256x256 para garantir a integridade do método. A partir da obtenção de uma imagem, o primeiro passo do método é gerar as duas matrizes $\operatorname{Cinza}_{\max }$ e $\operatorname{Cinza}_{\min }$. Na primeira iteração lê-se, de cada matriz, um box 2x2x2. Com base nestes valores são calculados os $n_{7}(i, j)$ (eq. 41), os $N_{7}$ (eq. 40) o $D_{7}$ (eq. 39) e novas matrizes Cinza_max e Cinza_min são geradas tendo agora o tamanho de $64 \times 64$. O limite para o término deste procedimento é o tamanho mínimo das matrizes definido em $8 \times 8$. Este limite foi fixado levando em conta testes ${ }^{73}$ de avaliação do método que quantificaram este valor como recomendável. Variações crescentes de $n$ correspondem às variações dos grids de $2 \times 2,4 \times 4,8 \times 8 \ldots .2 n \times 2 n$. No procedimento implementado, a variação de $n$ é decrescente. Na primeira iteração $n=7$, grid de $128 \times 128$ correspondentes às matrizes iniciais $C_{i n z a} a_{\max }$ e $C i n z a_{\min }$.

Em linhas gerais, o algoritmo implementado para o cálculo da dimensão fractal deve executar os seguintes passos:

1. Entrar com imagem de 256 tons de cinza.

2. Criar as matrizes $C i n z a_{\max }$ e $C i n z a_{\min }$ que armazenarão os tons máximos e mínimos de cinza da imagem. Estas matrizes são inicializadas com valores 0 e 255, respectivamente. Após a leitura da imagem os elementos destas matrizes contém os níveis de cinza máximo e mínimo da imagem. Este 
primeiro armazenamento das matrizes segue o procedimento recursivo de seleção dos máximos e mínimos;

3. Calcular a dimensão fractal da imagem por regressão linear através dos valores de log dos pares combinados.

Alguns dos métodos conhecidos para o cálculo da dimensão fractal ${ }^{74,75,76,77}$ são comparados por Sarkar e Chaudhuri ${ }^{48}$ principalmente com relação à precisão no cálculo e complexidade computacional. A precisão é medida com base em imagens de texturas naturais conhecidas (imagens de Brodatz) e em imagens sintéticas. A complexidade é comparada, em termos de tempo de CPU, graficamente. Os resultados destas comparações mostram que o método proposto por Sarkar e Chaudhuri tem respostas mais rápidas.

Para determinar o valor da dimensão fractal foi necessária a utilização dos seguintes recursos matemáticos:

1. Determinação do coeficiente angular através de regressão linear.

$$
b=\frac{n \sum(X Y)-\sum X \sum Y}{n \sum X^{2}-\left(\sum X\right)^{2}}
$$

Onde:

- $n$ é o número de pares ordenados;

- $\quad \sum X Y$ é o somatório do produto dos pares ordenados $x_{i}$ e $y_{i}$;

- $\quad \sum X$ é o somatório dos valores de $x_{i}$;

- $\quad \sum Y$ é o somatório dos valores de $y_{i}$;

- $\quad \sum X^{2}$ é o somatório dos valores de $x_{i}^{2}$; 
- $\quad\left(\sum X\right)^{2}$ é o quadrado do somatório dos valores de $x_{i}$;

2. Cálculo do coeficiente de correlação linear de Pearson.

Em estatística descritiva, o coeficiente de correlação de Pearson, também chamado de "coeficiente de correlação produto-momento" ou simplesmente de " $r$ de Pearson" mede o grau da correlação (e a direção dessa correlação - se positiva ou negativa) entre duas variáveis de escala métrica.

Este coeficiente, normalmente representado pela letra " $r$ " assume apenas valores entre -1 e 1 .

Quando:

$r=1$ Significa uma correlação perfeita positiva entre as duas variáveis;

$r=-1$ Significa uma correlação negativa perfeita entre as duas variáveis

- Isto é, se uma aumenta, a outra sempre diminui;

$r=0$ Significa que as duas variáveis não dependem linearmente uma da outra. No entanto, pode existir uma outra dependência que seja "não linear".

Assim, o resultado $r=0$ deve ser investigado por outros meios. Desta forma:

$$
r=\frac{\sum\left(x_{i}-\bar{x}\right) *\left(y_{i}-\bar{y}\right)}{\sqrt{\sum\left(x_{i}-\bar{x}\right)^{2} * \sum\left(y_{i}-\bar{y}\right)^{2}}}
$$

Assim com os valores de $b$ e $r$ aplicados aos cálculos da determinação da dimensão fractal, pode ser relacionada a co-linearidade dos resultados. 


\section{Capítulo 3- PROCEDIMENTO EXPERIMENTAL}

Neste capítulo serão abordados os procedimentos executados neste trabalho, como a funcionalidade do aplicativo elaborado para as análises dos métodos de processamento digital de imagens estudados. A seqüência de apresentação dos tópicos deste capítulo seguem a ordem de execução das atividades desenvolvidas.

\subsection{Imagens sintéticas}

Com a finalidade de validar o modelo utilizado foram criadas imagens baseadas na classificação da hidrofobicidade do guia STRI. Os algoritmos baseados na análise da morfologia matemática, no cálculo da dimensão fractal e descritores de textura foram utilizados para avaliar a textura das imagens sintéticas.

\subsubsection{Metodologia para Obtenção de Imagens Sintéticas}

Para a validação do aplicativo implementado, inicialmente foram obtidas imagens a partir de placas de silicone fornecidos por um fabricante de isoladores 
elétricos. Assim, estas placas têm a mesma composição dos isoladores elétricos atualmente utilizados nas linhas de transmissão.

Como sugerido em trabalhos realizados por outros autores ${ }^{35}$, as superfícies destas placas foram inicialmente submetidas ao desgaste por jato-de-areia, para a obtenção do HC01 até HC06. Porém, este procedimento se mostrou pouco eficiente pois, não foi possível controlar o desgaste das placas combinado ao $\mathrm{HC}$ desejado.

Buscando uma forma alternativa para obter diferentes $\mathrm{HC}$, foram produzidas soluções de álcool isopropílico e água destilada (AIA), de 0\%vol até $100 \%$ vol em frações de $10 \%$ vol, para definir os HC sobre as superfícies das placas sem desgaste. Neste trabalho, a referência do volume foi feito em relação a quantidade de álcool isopropílico na solução. Inicialmente, foram definidos os ângulos de molhamento de cinco gotas para cada solução, sendo estes ângulos relacionados ao guia da STRI. Posteriormente, foram obtidas cinco imagens da textura produzidas pelo borrifamento de cada solução sobre a placa de silicone, utilizando uma câmera digital com resolução de 640x480 pixels, rotuladas como original (OR). A análise da textura por morfologia matemática, dimensão fractal e descritores de texturas foi posteriormente comparada à classificação do guia da STRI. A dimensão das imagens de $640 \times 480$ pixels foi adotada por ser àquela encontrada nas câmeras atualmente embarcadas nos $P D A^{\prime}$ 's.

O álcool isopropílico foi escolhido pelo alto fator de apolaridade de suas cadeias carbônicas, permitindo o molhando completo da superfície do isolador. Além disso, ele é de fácil remoção (sem deixar resíduos), não agride quimicamente a borracha de silicone, apresenta baixo custo e baixa pressão de vapor. 


\subsubsection{Obtenção das curvas de abertura e fechamento nas imagens do guia da STRI}

Com o objetivo de definir texturas padrão para análise da $\mathrm{HC}$, foram realizadas as operações de abertura e fechamento nas imagens da STRI. A partir destas operações foram obtidas curvas do volume das imagens em função do tamanho do elemento estruturante, uma vez que, de acordo com Soille ${ }^{9}$, seria possível utilizar elementos quadrados para definir o tamanho dos elementos presentes na imagem. $O$ valor do volume aumenta para a operação de abertura e reduz quando aplica-se a operação de fechamento, mostrando a funcionalidade do processo utilizado. Para ser possível realizar a comparação entre as curvas, elas foram normalizadas de 0 até 1,0 .

Após este procedimento, foram obtidas as derivadas para a definição dos elementos presentes na imagem. Posteriormente, calculou-se as integrais destas curvas como forma de quantificação das estruturas presentes na imagem.

Os resultados obtidos com estas imagens não apresentaram nenhuma correlação que pudesse gerar algum ajuste matemático. Desta forma, a validação do modelo proposto neste trabalho, foi realizada da análise das imagens sintéticas criadas em condições laboratoriais.

\subsubsection{Tratamentos Digitais}

Uma vez obtidas as imagens originais $(O R)$, o efeito do gradiente de iluminação natural do ambiente foi reduzido com aplicação de métodos de processamento digital de imagens, tais como, equalização de histograma (EQU), 
aplicação do filtro White Top-Hat (WTH), aplicação do filtro White Top-Hat após equalização de histograma (EQU+WTH), e novamente equalização de (EQU+WTH+EQU), e ainda detecção de bordas por Sobel (SOB).

\subsubsection{Análise da variação no gama das imagens}

Com o objetivo de analisar a condição de luminosidade das imagens, os valores do gama foram alterados de forma verificar sua influência na variação dos resultados. Imagens 0\%AIA tiveram sua iluminação modificada deste gama igual a 10 (escura), até 300 (clara) em uma escala logarítmica, onde gama igual a 100 representa a imagem sem modificação.

\subsubsection{Análise de resolução, escala e tamanho das imagens}

A resolução, o escala e o tamanho das imagens foram avaliados de forma a considerar sua interferência nos resultados da HC. Para isso, uma imagem 0\%AIA com tamanho $1800 \times 1800$ pixels foi obtida uma câmera digital de 6,0MP. A partir desta imagem foram obtidas imagens com diferentes resoluções, escalas e tamanhos, variando entre 200×200 pixels até 1800×1800 pixels. Este procedimento visa simular uma situação real, onde diferentes operadores podem alterar a distância de obtenção das imagens.

\subsection{Desenvolvimento do Aplicativo para Microcomputadores}

Os aplicativos para implementação e testes dos algoritmos foram 
desenvolvidos em $\mathrm{C}++$. Esta linguagem é de fácil aplicabilidade na manipulação de imagens e apresenta uma velocidade de processamento relativamente alta comparada com aplicativos atualmente utilizados para este fim. A grande maioria dos trabalhos revisados utilizam $\circ$ Matlab $^{\circledR}$ para a análise das imagens. Apesar deste aplicativo possuir diversas ferramentas prontas para a análise de imagens, optou-se por desenvolvê-las para a inovadora implementação em dispositivos portáteis. Neste trabalho o dispositivo utilizado foi um TREO750 da Palm que possui um processador Samsung 300MHz e 128MBytes de memória RAM.

\subsubsection{Algoritmo para detecção de bordas através de matrizes de convolução}

Para reduzir o número de iterações desnecessárias, foi incluída uma variável para limitar o ciclo de cálculos em função do tamanho da matriz. Este procedimento reduziu em $40 \%$ o tempo de execução da rotina original quando era considerada uma matriz de $3 \times 3$. O pseudo-algoritmo, a seguir, ilustra o funcionamento da rotina de detecção das bordas de uma imagem em escala de cinza. O algoritmo para o cálculo da convolução está descrito a seguir.

1)Início;

2)Calcula a resposta da máscara Sobel sobre um pixel;

3)Escreve em uma nova imagem, a resposta da máscara na posição do pixel analisado em 2);

4)Desloca uma posição de pixel na imagem analisada;

5)Realiza a leitura da última coluna da máscara e descarta os valores da primeira 
coluna (processo de recursividade);

6)Retorna para 2);

7)Repete passos de 2) até 5) até fim da imagem;

8)Fim.

\subsubsection{Algoritmo para determinação da HC utilizando binarização e morfologia matemática}

A partir da limiarização da imagem original, os operadores matemáticos de abertura e fechamento, podem ser aplicados com maior confiabilidade. Apesar da possibilidade de aplicação dos operadores poderem ser aplicados nas imagens em escala de cinza, os melhores resultados foram obtidos utilizando as imagens binárias. O pseudoalgoritmo a seguir, foi utilizado para binarizar as imagens capturadas.

1)Início;

2)Define do limiar de binarização;

3)Se o valor do pixel é maior do que o limiar, escreve branco, senão preto;

4)Repete 3) até o final da imagem;

5)Exibe imagem binarizada;

6)Fim.

As imagens binarizadas foram submetidas às rotinas de abertura $e$ fechamento com a aplicação do elemento estruturante quadrado de lado variando de $3 \times 3$ até $101 \times 101$. Este limite superior foi definido com base em um quarto da altura 
da imagem original, nas quais as gotas não apresentam dimensões superiores a este valor. Posteriormente, foi obtida uma curva do volume das imagens em função do tamanho do elemento estruturante. Esta curva é derivada do volume em função do tamanho do elemento estruturante. Os valores de picos da curva da derivada são definidos para determinar o tamanho dos elementos presentes na imagem.

De acordo com Soille ${ }^{9}$, estes pontos de máximo e mínimo representam o tamanho dos elementos presentes na imagem analisada. Para o caso do estudo da hidrofobicidade, estes picos indicam a presença de gotas e a distribuição de seus tamanhos.

\subsubsection{Algoritmo para cálculo da dimensão fractal}

As análises foram realizadas em imagens do tipo bitmap. Deve ser observado que, na implementação aqui mostrada, a principal preocupação é a aplicação final do cálculo da dimensão fractal de imagens. Em termos de eficiência, o algoritmo desenvolvido é capaz de medir dimensões fractais em todo intervalo entre 2 e 3 (inclusive). Características importantes desta implementação (visando a diminuição do tempo de processamento) são: o uso de um procedimento recursivo no qual é feita uma variação decrescente no tamanho dos box usados no cálculo; a leitura única das informações sobre os tons de cinza da imagem e o cálculo da dimensão fractal da imagem são feitos por regressão linear utilizando o método dos mínimos quadrados para a determinação do coeficiente angular em um gráfico log-log. A rotina para o cálculo da dimensão fractal está representada no pseudo-algoritmo a seguir. 
1)Início;

2)Inicializa $B O X=2$;

3)Determina do nível de cinza máximo e mínimo no BOX relacionado a cada pixel da imagem;

4)Calcula $n_{n}=\sum \frac{\operatorname{Cinza}_{\max }-\operatorname{Cinza}_{\min }}{B O X}+1$;

5)Calcula $D_{n}=\frac{\log n_{n}}{2^{B O X}}$

6)Soma 1 no tamanho do BOX até 5. Retorna para 3);

7)Calcula da dimensão fractal pela regressão linear de $D_{n}$ vs BOX; 8)Fim.

Este algoritmo visa a determinação da dimensão fractal de imagens em escala de cinza. Este procedimento otimiza o processamento, uma vez que não são necessários procedimentos auxiliares, tais como binarização ou detecção de bordas.

\subsubsection{Determinação da Entropia, Energia, Variância e Homogeneidade} das imagens

Para o cálculo dos descritores de textura entropia, energia, variância e homogeneidade, baseados na GLCM das imagens, foi implementado o algoritmo com pseudo-algoritmo descrito a seguir:

1)Início;

2)Obtém a GLCM com deslocamento $d x=1$; 
3)Normaliza a GLCM em função do tamanho da imagem;

4)Calcula entropia por $S=-\sum G L C M \times \log (G L C M)$;

5)Calcula energia por $E=\sum(G L C M)^{2}$;

6)Calcula variância por $\quad \sigma_{2}=\sum(i-\mu)^{2} \times \log (G L C M)$;

7)Calcula homogeneidade por $\quad H=\sum \frac{G L C M}{1+|i-j|}$;

8)Exibe o valor da entropia, energia, variância e homogeneidade;

9)Fim.

Pode ser observado que, inicialmente é obtida a GLCM da imagem, através da varredura dos pixels e acumulação dos respectivos valores. Posteriormente, é feita a normalização baseada no tamanho da imagem, de forma a normalizar o valor para qualquer imagem analisada. Após esta etapa, determina-se o valor dos descritores de textura da imagem. Toda a rotina não demora mais que um segundo.

O deslocamento definido através de um vetor com direção de $0^{\circ}$ e módulo igual a 1 foi adotado de forma aleatória para a GLCM, uma vez que as imagens não apresentam orientação preferencial. Assim o deslocamento pode ser definido em qualquer direção. 


\section{Capítulo 4- RESULTADOS E DISCUSSÃO}

\subsection{Desenvolvimento dos Aplicativos}

Inicialmente para a validação do modelo proposto foi desenvolvido um aplicativo para microcomputador. Isso foi realizado pela praticidade de elaboração e maior velocidade de processamento do que no PDA.

Nos itens a seguir está mostrado o aplicativo elaborado para a validação do modelo.

\subsubsection{Aplicativo de validação no microcomputador}

O aplicativo desenvolvido tem as seguintes funcionalidades:

1. Leitura de imagens de até $640 \times 480$ pixels;

2. Processamento da função White top-hat;

3. Exibição do histograma e cálculo dos descritores de textura estudados;

4. Definição da matriz de convolução a ser utilizada na detecção de bordas;

5. Exibição e gravação da imagem com as bordas detectadas; 
6. Determinação da morfologia matemática a ser aplicada;

7. Determinação do limiar (threshold) para a aplicação das rotinas de binarização;

8. Cálculo da dimensão fractal.

A partir das funcionalidades descritas acima foi possível validar o método de classificação da hidrofobicidade.

A figura 25 mostra a janela do aplicativo desenvolvido para microcomputador. Neste formulário podem ser abertas várias imagens. Ele mostra a imagem sob análise que será avaliada pelas ferramentas do aplicativo.

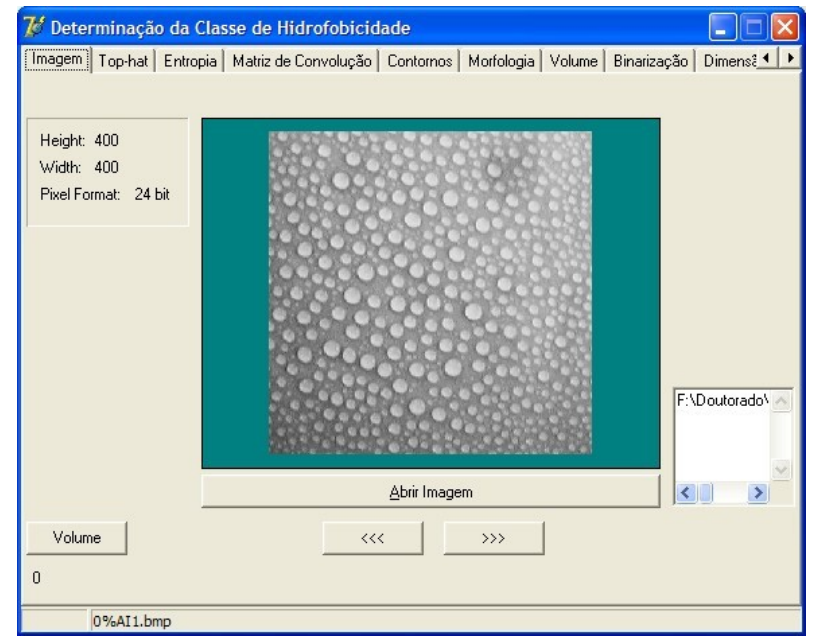

Figura 25. Formulário de abertura das imagens a serem analisadas.

A figura 26 mostra o formulário para a parametrização e obtenção das imagens com aplicação do WTH. Nesta situação, pode ser selecionado o tamanho do elemento estruturante para a aplicação do filtro. Após a aplicação da ferramenta, o aplicativo exibe a imagem final, que pode ser gravada. 


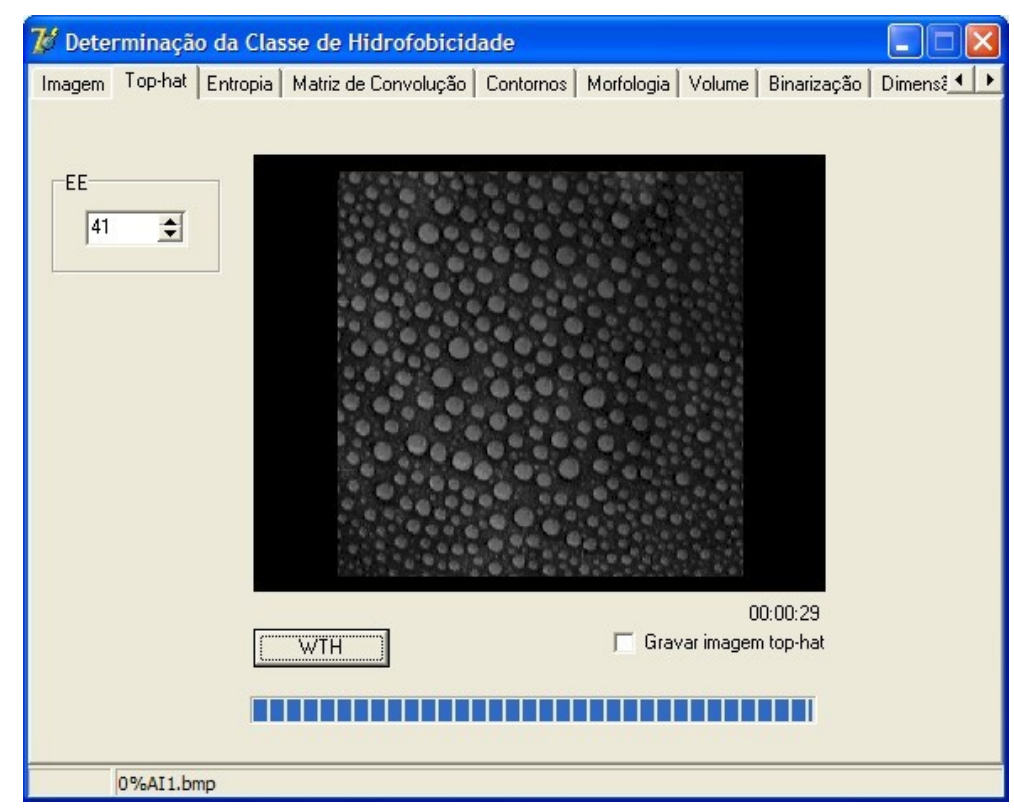

Figura 26. Formulário para parametrização e obtenção da imagem com correção de iluminação.

A obtenção dos valores dos descritores de textura para a imagem aberta através do primeiro formulário pode ser realizada pelo formulário mostrado na figura 27. Neste caso é mostrado o histograma normalizado da imagem e os valores da entropia, energia, variância e homogeneidade.

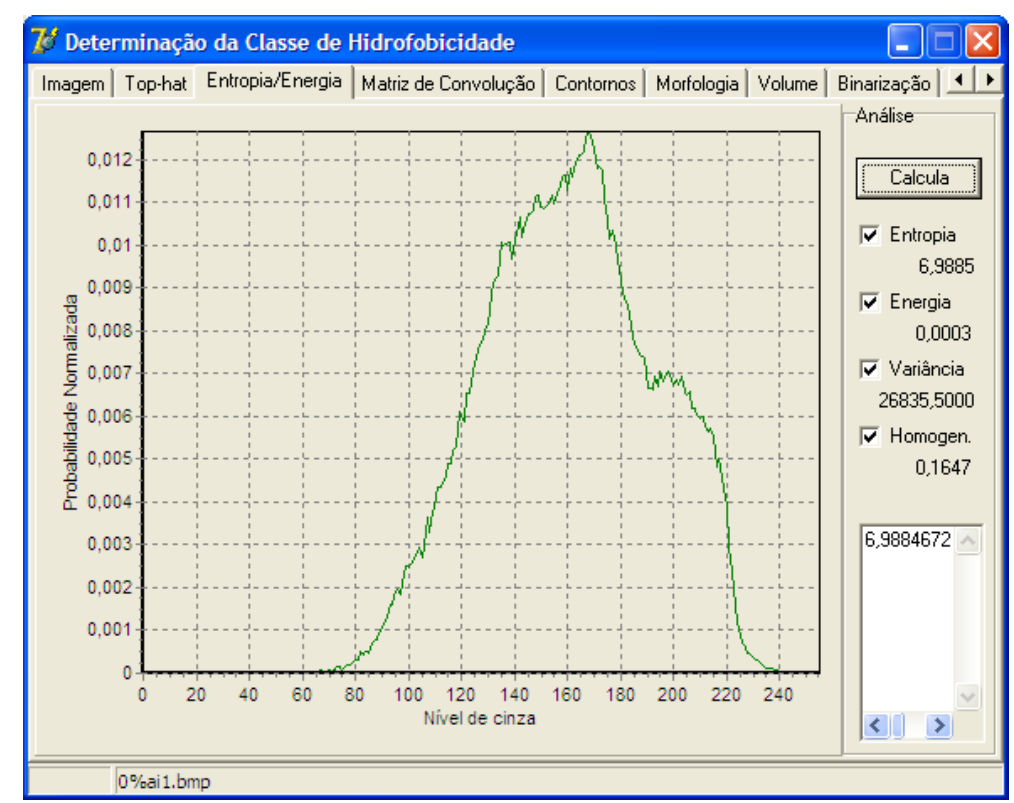

Figura 27. Obtenção do valor da entropia da imagem e visualização do histograma. 
A figura 28 ilustra o formulário para a definição da matriz de convolução, assim como a inserção de valores customizados. O usuário pode selecionar o tipo de máscara que deseja aplicar, ou ainda criar uma máscara de acordo com uma necessidade específica.

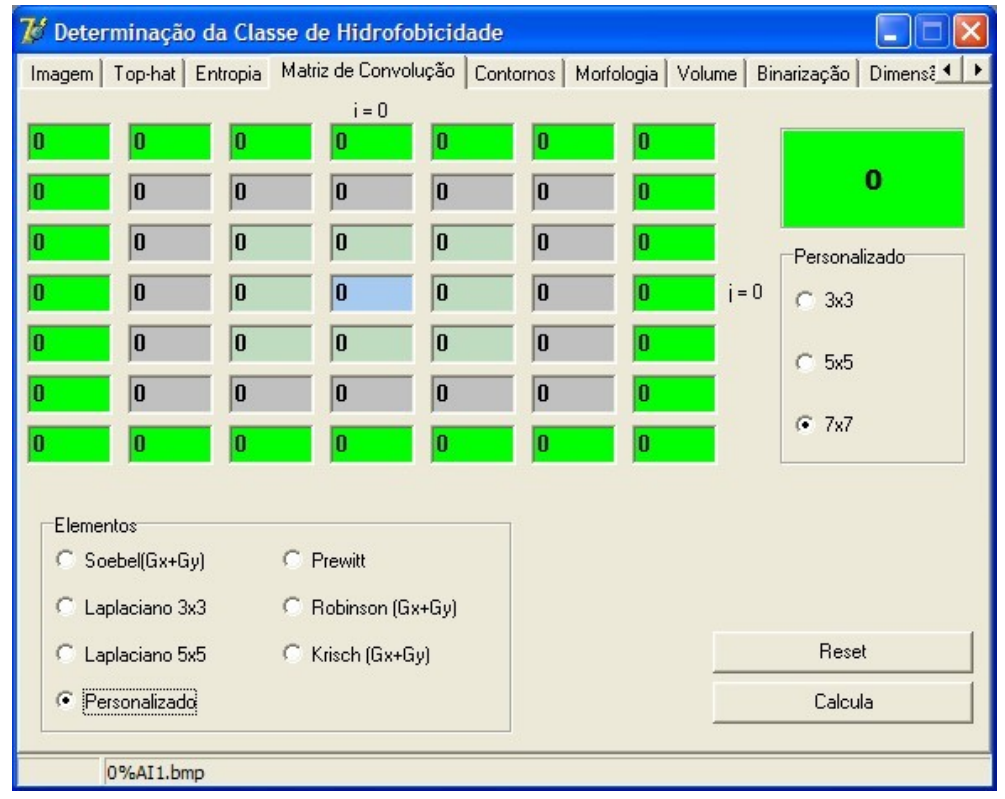

Figura 28. Formulário para definição da matriz de convolução para a detecção de bordas.

A figura 29 mostra o formulário referente à imagem resultante da aplicação da detecção de contornos. Pode ser observada a obtenção dos contornos da imagem da figura 25 com a aplicação do operador Sobel. 


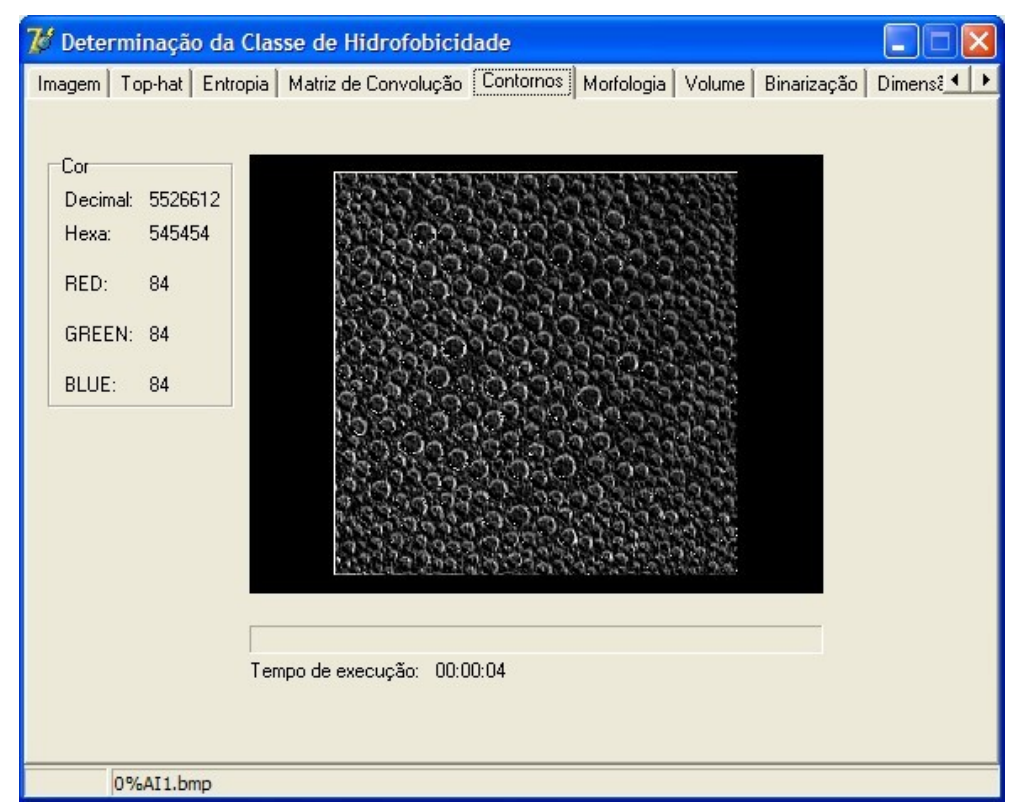

Figura 29. Formulário de obtenção da imagem gerada por detecção de contornos.

A definição dos parâmetros a serem utilizados na morfologia matemática é realizada no formulário ilustrado na figura 30 . Neste formulário pode ser definida a faixa dos elementos estruturantes a serem aplicados, se o processo será de abertura e/ou fechamento, e ainda se a convergência no valor do volume da imagem será monitorada. 


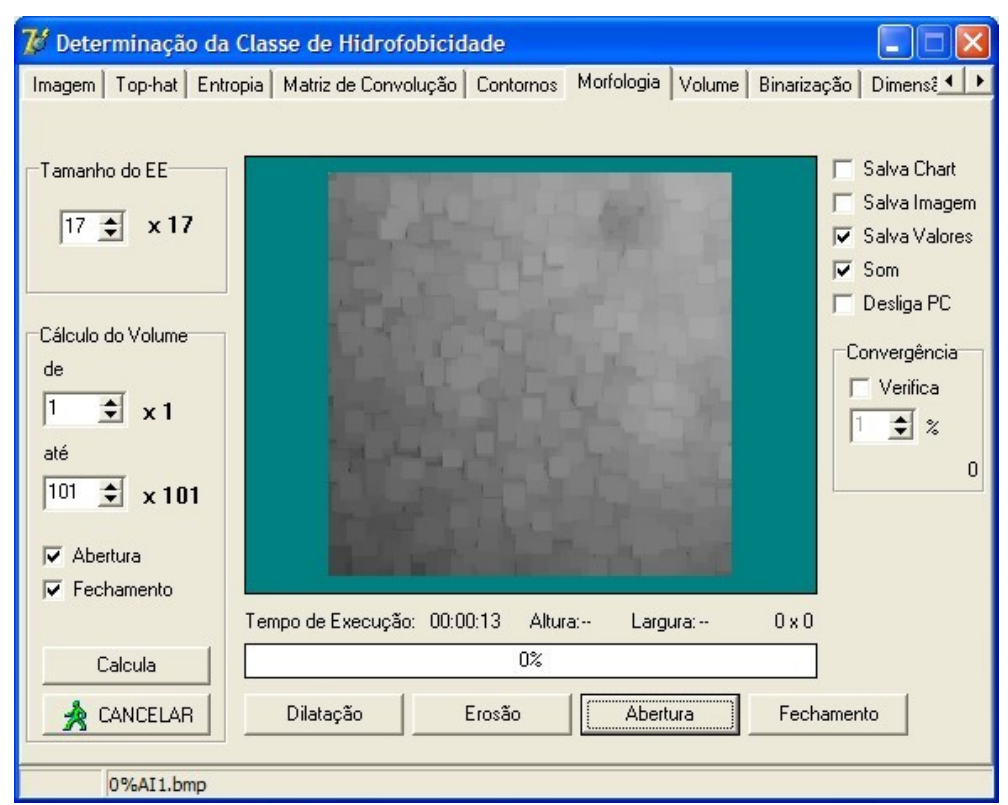

Figura 30. Formulário para parametrização da morfologia matemática.

Na figura 31 está apresentado o formulário para a obtenção do valor da dimensão fractal de imagens em escala de cinza. O tamanho do box pode ser variado de 1 até 11 . Através deste formulário são obtidos os valores do coeficiente angular da reta, neste caso $d f$, e o coeficiente de correlação.

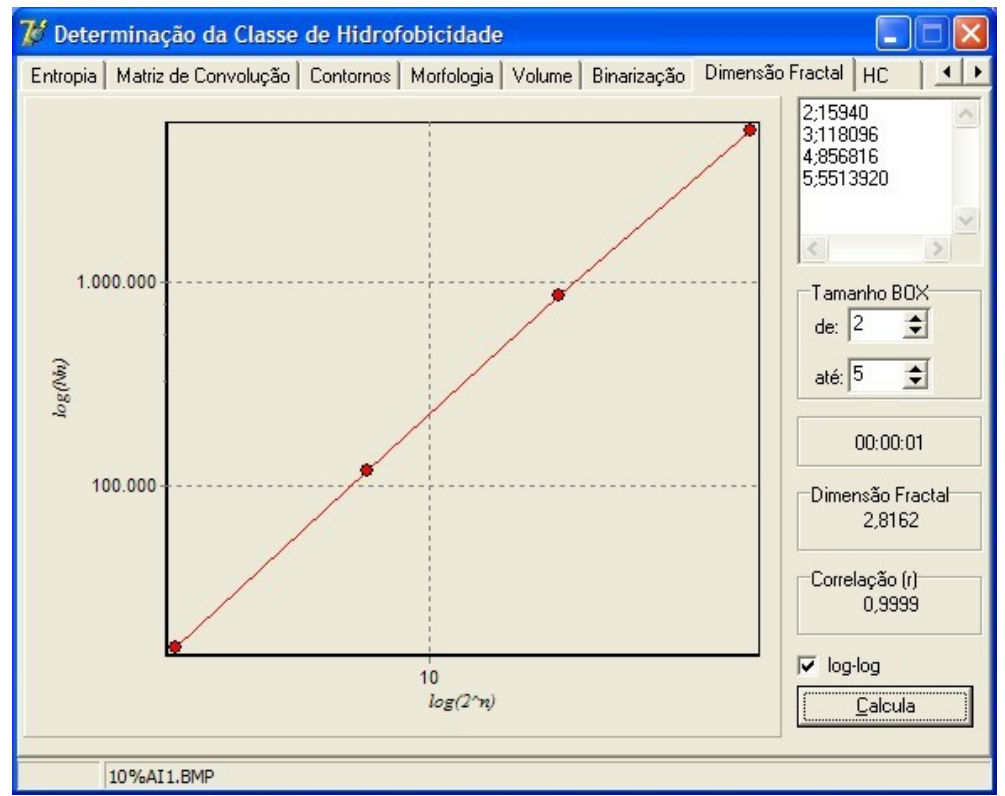

Figura 31. Formulário para exibição dos valores obtidos a partir do cálculo da dimensão fractal da imagem original. 
A partir deste aplicativo foi possível aplicar os métodos estudados para determinar o melhor procedimento a ser utilizado na classificação da hidrofobicidade.

\subsubsection{Imagens sintéticas}

A seguir serão mostrados os resultados obtidos para as imagens produzidas em ambiente controlado.

\subsubsection{1. Ângulo de molhamento}

Para definir um padrão de molhamento foram medidos os ângulos de contato das gotas de solução de 0 até $100 \%$ AIA, sobre uma superfície plana e horizontal. O material desta superfície tem a mesma composição do isolador elétrico. A Figura 32 exemplifica a imagem de uma gota de água destilada ( $0 \% A I A)$, utilizada para medir o ângulo de contato.

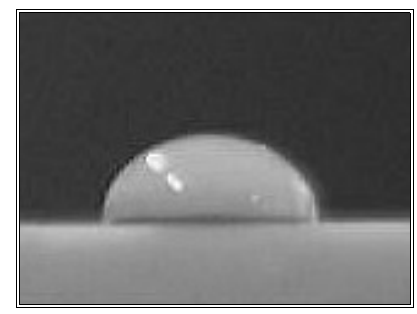

Figura 32. Imagem de uma gota de água destilada sobre uma superfície plana de borracha de silicone.

A partir das imagens das gotas foi realizada a detecção de contornos utilizando Sobel, pois este operador apresentou a melhor definição dos contornos 
entre as matrizes testadas. A imagem da gota 100\%AIA não foi apresentada, pois não pôde ser determinado o ângulo de contato devido à sua hidrofilicidade. A figura 33 mostra a evolução do perfil das gotas para soluções variando de 0 até $90 \% \mathrm{AIA}$.
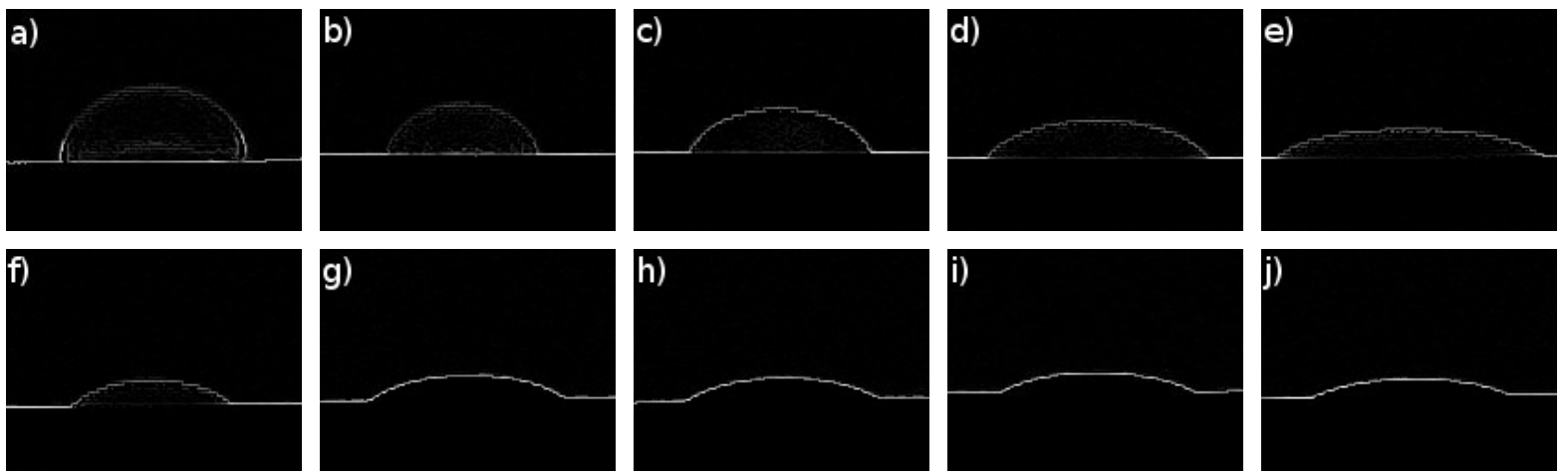

Figura 33. Imagens obtidas através da detecção de contornos utilizando Sobel em gotas com a) $0 \%$, b) $10 \%$, c) $20 \%$, d) $30 \%$, e) $40 \%$, f) $50 \%$, g) $60 \%$, h) $70 \%$, i) $80 \%$ e j) $90 \%$ AIA sobre uma superfície horizontal.

Desta forma, nota-se a evolução na redução do ângulo de contato com a adição do álcool. Este efeito é função da redução da tensão superficial, uma vez que a solução passa a apresentar uma característica mais apolar decorrente da presença de cadeias orgânicas do álcool. Para comparar estes resultados com os padrões da STRI foi gerada uma curva, ilustrada na figura 34 . A solução $0 \% A I$ apresenta HC01; as soluções de 10 e 20\%vol AIA representam HC02 e HC03; as soluções de 30 até $80 \%$ vol AIA representam HC03; para a solução acima de $80 \%$ vol AIA estaria na faixa do $\mathrm{HC} 04, \mathrm{HC} 05$ e HC06, porém no próprio guia da STRI estes índices não são definidos pelo ângulo de contato, mas pela textura da imagem analisada. 


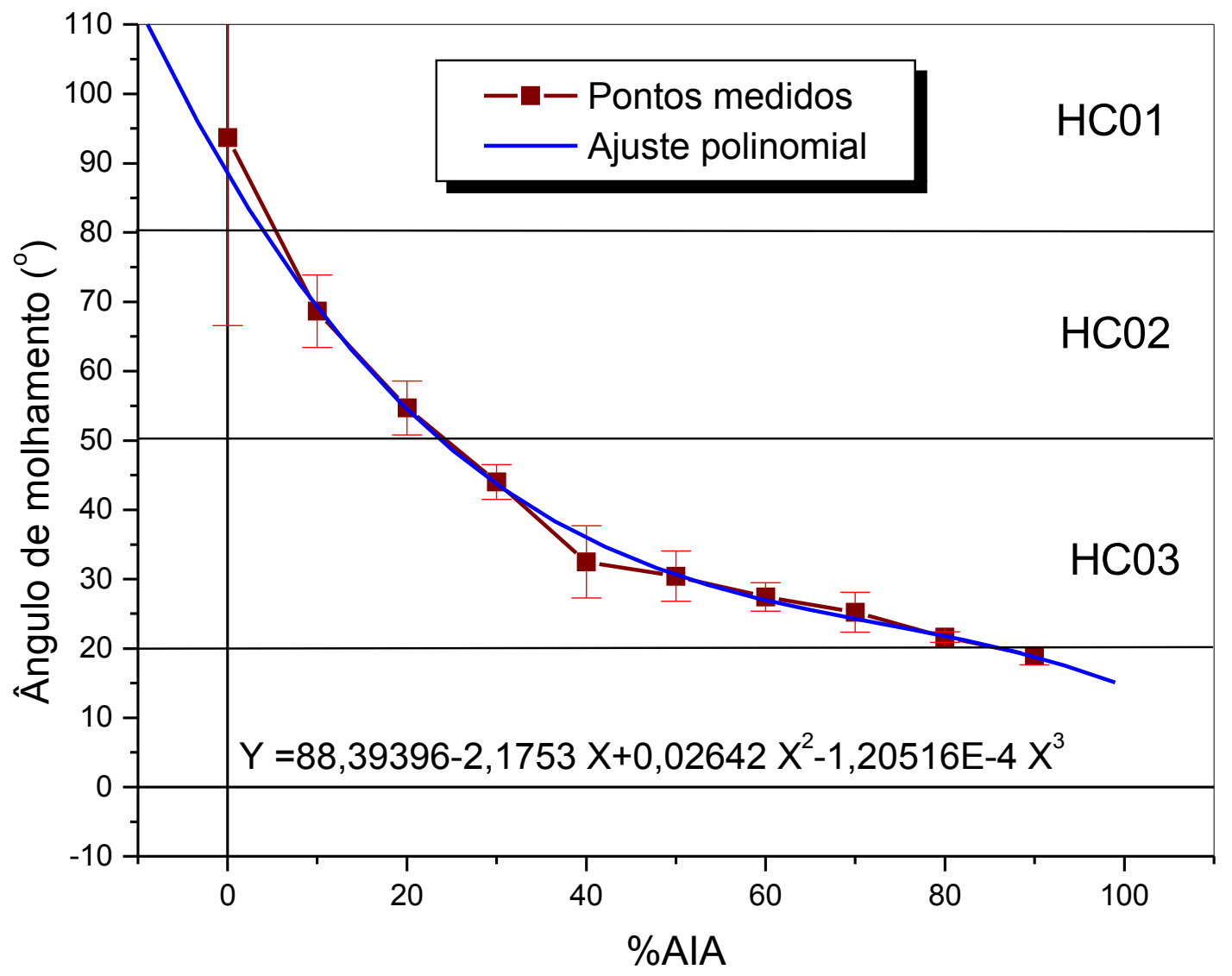

Figura 34. Relação do HC em função da curva da solução AIA vs. ângulo de contato

A figura 35 mostra as imagens das texturas obtidas a partir das soluções de 0 até $90 \%$ AIA. Para uma análise estatística foram obtidas dez imagens para cada solução. Nestas imagens foram aplicados os algoritmos de morfologia matemática, cálculo da dimensão fractal e descritores de textura. Abaixo de cada imagem está indicada a classificação da STRI. Através da comparação destas imagens com as disponíveis no guia da STRI (figura 7), é possível observar a semelhança entre as texturas, indicando a validade do método proposto. 


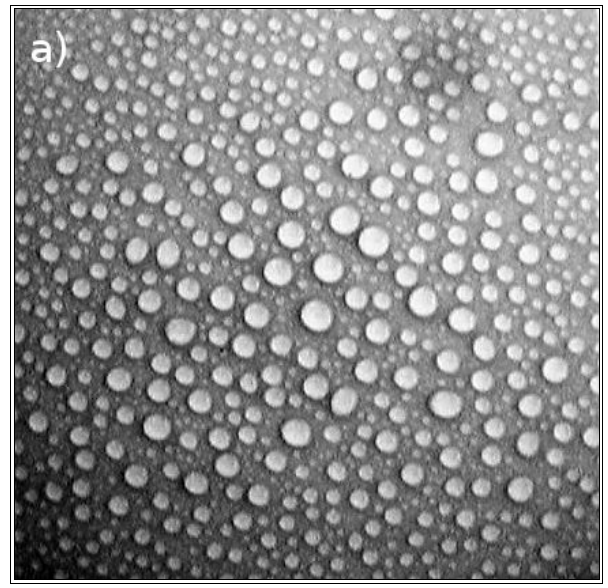

$\mathrm{HC} 01$

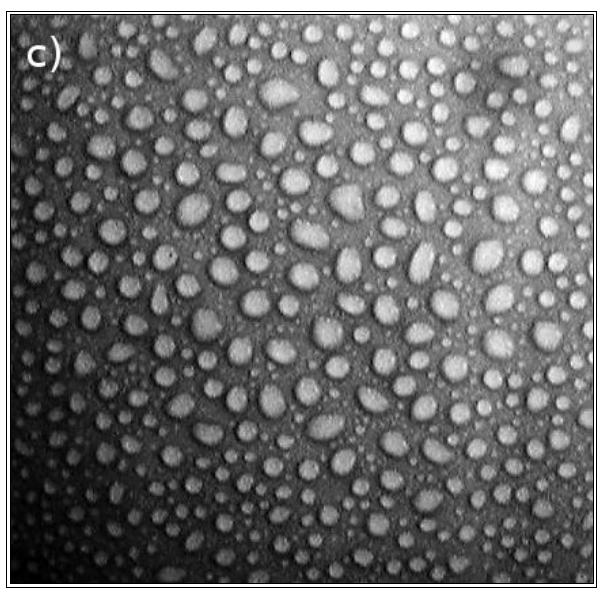

$\mathrm{HCO} 2$

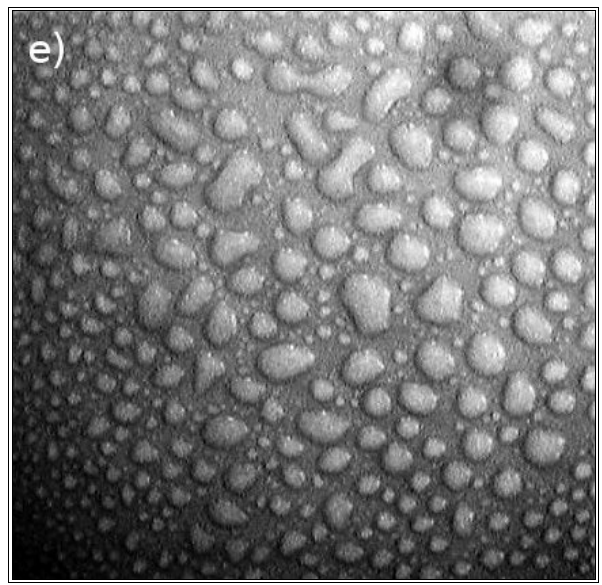

$\mathrm{HCO} 3$

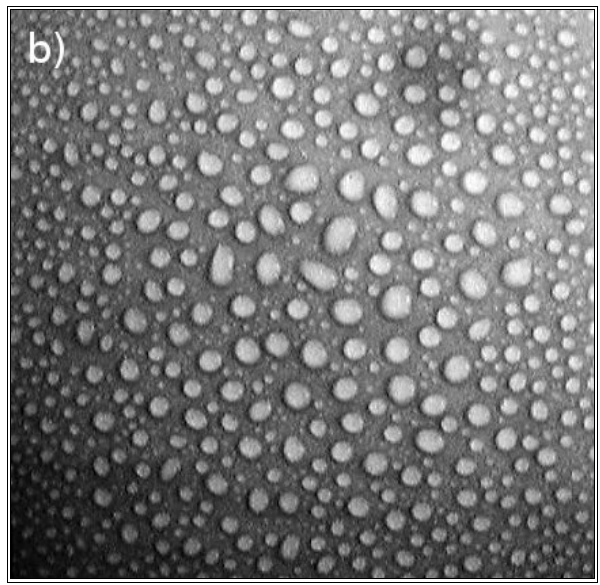

$\mathrm{HCO} 2$

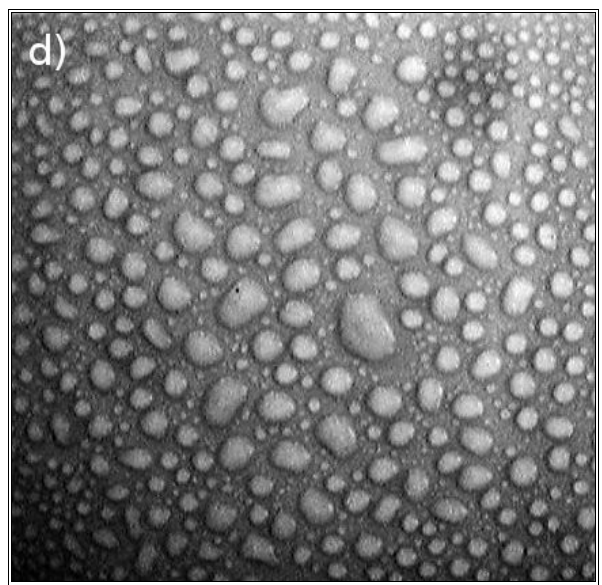

$\mathrm{HCO} 3$

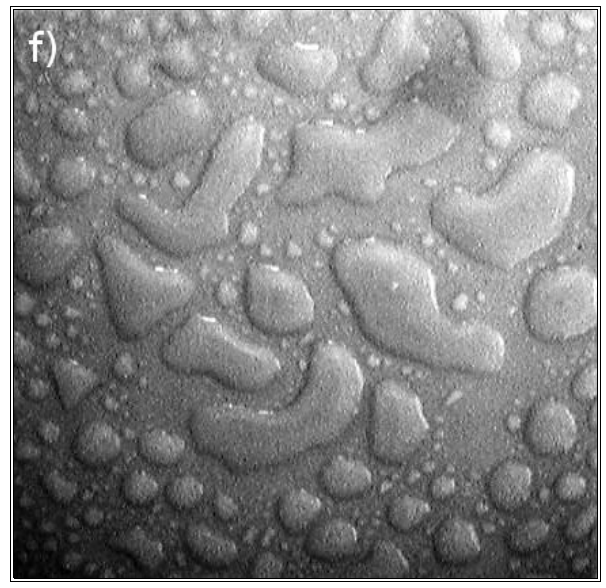

$\mathrm{HCO} 3$ 


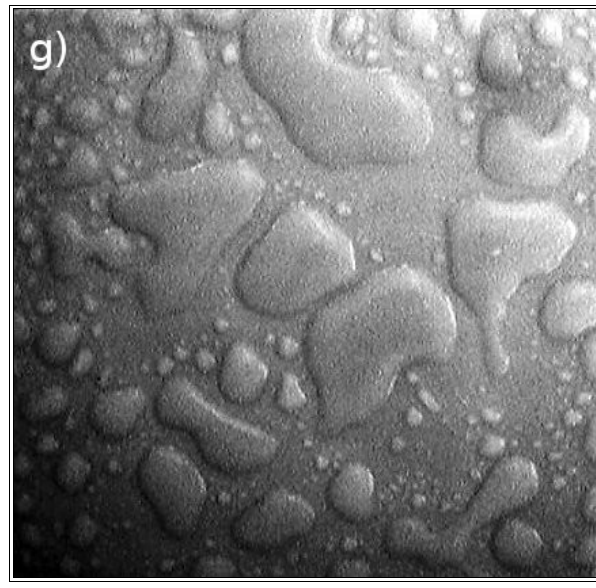

$\mathrm{HCO} 4$

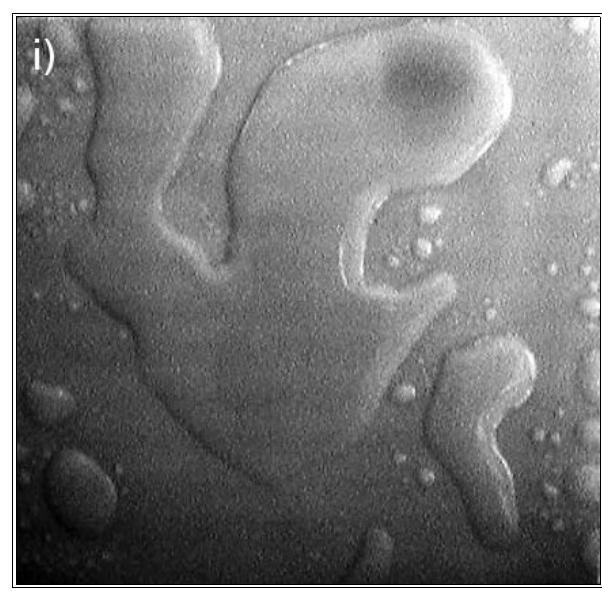

$\mathrm{HC05}$

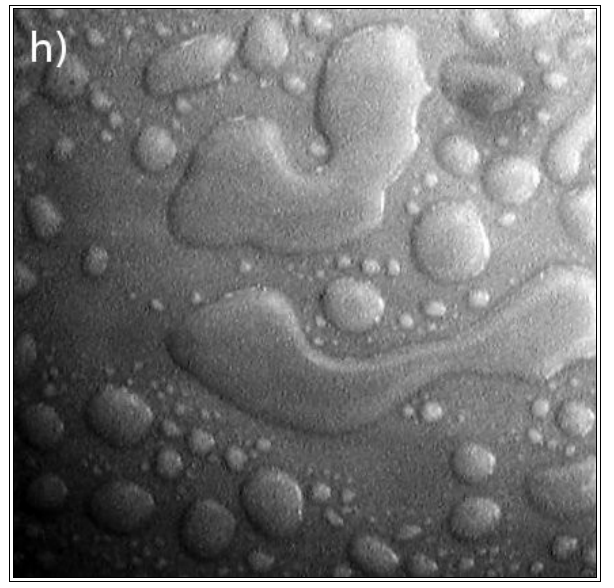

$\mathrm{HCO} 4$

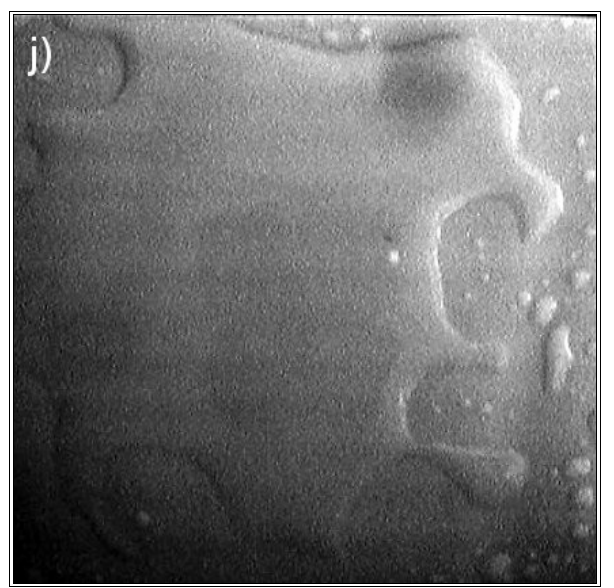

$\mathrm{HCO6}$

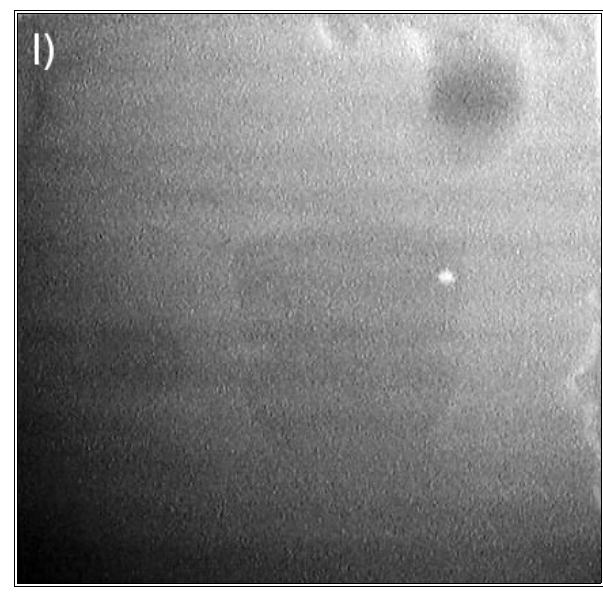

$\mathrm{HCO} 7$

Figura 35. Imagens sintéticas utilizadas para validação da metodologia. a) $0 \%$, b) $10 \%$, c) $20 \%$, d) $30 \%$, e) $40 \%$, f) $50 \%$, g) $60 \%$, h) $70 \%$, i) $80 \%$, j) 90 e l) $100 \%$ vol AlA. 


\subsubsection{Ajuste de luminosidade}

Uma grande dificuldade encontrada para a obtenção das imagens foi a condição de luminosidade, que influência no histograma, afetando determinação dos valores da morfologia matemática, dimensão fractal e descritores de textura. Desta forma, foi utilizado o processo de White Top-Hat para reduzir a interferência deste fator. A determinação do tamanho do elemento estruturante para a aplicação do filtro foi baseada na sua influência sobre a imagem gerada. Os volumes das imagens filtradas foram medidos em função do tamanho do elemento estruturante, conforme figura 36 .

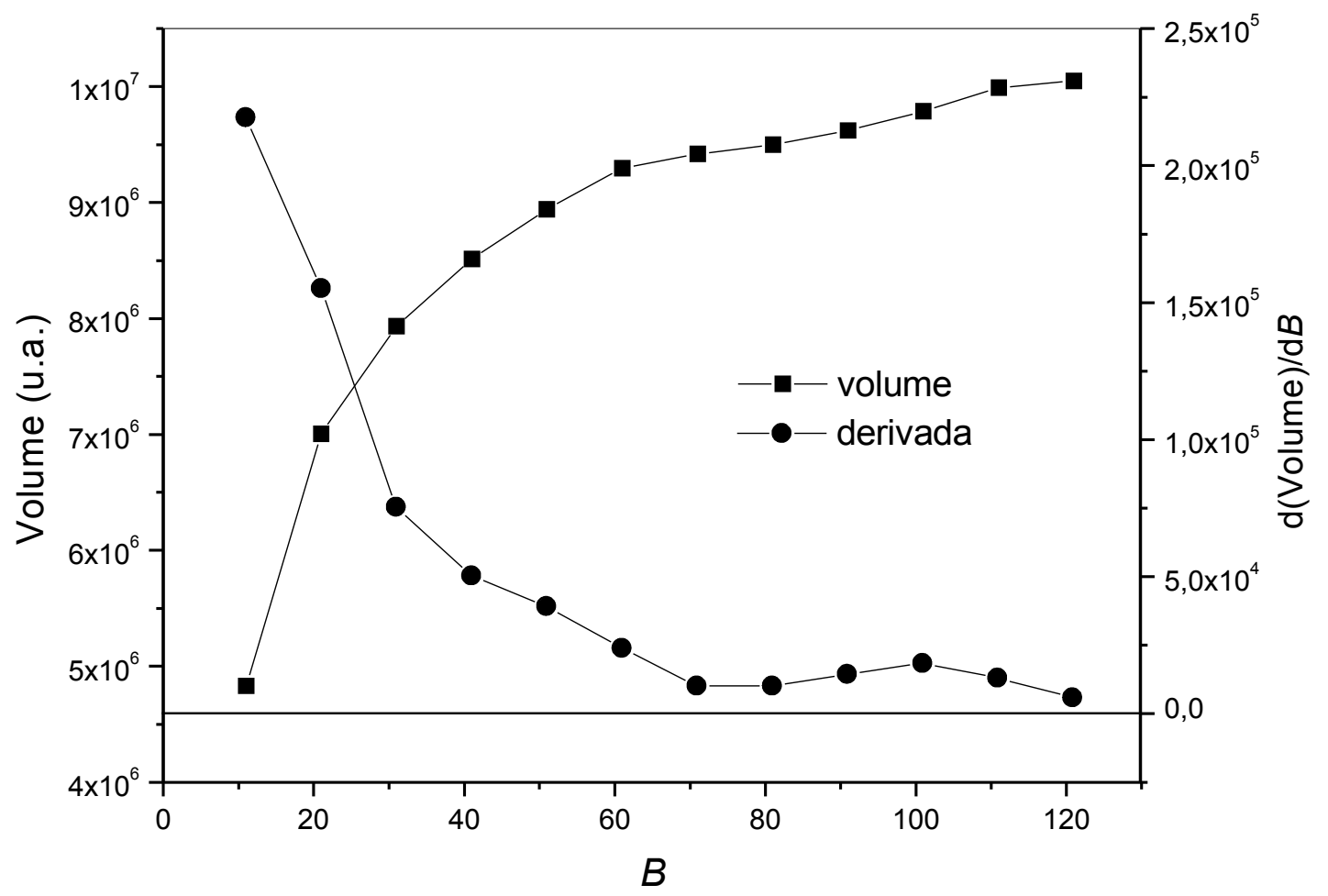

Figura 36. Volume e derivada do volume das imagens white top-hat em função do tamanho do elemento estruturante. 
Pode ser observado que a derivada do volume em relação ao tamanho do elemento estruturante apresenta convergência para $B>41 \times 41$, sugerindo que este tamanho seja o ideal para uma imagem de (400x400)pixels, referente a uma imagem de um objeto de $(10 \times 10) \mathrm{cm}$. Além disso, o aumento do tamanho do elemento estruturante provoca um aumento considerável no tempo de processamento.

\subsubsection{Análise por Morfologia Matemática}

Nesta seção serão descritos os métodos de avaliação do tempo de processamento e dos resultados obtidos pela avaliação por morfologia matemática.

\subsection{Avaliação do tempo de processamento.}

Como uma das formas de avaliar esta metodologia foi determinado o tempo de processamento das imagens. Para isso, as imagens foram processadas em um microcomputador Pentium IV 1,7 MHz, com 512Mb de memória RAM. A figura 37 ilustra o tempo de processamento utilizado para analisar as imagens através de morfologia matemática com e sem a implementação do algoritmo recursivo. Pode ser notada a significativa redução do tempo de processamento com a recursividade do algoritmo, assim como observado por Chaudhuri ${ }^{48}$. 


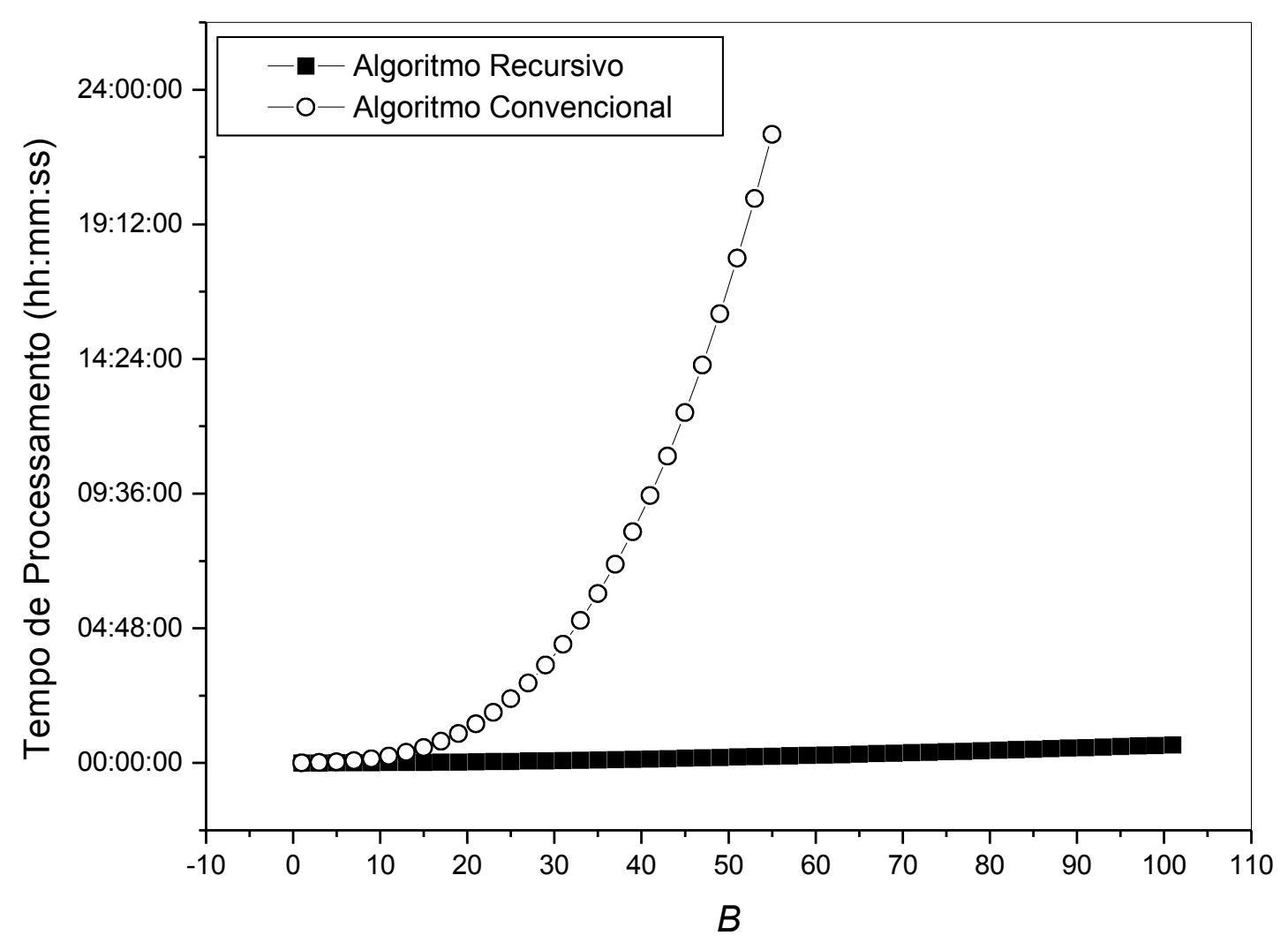

Figura 37. Tempo de processamento em função do tamanho do elemento estruturante.

Desta forma, a implementação do algoritmo recursivo reduziu significativamente o tempo de processamento, contribuindo para a sua utilização em dispositivos móveis.

\subsubsection{Avaliação das imagens por morfologia matemática}

A figura 38 apresenta as curvas do volume de abertura para as imagens OR, onde pode ser observado que há uma rápida convergência em função da textura das imagens de AIA. Para as imagens 100\%AIA, houve convergência para o $B \geq 15$, 
enquanto que para as imagens $0 \% \mathrm{AIA}$ a convergência ocorreu em torno de 41 . Isto está associado à ausência de elementos definidos nas imagens $100 \% \mathrm{AIA}$, efeito que é reduzido com a evolução das imagens na direção de 0\%AIA.

Com relação às outras figuras não foi observada uma relação direta entre as curvas de abertura com a textura da imagem. Isto pode estar associado ao fato da alteração dos valores de abertura com o tratamento das imagens.

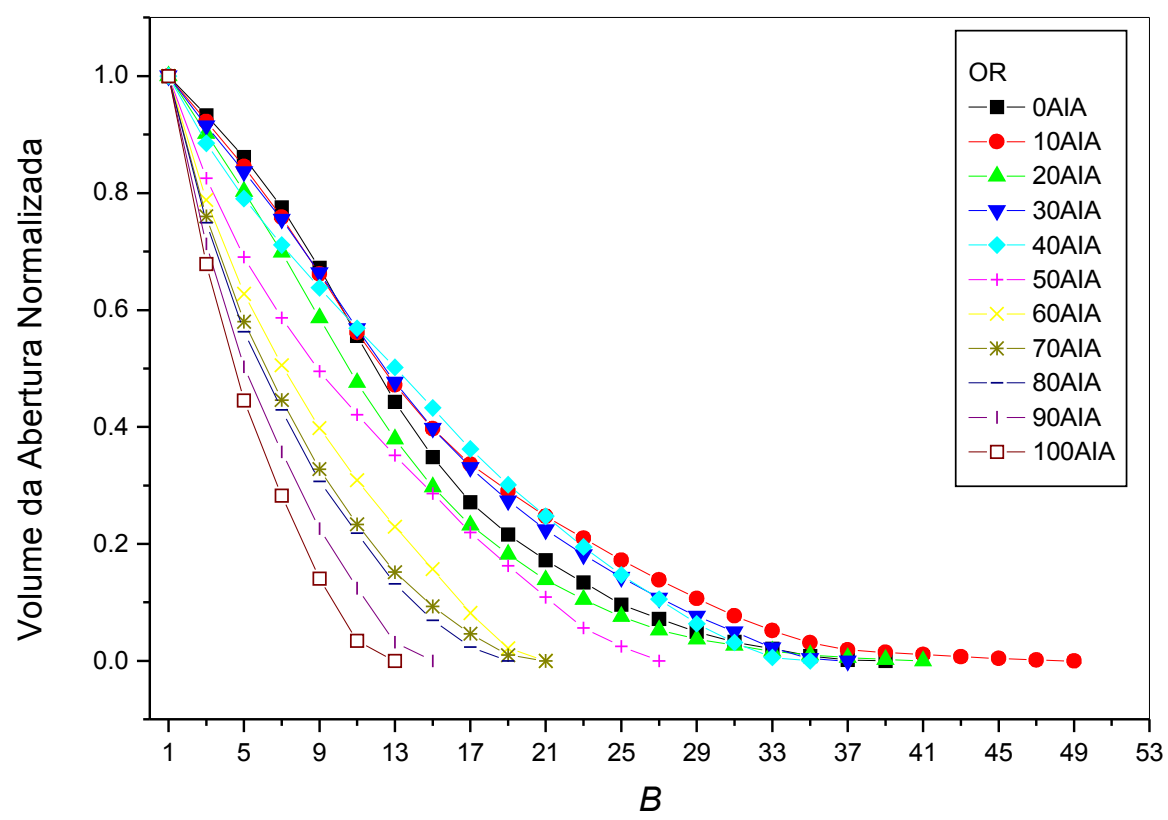

Figura 38. Curvas da Abertura Normalizada em função de $B$ para imagens OR. 


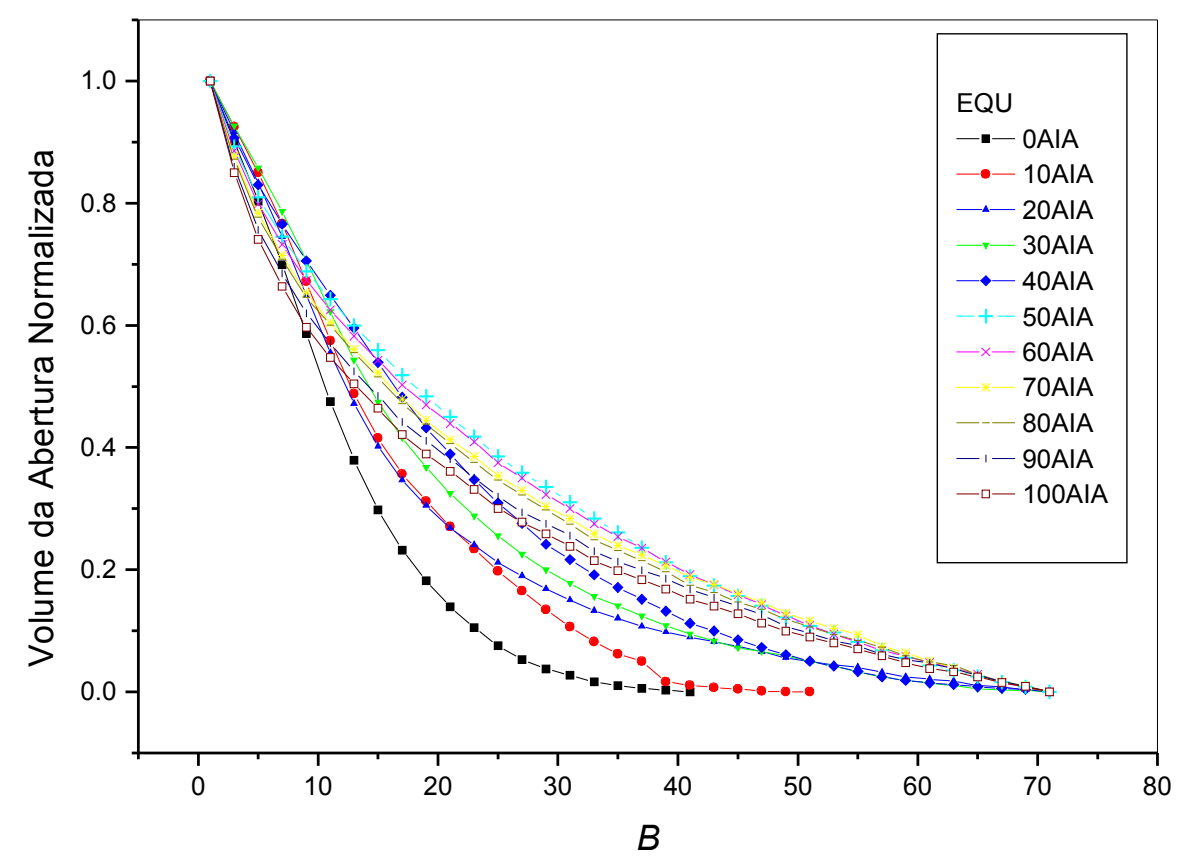

Figura 39. Curvas da Abertura Normalizada em função de $B$ para imagens EQU.

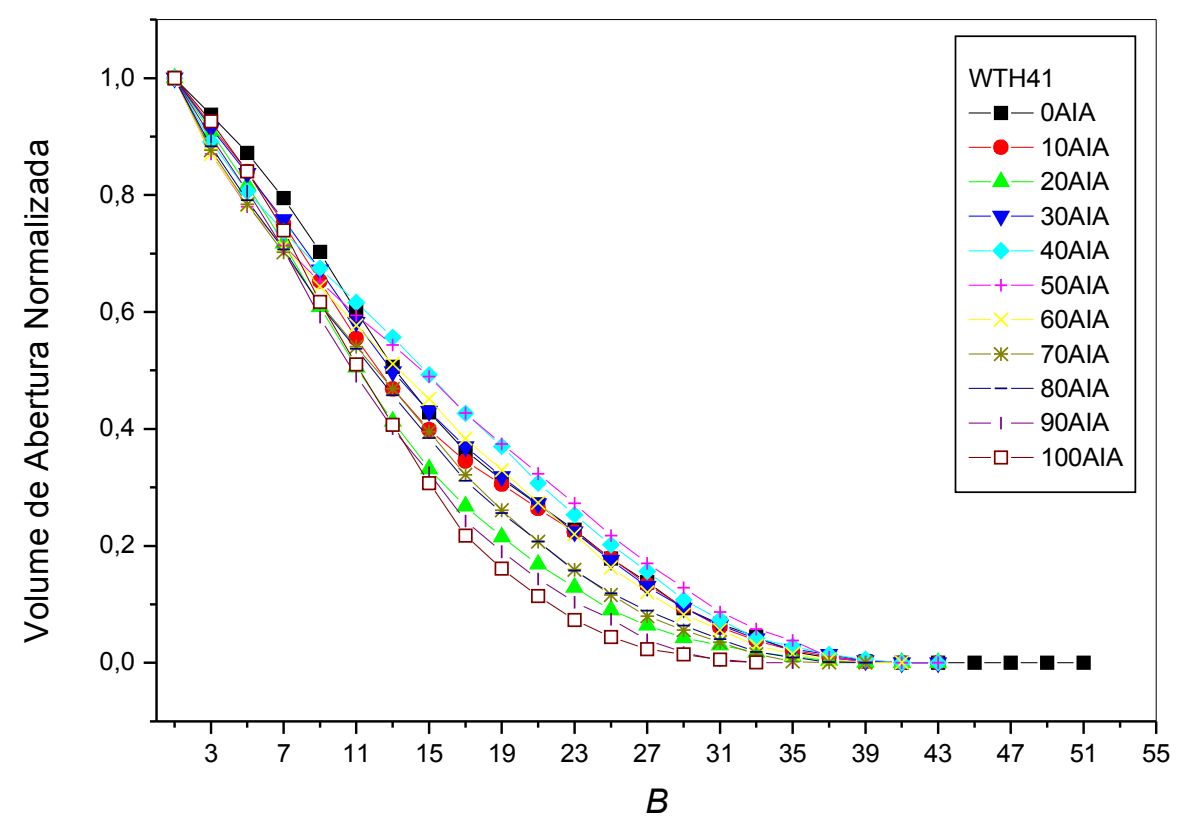

Figura 40. Curvas da Abertura Normalizada em função de $B$ para imagens WTH41. 


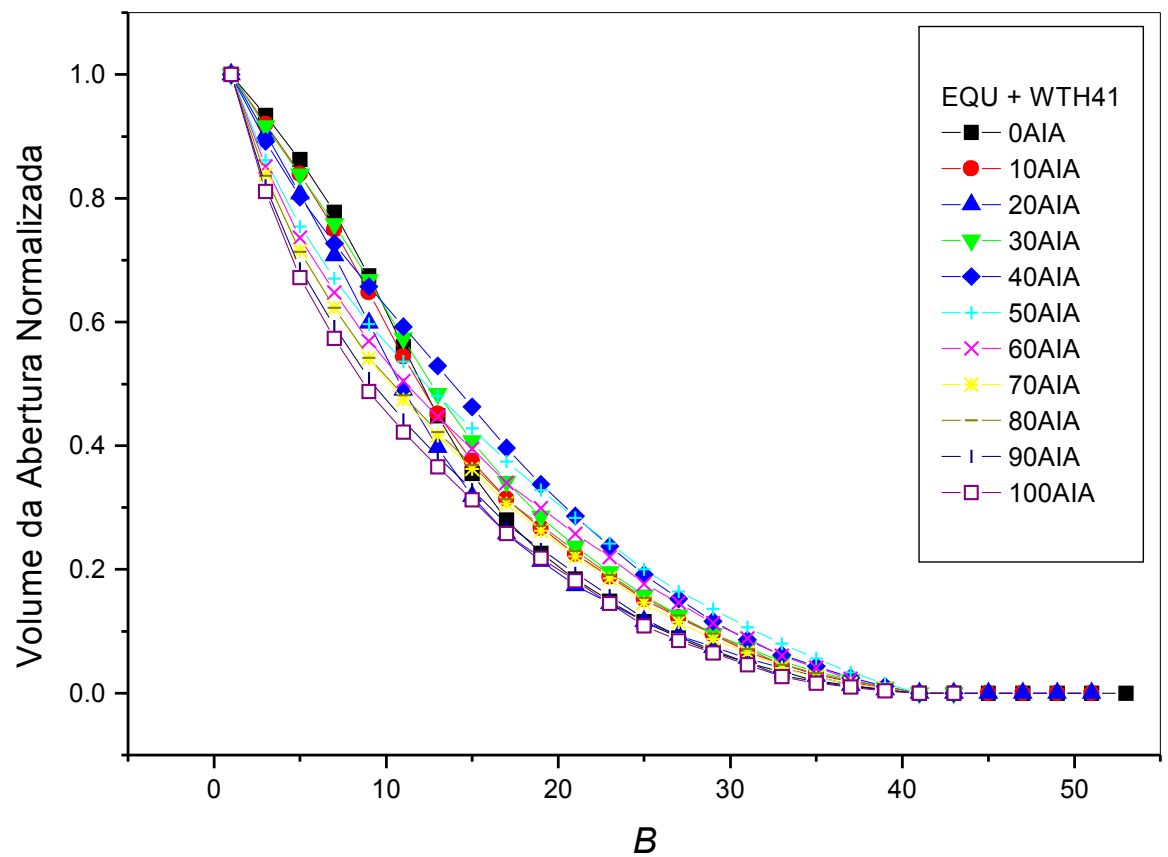

Figura 41. Curvas da Abertura Normalizada em função de $B$ para imagens EQU+WTH41.

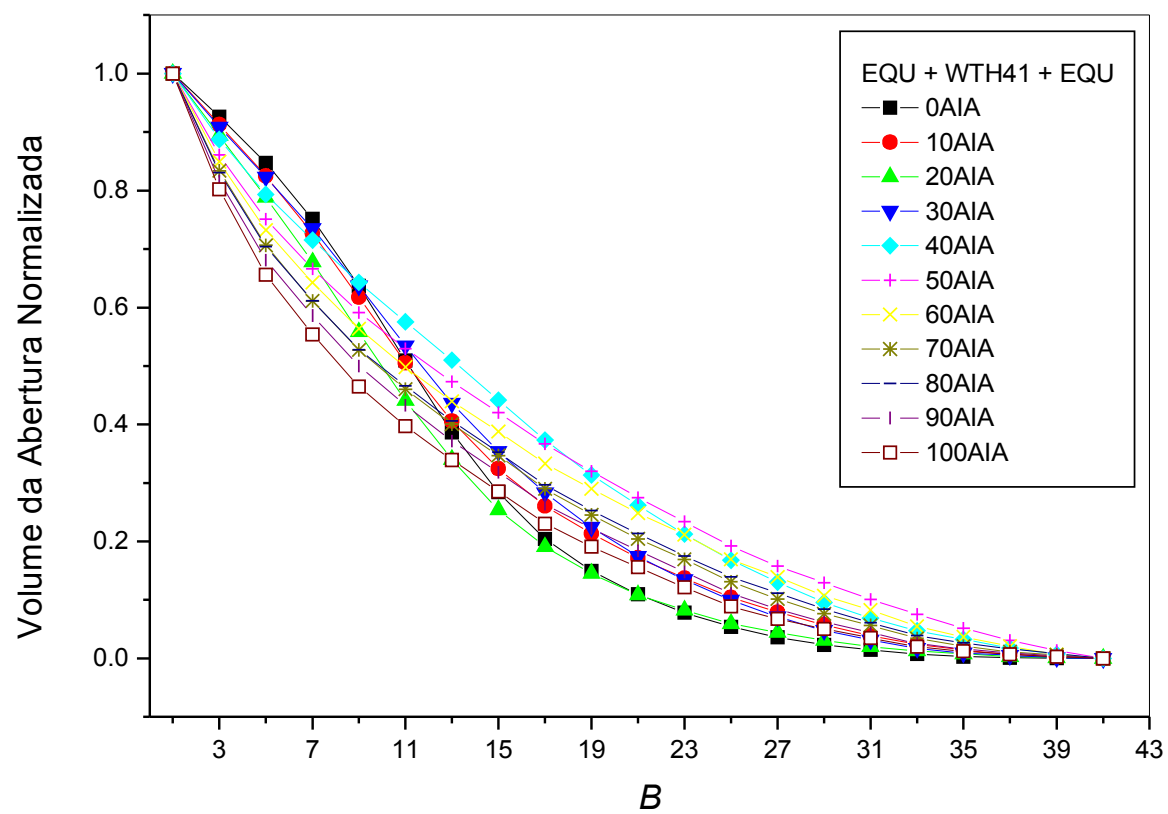

Figura 42. Curvas da Abertura Normalizada em função de B para imagens EQU+WTH41+EQU. 
Nota-se ainda que as imagens com a aplicação do filtro WTH41 tendem a apresentar o mesmo comportamento e convergem quando o elemento estrutural é igual a 41. Isto está relacionado ao tamanho do elemento utilizado no filtro, definindo o ponto de convergência, uma vez que este filtro atua como um passa-alta.

$\mathrm{Na}$ figura 47 pode ser observada a derivada do volume da abertura normalizada em função do tamanho do elemento estruturante. Pode ser notado que o primeiro mínimo, relativo ao tamanho do elemento predominante na imagem, se desloca conforme a evolução na textura da imagem. Porém, para valores acima de $50 \%$ AlA não houve modificação relativa a este ponto. Isto pode estar relacionado com o fato de que o molhamento não apresenta uma estrutura uniforme, o que não poderia ser identificado através do elemento estruturante.

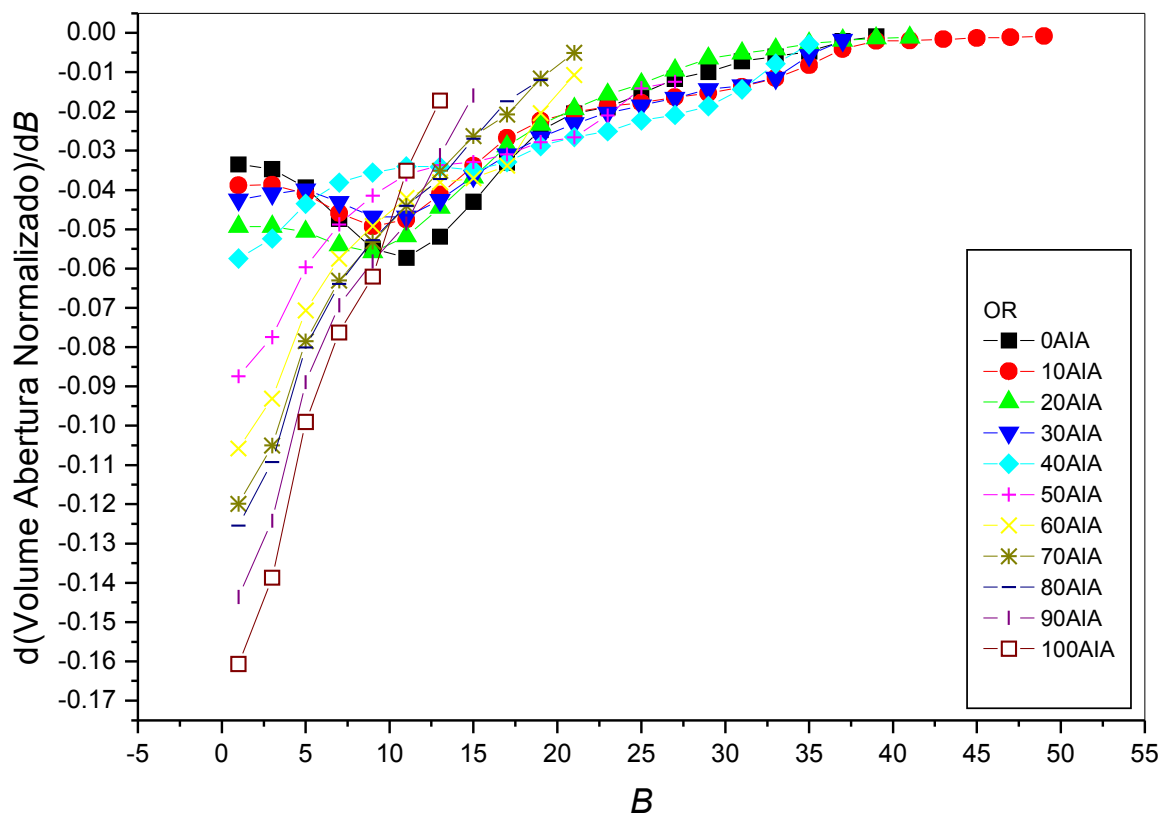

Figura 43. Curvas da derivada da abertura normalizada em função do tamanho do elemento estruturante para as imagens OR. 


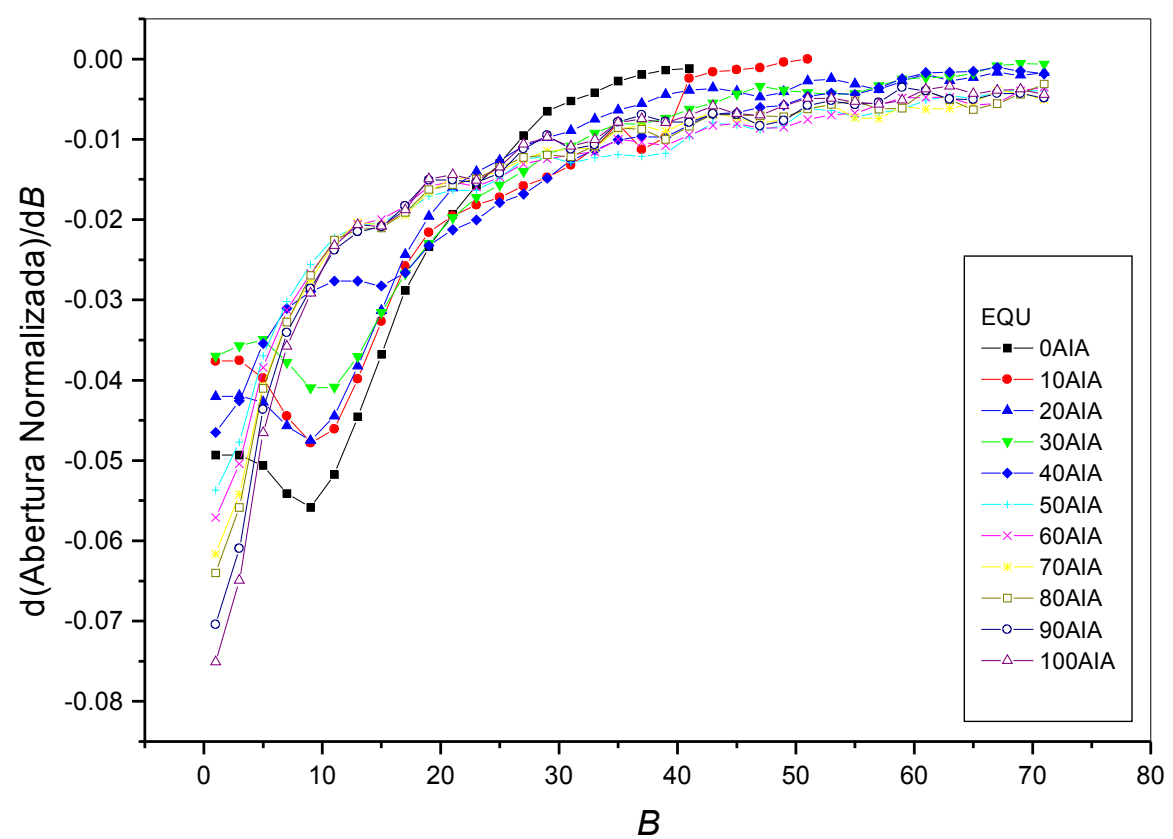

Figura 44. Curvas da derivada da abertura normalizada em função do tamanho do elemento estruturante para as imagens EQU.

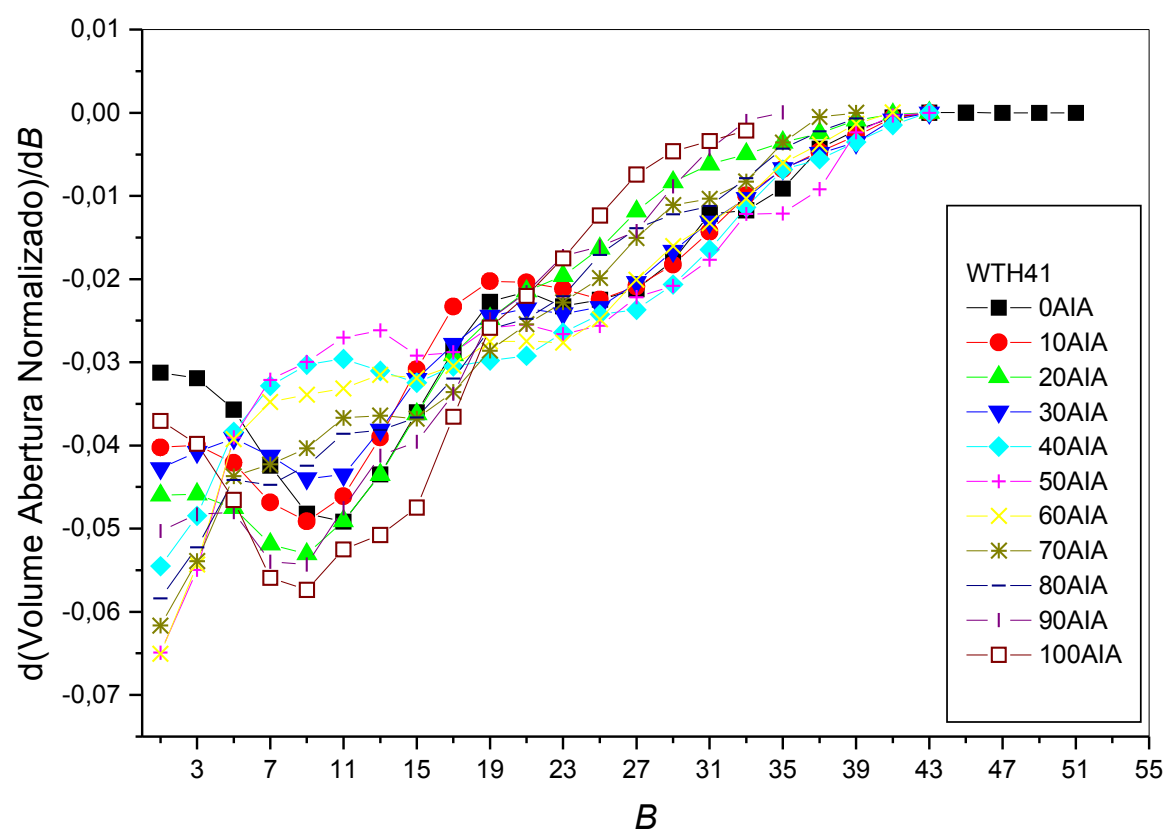

Figura 45. Curvas da derivada da abertura normalizada em função do tamanho do elemento estruturante para as imagens WTH41. 


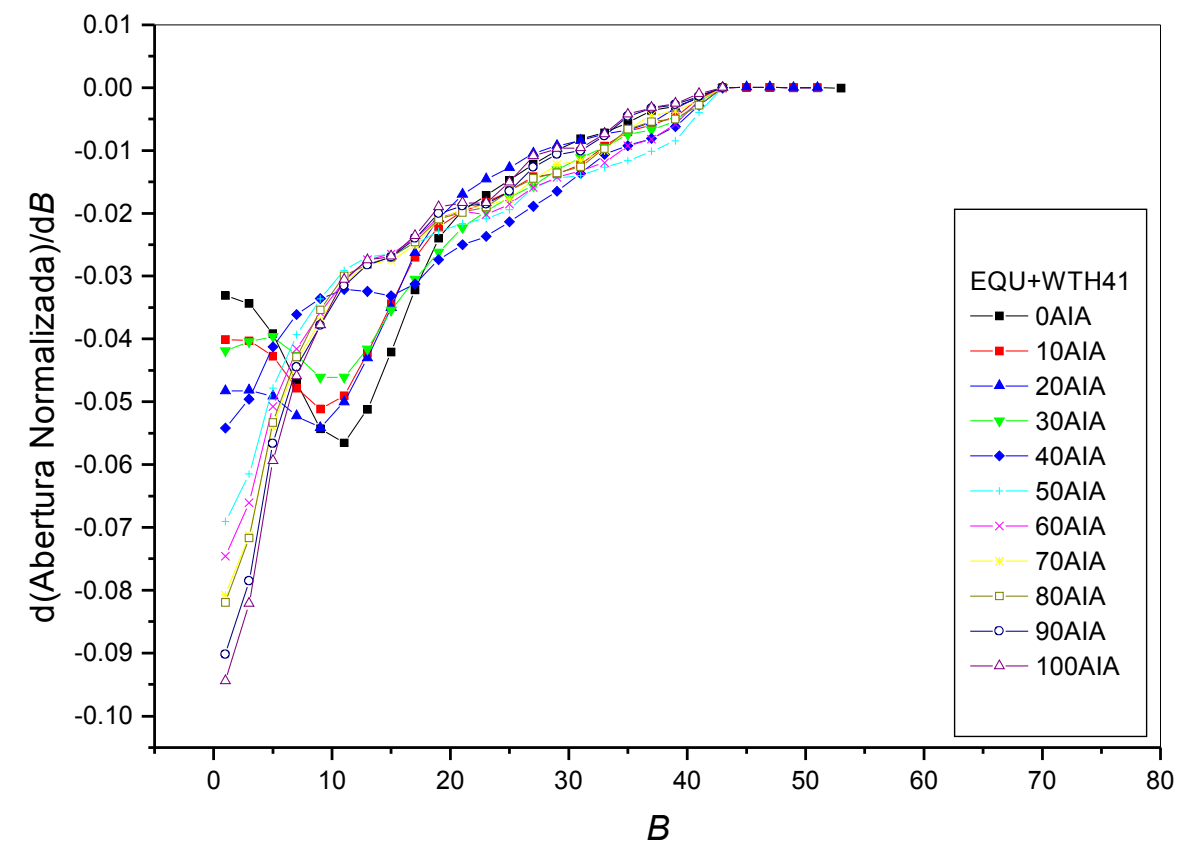

Figura 46. Curvas da derivada da abertura normalizada em função do tamanho do elemento estruturante para as imagens EQU+WTH41.

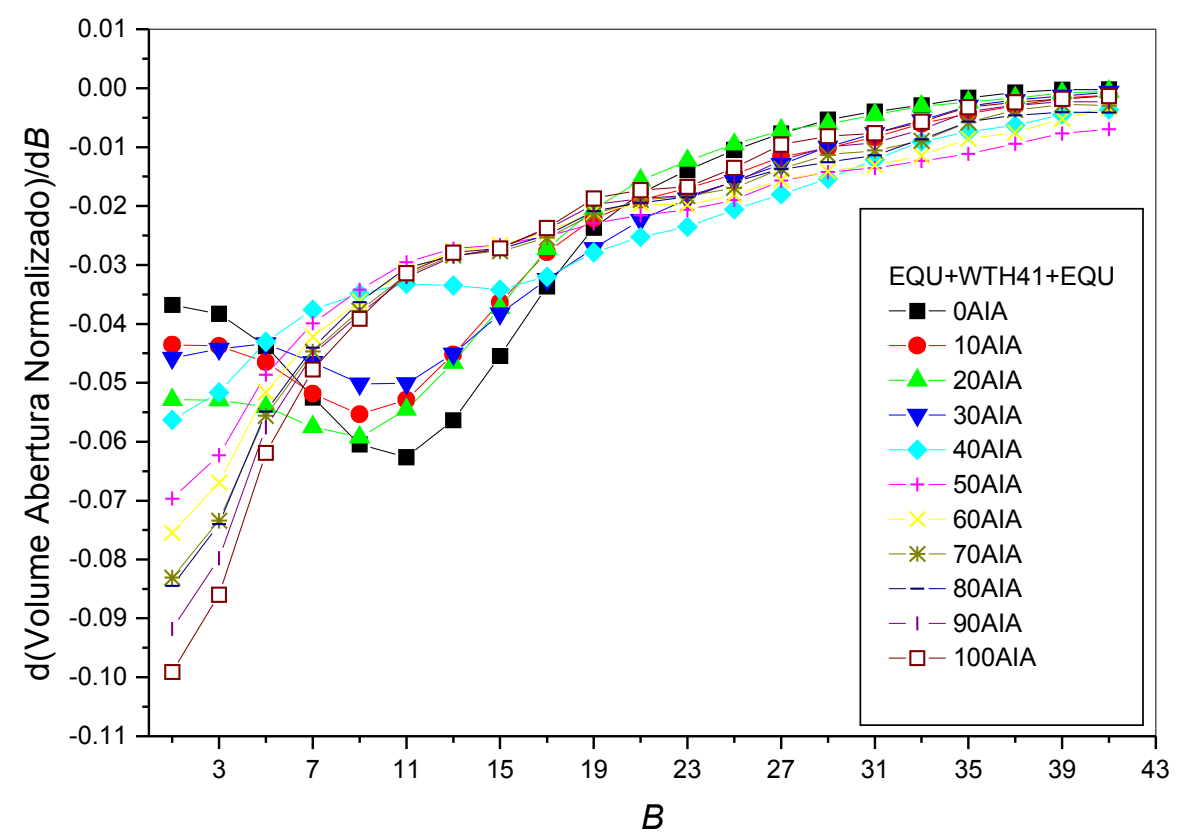

Figura 47. Curvas da derivada da abertura normalizada em função do tamanho do elemento estruturante para as imagens EQU+WTH41+EQU. 
Pode ser notado através das figuras 43, 44, 45, 46 e 47, que o valor inicial da curva das derivadas das curvas se torna menor, em módulo, com o aumento do valor de AIA. Desta forma, pôde ser gerada uma curva com a relação entre esta derivada inicial em função das imagens de AIA, conforme a figura 48.

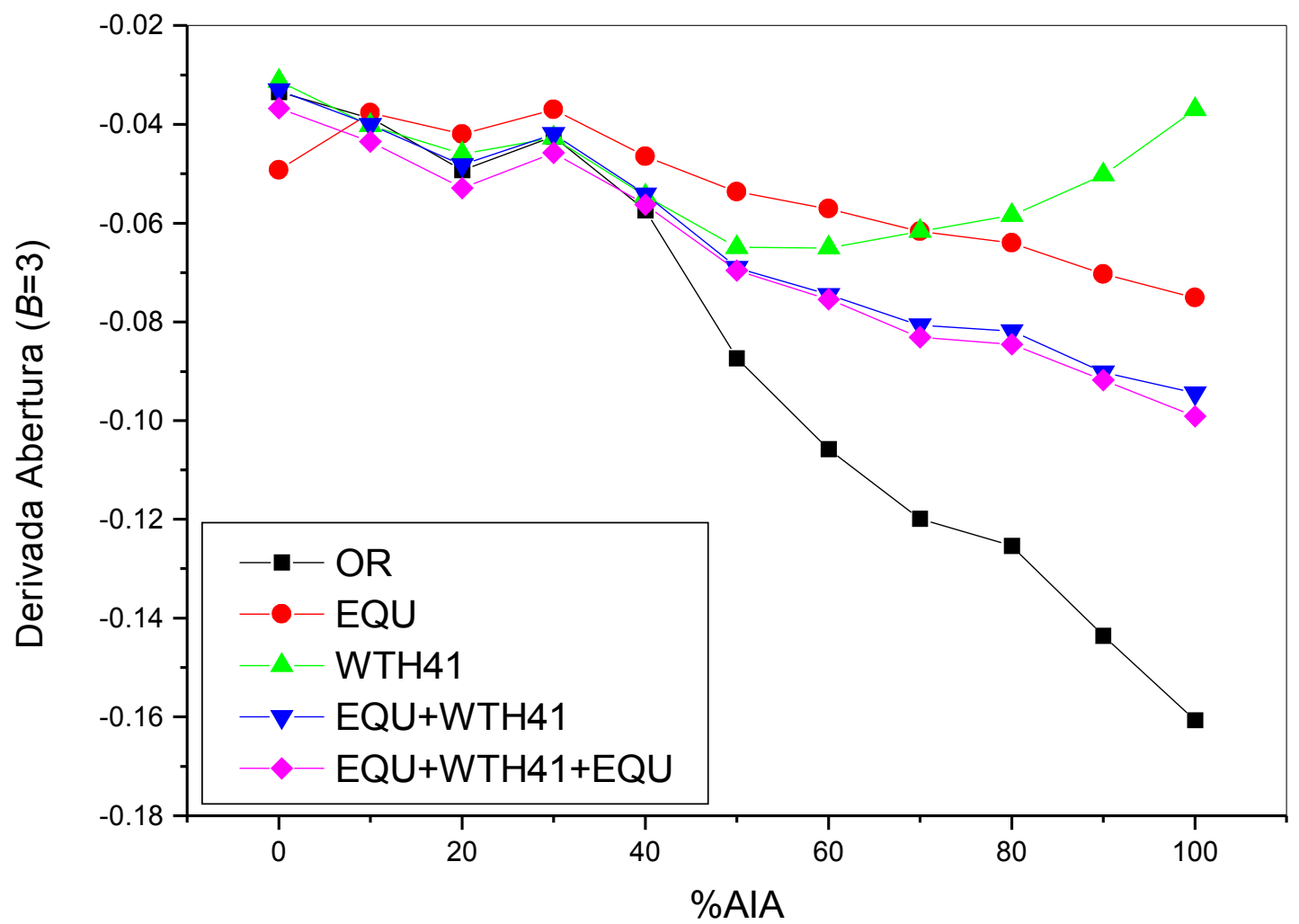

Figura 48. Derivada para $B=3$ da abertura em função das imagens de AIA.

Através da figura 48 observa-se que a curva para as imagens OR apresentam uma tendência mais acentuada que as demais. Assim, a obtenção de uma relação matemática neste caso se torna mais apropriada pelo aumento da diferença na classificação dentre as imagens. Porém, as curvas para imagens otimizadas, 
EQU+WTH41 e EQU+WTH41+EQU apresentam comportamentos semelhantes, podendo ser utilizadas como referência na classificação da hidrofobicidade.

Com base nestas observações, as curvas foram ajustadas linearmente. A Tabela 2 mostra os valores dos coeficientes de correlação, linear e angular de cada curva.

Tabela 2. Valores dos coeficientes de correlação, angular e linear referente ao ajuste linear das curvas apresentadas na figura 48.

\begin{tabular}{|c|c|c|c|}
\hline Imagem & Coef. de correlação & Coef. angular & Coef. linear \\
\hline OR & $-0,99639$ & $-0,01129$ & $-0,02729$ \\
\hline EQU & $-0,99759$ & $-0,0004037$ & $-0,03344$ \\
\hline EQU+WTH41 & $-0,99500$ & $-0,0006158$ & $-0,03523$ \\
\hline EQU+WTH41+EQU & $-0,99704$ & $-0,0006045$ & $-0,03852$ \\
\hline
\end{tabular}

O ajuste da curva para as imagens EQU apresentou o maior valor do coeficiente de correlação, refletindo um bom resultado para as curvas EQU+WTH41 e EQU+WTH41+EQU. Desta forma, a equação a ser implementada para a classificação da hidrofobicidade por este método, deverá ser definida por:

$$
A I A=2477,08 \times \frac{d\left(V_{a b}\right)}{d B_{3}}-82,83
$$

onde $\frac{d\left(V_{a b}\right)}{d B_{3}}$ é a derivada do volume da abertura para um elemento estruturante de tamanho $3 \times 3$.

\subsubsection{Análise por Dimensão Fractal}

Nesta etapa do trabalho, as imagens foram analisadas de acordo com o valor 
da dimensão fractal. Inicialmente foram analisadas as imagens binárias, por detecção de bordas, e posteriormente as imagens em escala de cinza.

\subsection{Imagens com deteç̧ão de bordas por Sobel}

Inicialmente as imagens foram submetidas à detecção de bordas por Sobel e posteriormente binarizadas. A seguir, estas imagens foram avaliadas através da dimensão fractal. . A dependência da dimensão fractal das imagens em função de AIA pode ser observado na figura 49. As imagens EQU+WTH41 e EQU+WTH41+EQU não puderam ser avaliadas pois não apresentaram bordas.

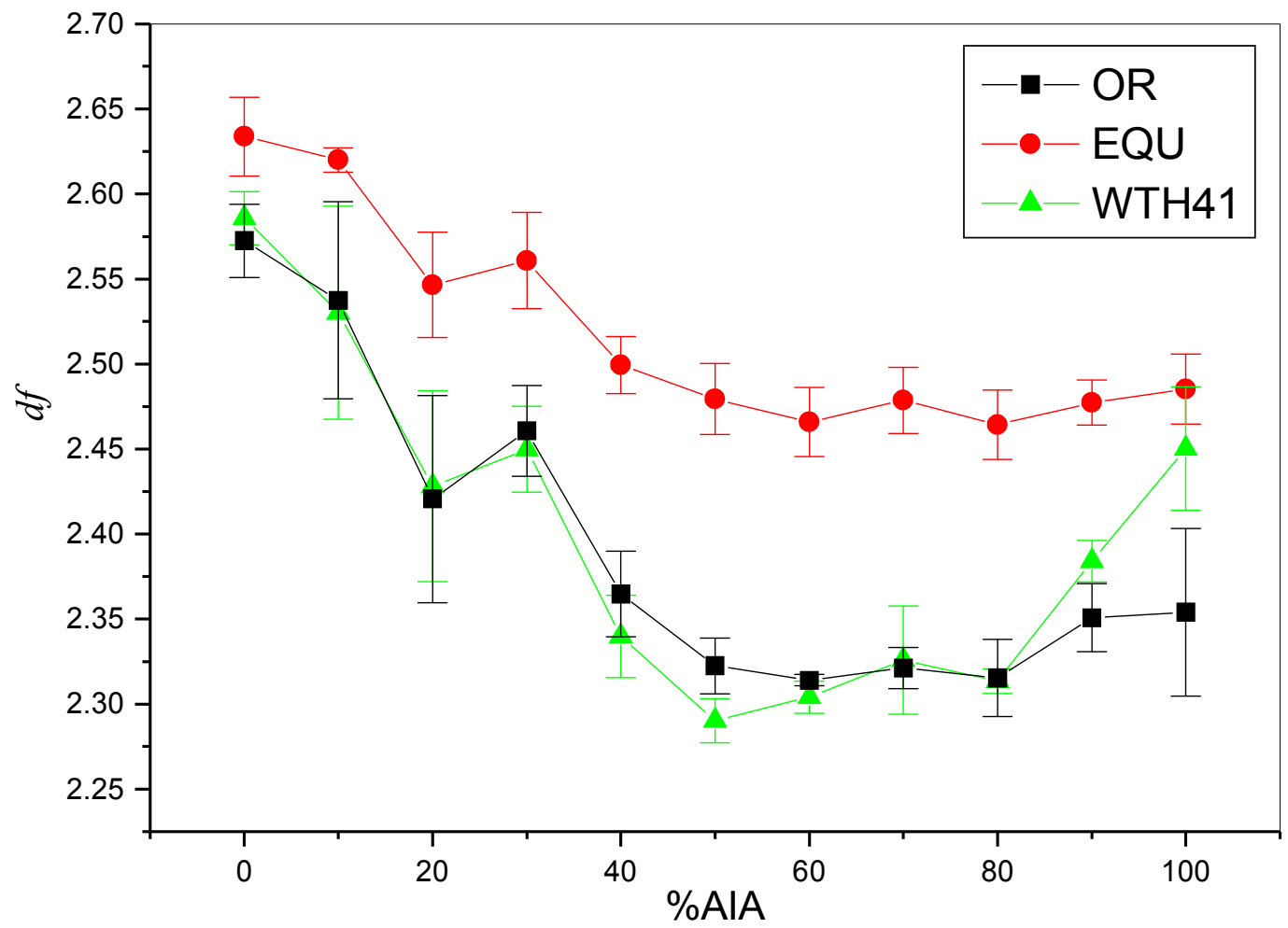

Figura 49. Valores da dimensão fractal das imagens com detecção de bordas em função de AIA. 
Pode ser observado que as curvas não apresentam um comportamento que possa gerar uma função injetora, podendo gerar ambigüidade nos resultados.

\subsection{Imagens em escala de cinza}

Outra forma de analisar a textura das imagens é utilizar a imagem em escala de cinza, ou seja, sem o processo de binarização. Na figura 50 pode ser visualizada a relação entre o valor da dimensão fractal e as imagens de AIA. A partir destas curvas não foi possível determinar uma função injetora, exceto para as imagens WHT41.

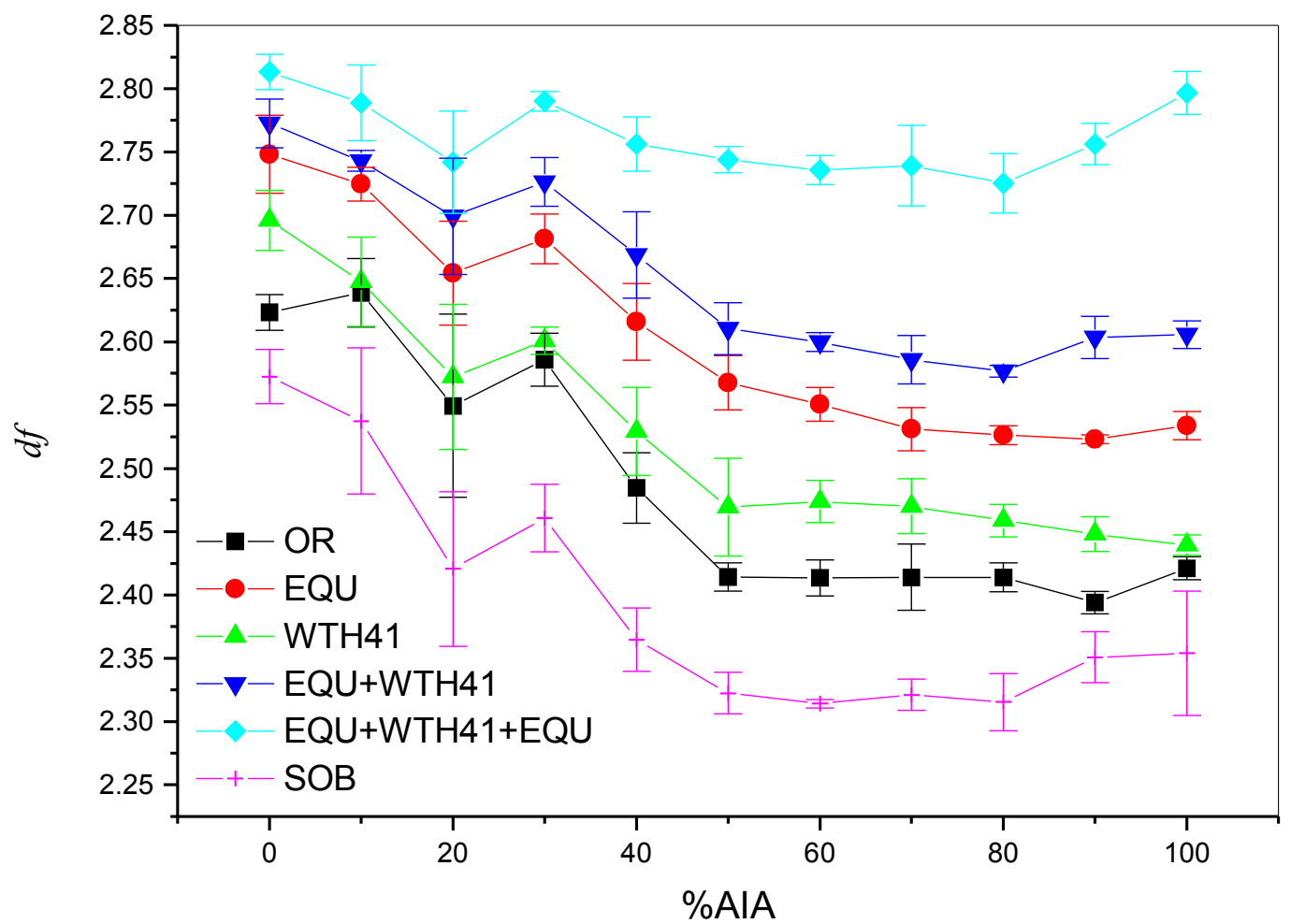

Figura 50. Relação entre as soluções de AIA e a dimensão fractal para as imagens OR, EQU, WTH41, EQU+WTH41 e EQU+WTH41+EQU. 
Nota-se a tendência de convergência para as imagens acima de 50\%AIA. As curvas apresentam relativa semelhança entre si e a diferença entre os valores está relacionada com a alteração na complexidade da imagem com a aplicação dos tratamentos de imagem.

As curvas para as imagens OR, EQU, WTH41 e EQU+WTH41 puderam ser matematicamente ajustadas, obtendo-se funções injetoras. Porém a curva para as imagens WTH41 apresentou uma dispersão relativamente pequena em comparação com as demais. Desta forma, o melhor ajuste foi uma função exponencial descrita a seguir:

$$
A I A=97,0207 \times \exp \frac{(2,4394-d f)}{0,08067}
$$

Esta função apresenta simplicidade de implementação para uma posterior classificação da hidrofobicidade em dispositivos móveis.

\subsubsection{Descritores de Texturas}

Os resultados que serão discutidos a seguir, tratam das análises dos descritores de texturas por entropia, energia, variância e homogeneidade. Haralick ${ }^{38}$ sugere que a análise da textura de imagens deve ser feita aplicando os descritores e posteriormente avaliando seu comportamento em função do sistema em estudo.

No caso deste trabalho, não foram encontradas muitas referências de outros autores que analisam a hidrofobicidade de isoladores elétricos através do uso de 
descritores de texturas, porém o método está explícito no Capítulo 2.

Assim os descritores de textura entropia, energia, variância e homogeneidade serão analisados de forma a verificar o método mais apropriado para este tipo de sistema.

\subsubsection{Análise por Entropia}

A partir da figura 51 podem ser observadas as curvas das imagens de AIA e os resultados de suas entropias. Nesta figura, nota-se uma linearidade significativa e baixos valores de dispersão para todos os tipos de imagens em comparação com os resultados determinados através da análise por Morfologia Matemática e por Dimensão Fractal, indicando que o uso de descritores de textura são mais eficientes para esse tipo sistema onde o objetivo é a caracterização do molhamento de superfícies. 


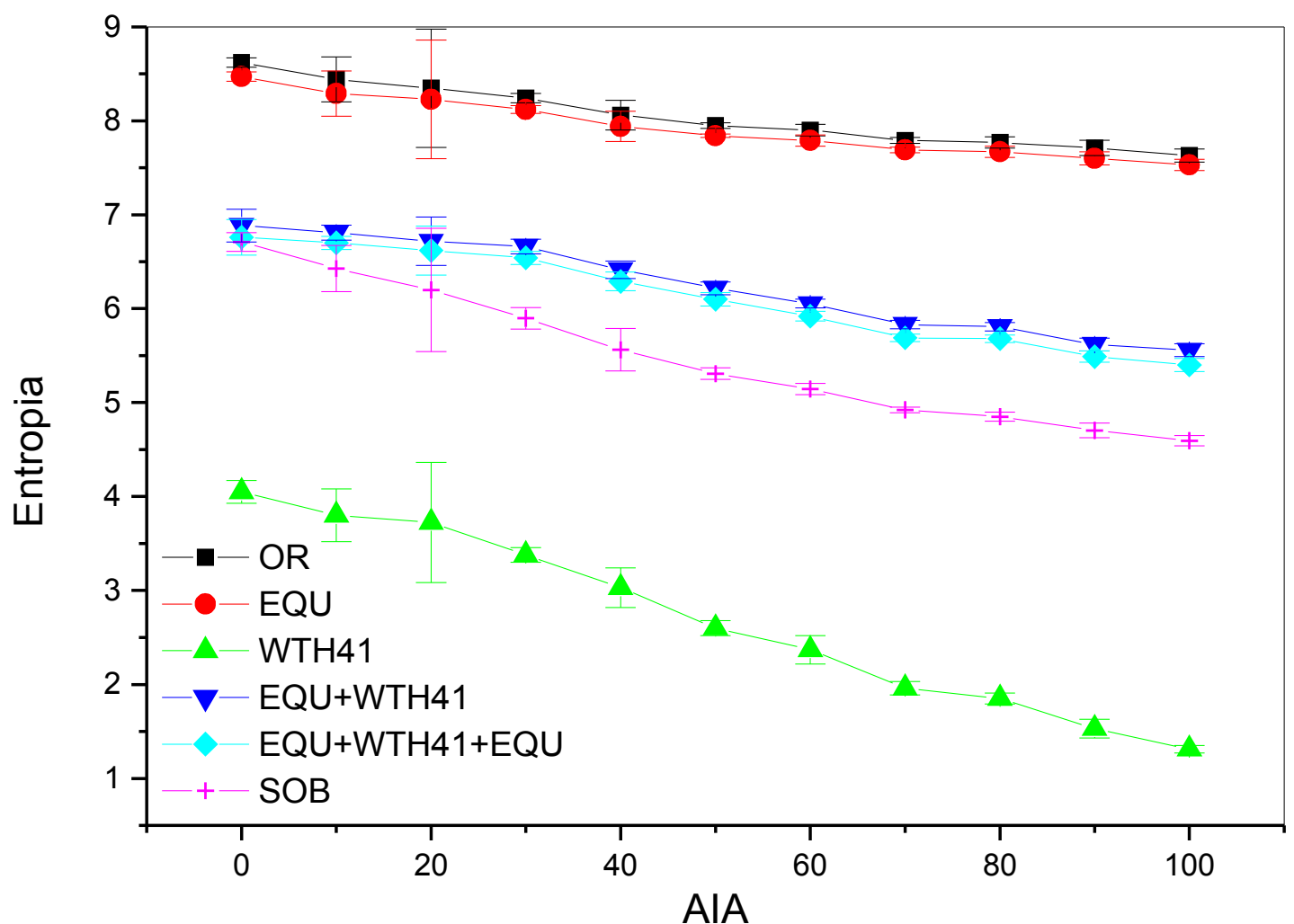

Figura 51. Relação entre a entropia e as imagens de AIA e para as imagens OR, EQU, WTH41, EQU+WTH41, EQU+WTH41+EQU e SOB.

Todas as curvas foram ajustadas linearmente, conforme ilustrado na tabela 3 , porém, a curva correspondente às imagens WTH41 apresentou um maior coeficiente angular e de correlação, sendo por isso, selecionada para ser utilizada na classificação da hidrofobicidade.

Tabela 3. Valores dos coeficientes angular, linear e correlação para ajustes das curvas de AIA vs Entropia.

\begin{tabular}{|c|c|c|c|}
\hline AMOSTRA & Coeficiente angular & Coeficiente linear & Correlação \\
\hline OR & $-0,01079 \pm 0,00103$ & $8,57199 \pm 0,06231$ & $-0,96160$ \\
\hline EQU & $-0,01017 \pm 0,00116$ & $8,41560 \pm 0,06785$ & $-0,94596$ \\
\hline
\end{tabular}




\begin{tabular}{|c|c|c|c|}
\hline WTH41 & $-0,02922 \pm 0,00156$ & $4,18900 \pm 0,12403$ & $-0,98742$ \\
\hline EQU+WTH41 & $-0,01478 \pm 0,00093$ & $6,95842 \pm 0,06342$ & $-0,98269$ \\
\hline EQU+WTH41+EQU & $-0,01526 \pm 0,00098$ & $6,85621 \pm 0,06747$ & $-0,98192$ \\
\hline SOB & $-0,02027 \pm 0,00204$ & $6,43363 \pm 0,14773$ & $-0,95735$ \\
\hline
\end{tabular}

Assim, a equação para a determinação dos valores de AIA, em função da entropia da imagem poderá ser definida como:

$$
A I A=(-34,49905 \pm 2,76697)+(141,26567 \pm 7,72408) \times S \quad \text { eq. } 47
$$

\subsubsection{Análise por Energia}

Na figura 52 podem ser observadas as curvas referentes às imagens de AIA e os correspondes valores de energia.

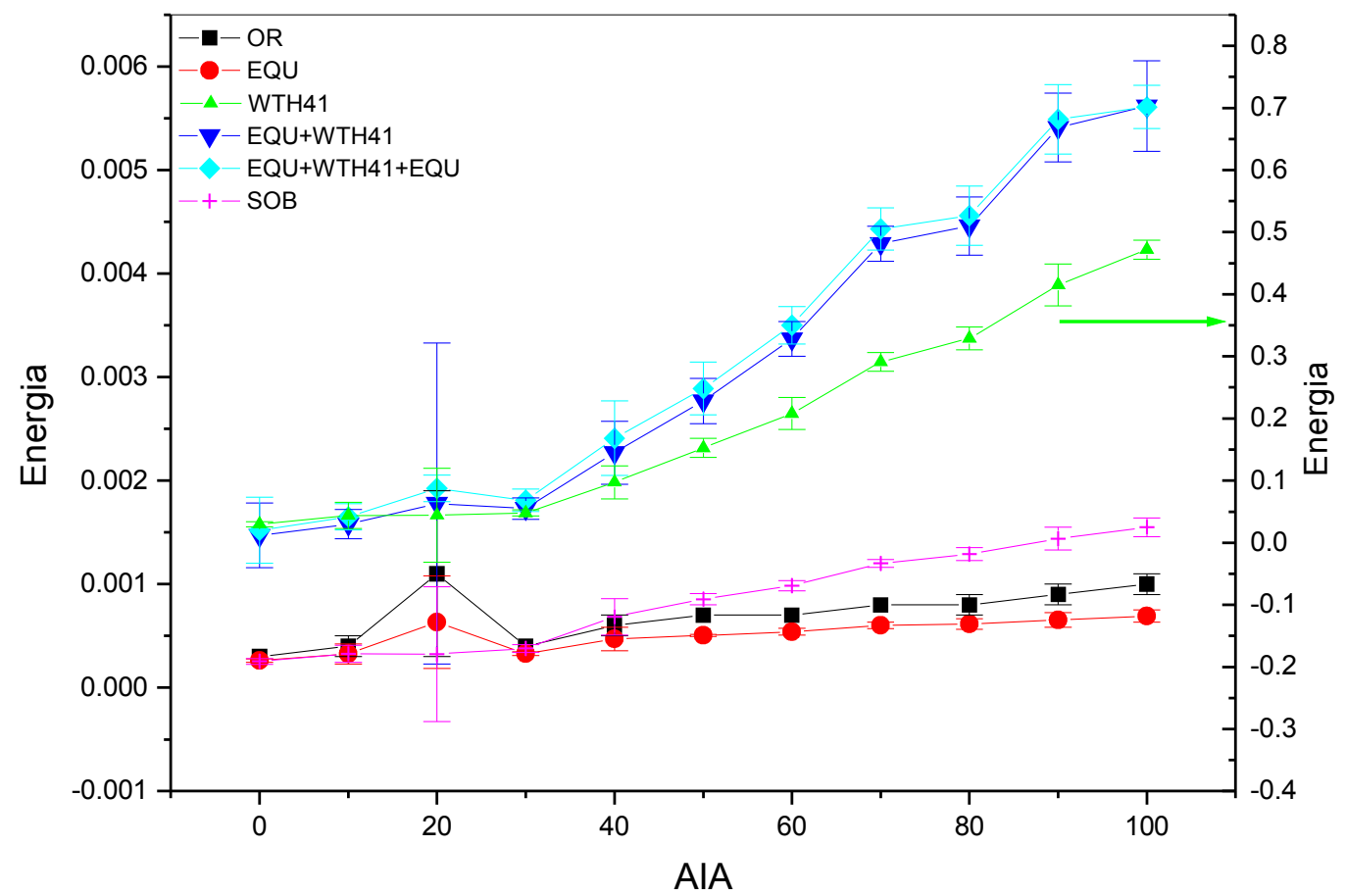

Figura 52. Relação entre a energia e as imagens de AIA e para OR, EQU, WTH41, EQU+WTH41, EQU+WTH41+EQU e SOB. 
A figura 44 mostra uma tendência linear para as curvas obtidas de energia em função das imagens AIA. A tabela 4 mostra os ajustes lineares destas curvas, indicando que as imagens SOB, que apresentaram o maior coeficiente de correlação, são mais indicadas para a implementação deste método.

Nota-se a relativa similaridade entre as curvas OR, EQU e SOB, no que diz respeito à sobreposição e desvio reduzido, indicando que este descritor apresenta relativa independência ao tipo de imagem utilizada. Porém o coeficiente de inclinação pequeno pode induzir erros na tradução da energia em AIA.

Tabela 4. Valores dos coeficientes angular, linear e de correlação para ajustes das curvas de imagens de AIA vs Energia.

\begin{tabular}{|c|c|c|c|}
\hline AMOSTRA & Coeficiente angular & Coeficiente linear & Correlação \\
\hline OR & $\begin{array}{l}238483,895 \\
\pm 14916,093\end{array}$ & $\begin{array}{c}-57,509 \\
\pm 7,000\end{array}$ & 0,98285 \\
\hline EQU & $\begin{array}{r}183809,140 \\
\pm 42704,002 \\
\end{array}$ & $\begin{array}{l}-44,027 \\
\pm 22,661 \\
\end{array}$ & 0,82039 \\
\hline WTH41 & $\begin{array}{r}199,35134 \\
\pm 17,92934\end{array}$ & $\begin{array}{c}11,3858 \\
\pm 4,42732\end{array}$ & 0,96547 \\
\hline EQU+WTH41 & $\begin{array}{c}20650,771 \\
\pm 1662,154\end{array}$ & $\begin{array}{c}-15,236 \\
\pm 5,805\end{array}$ & 0,97206 \\
\hline EQU+WTH41+EQU & $\begin{array}{r}20874,059 \\
\pm 1602,182\end{array}$ & $\begin{array}{r}-17,927 \\
\pm 5,725\end{array}$ & 0,97450 \\
\hline SOB & $\begin{array}{c}67778,223 \\
\pm 3835,832\end{array}$ & $\begin{array}{l}-7,223 \\
\pm 3,688\end{array}$ & 0,98589 \\
\hline
\end{tabular}

Desta forma, o modelo proposto para a classificação da hidrofobicidade baseado na energia é: 


$$
A I A=(-7,223 \pm 3,688)+(67778,223 \pm 3835,832) \times E
$$

Porém, a viabilidade do uso desta equação em comparação com os outros métodos será discutido no item 99

\subsubsection{Análise por Variância}

A partir da figura 53 podem ser observadas as curvas de variância em função das imagens de AIA.

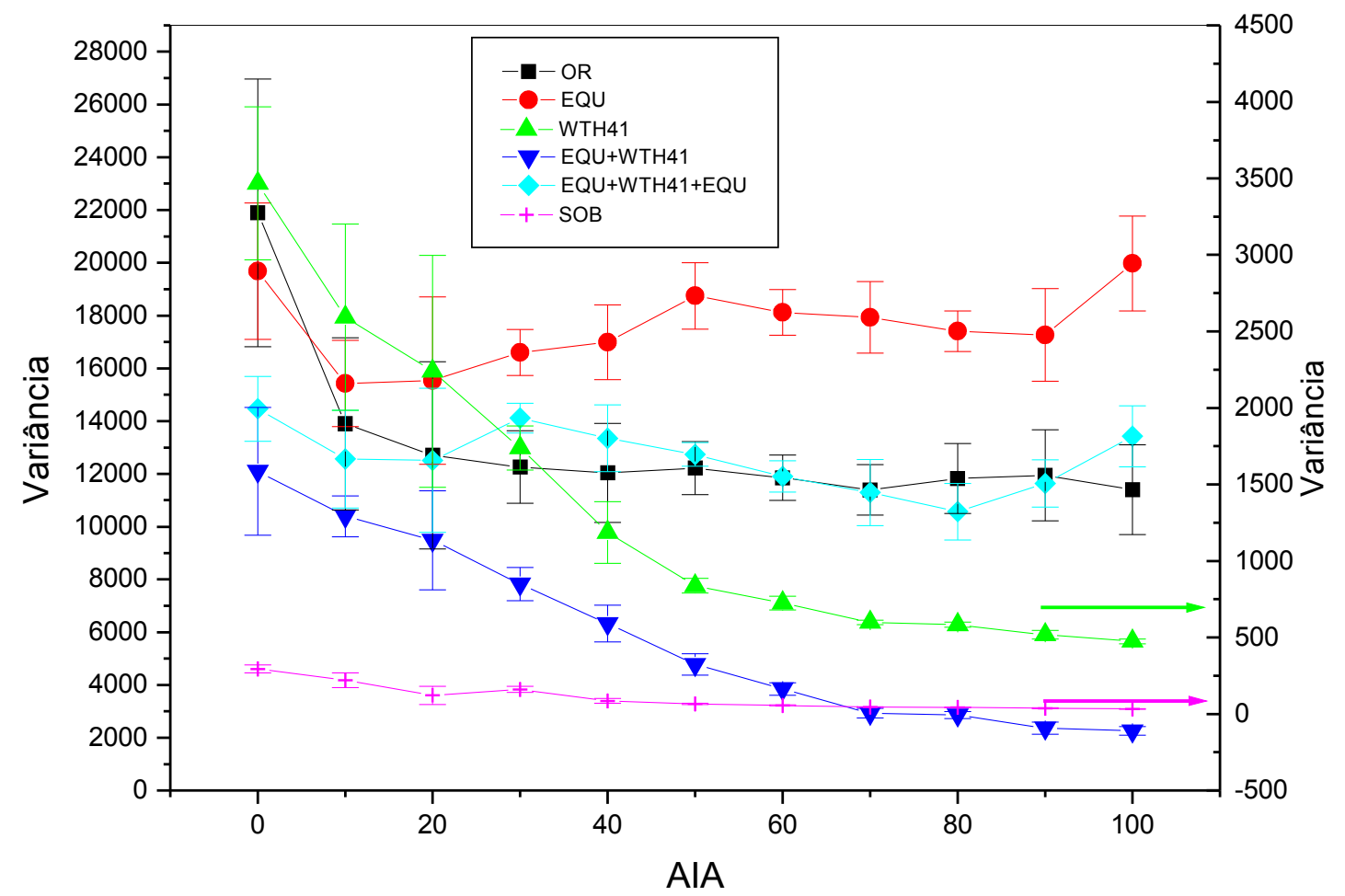

Figura 53. Comportamento da variância em função das imagens de AIA e para OR, EQU, WTH41, EQU+WTH41, EQU+WTH41+EQU e SOB. 
A partir das curvas apresentadas na figura 53 pode ser notado que para as imagens WTH41, EQU+WTH41 e SOB apresentaram um comportamento unívoco, sendo ajustadas com um polinômio de terceira ordem de acordo com a tabela 5.

Tabela 5. Valores dos coeficientes dos polinômios ajustados a partir das curvas de variância vs imagens de AIA

\begin{tabular}{|c|c|c|c|c|c|}
\hline AMOSTRA & $\mathrm{a}$ & $\mathrm{b}$ & $\mathrm{c}$ & $\mathrm{d}$ & Correlação \\
\hline \multirow{2}{*}{ WTH41 } & $-1,09488 \mathrm{E}-8$ & $7,59436 \mathrm{E}-5$ & $-0,17818$ & 159,55947 & \multirow{2}{*}{0,965} \\
& $\pm 3,94056 \mathrm{E}-9$ & $\pm 2,34372 \mathrm{E}-5$ & $\pm 0,03993$ & $\pm 17,46766$ & \\
\hline \multirow{2}{*}{ EQU+WTH41 } & $-1,8789 \mathrm{E}-10$ & $4,63452 \mathrm{E}-6$ & $-0,04262$ & 167,94299 & \multirow{2}{*}{0,985} \\
& $\pm 6,45399 \mathrm{E}-11$ & $\pm 1,38311 \mathrm{E}-6$ & $\pm 0,00886$ & $\pm 15,92868$ & \\
\hline \multirow{2}{*}{ SOB } & $-2,06503 \mathrm{E}-5$ & 0,01182 & $-2,22238$ & 155,15172 & \multirow{2}{*}{0,967} \\
& $\pm 5,83891 \mathrm{E}-6$ & $\pm 0,00284$ & $\pm 0,38777$ & $\pm 13,45921$ & \\
\hline
\end{tabular}

Pode ser notado que o coeficiente de correlação para a curva formada pelos valores de variância das imagens EQU+WTH41 é ligeiramente maior do que para as outras curvas, representando um modelo candidato para implementação.

Assim, a equação proposta para a classificação da hidrofobicidade utilizando esse modelo seria:

$$
\begin{gathered}
A I A=(-1,8789 \pm 0,6454) \times 10^{-10} \times \sigma_{2}^{3}+(4,6345 \pm 1,3831) \times 10^{-6} \times \sigma_{2}^{2} \\
+(-0,0426 \pm 0,0089) \times \sigma_{2}+167,9430 \pm 15,9287
\end{gathered}
$$

No item 99este método será comparado com os outros de forma a verificar sua viabilidade de implementação. Em uma análise prévia, nota-se que o uso de um polinômio de terceiro grau poderia tornar sua implementação pouco atrativa em dispositivos móveis, porém os outros parâmetros serão avaliados afim de verificar sua aplicabilidade. 


\subsubsection{Análise por Homogeneidade}

A figura 54 exibe as curvas de homogeneidade em função das texturas das imagens de AIA.

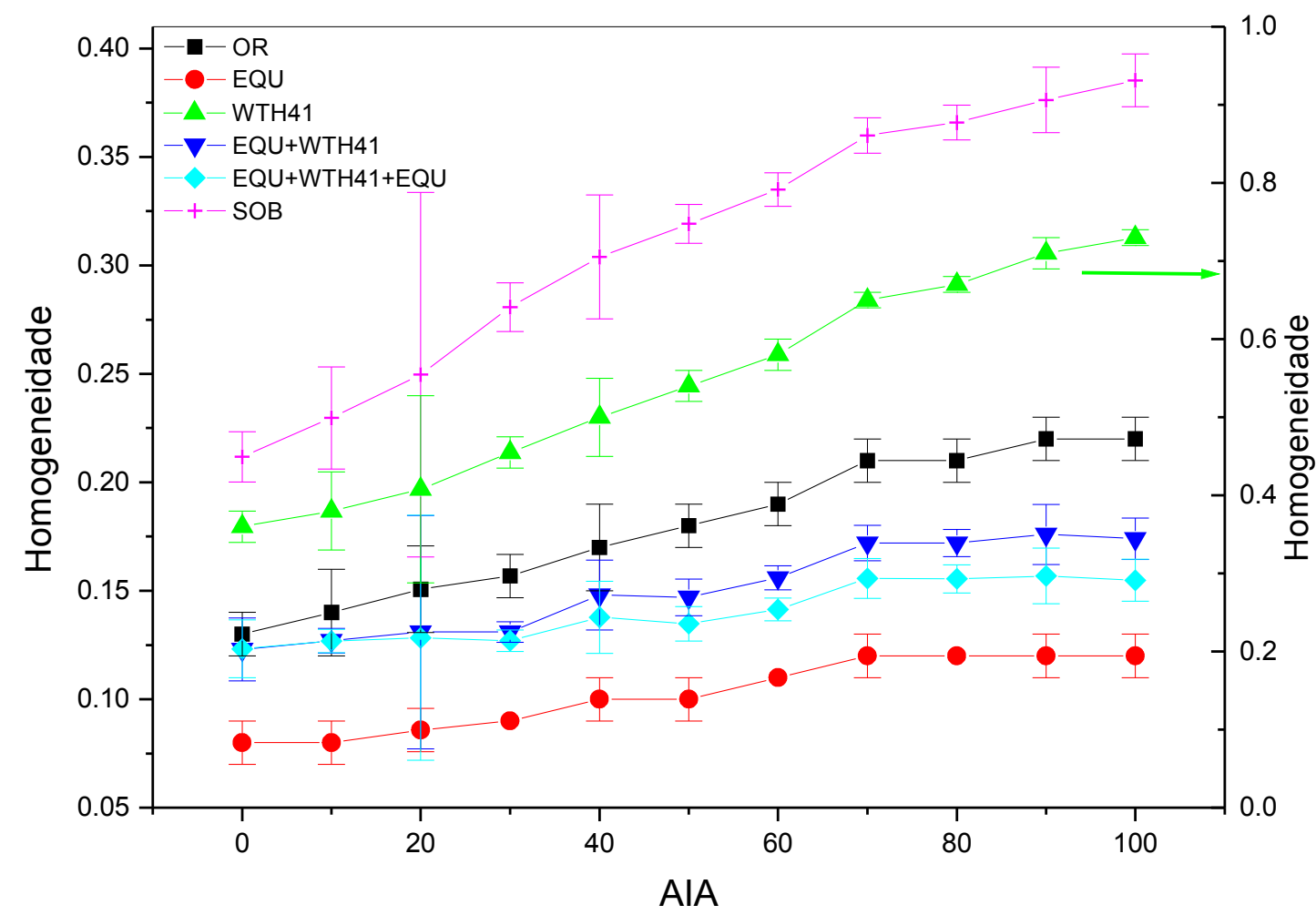

Figura 54. Homogeneidade em função das imagens de AIA para OR, EQU, WTH41, EQU+WTH41, EQU+WTH41+EQU e SOB.

As curvas apresentadas na figura 54 foram ajustadas linearmente e os valores dos coeficientes angulares, lineares e de correlação estão mostrados na tabela 6.

Tabela 6. Valores dos coeficientes angular, linear e de correlação para ajustes das curvas de AlA vs Homogeneidade.

\begin{tabular}{|c|c|c|c|}
\hline AMOSTRA & Coeficiente angular & Coeficiente linear & Correlação \\
\hline OR & $1004,54821 \pm 46,67138$ & $-130,5966 \pm 8,51576$ & 0,99043 \\
\hline
\end{tabular}




\begin{tabular}{|c|c|c|c|}
\hline EQU & $1942,85287 \pm 162,51737$ & $-148,84017 \pm 16,82943$ & 0,96993 \\
\hline WTH41 & $246,23575 \pm 7,79524$ & $-83,91797 \pm 4,35508$ & 0,99552 \\
\hline EQU+WTH41 & $1564,06527 \pm 126,62323$ & $-185,59945 \pm 19,23513$ & 0,97175 \\
\hline EQU+WTH41+EQU & $2360,44246 \pm 260,70129$ & $-280,94739 \pm 36,70179$ & 0,94925 \\
\hline SOB & $538,13297 \pm 28,90638$ & $-117,16907 \pm 9,1349$ & 0,98726 \\
\hline
\end{tabular}

A partir dos valores apresentados na tabela 6 pode ser observado que 0 coeficiente de correlação para as imagens WTH41 apresenta o maior valor entre as imagens analisadas. Desta forma, o modelo para classificação da hidrofobicidade baseado na homogeneidade é:

$$
A I A=(-83,9180 \pm 4,3551)+(246,2358 \pm 7,7952) \times H
$$

No item 99este método será comparado com os outros de forma a verificar sua viabilidade de implementação.

\subsubsection{Definição do método a ser utilizado para classificação da hidrofobicidade}

Como forma de viabilizar a implementação da metodologia proposta, os métodos estudados foram comparados quanto à correlação dos resultados, velocidade de processamento e simplicidade computacional de implementação. 0 tempo de processamento foi determinado executando os modelos em um microcomputador com processador Intel ${ }^{\circledR} 1,6 \mathrm{GHz}$. O comparativo entre os métodos analisados para uma imagem 400 x 400 pixels é apresentado na tabela 7. 
Tabela 7. Tabela comparativa entre os métodos estudados para a avaliação de desempenho.

\begin{tabular}{|l|c|c|c|c|}
\hline \multicolumn{1}{|c}{ Método } & Correlação & $\begin{array}{c}\text { Tempo de } \\
\text { processamento } \\
\text { (s) }\end{array}$ & $\begin{array}{c}\text { Tipo de Imagem } \\
\text { (Melhor Ajuste) }\end{array}$ & Tipo de ajuste \\
\hline Morf. Matemática & 0,998 & 40,30 & EQU & derivada/linear \\
\hline Dimensão Fractal & 0,740 & 1,64 & WTH41 & exponencial \\
\hline Entropia & 0,987 & 1,52 & WTH41 & linear \\
\hline Energia & 0,986 & 1,52 & SOB & linear \\
\hline Variância & 0,985 & 1,50 & EQU+WTH41 & Pol. $3^{\circ}$ ordem \\
\hline Homogeneidade & 0,986 & 1,54 & WTH41 & linear \\
\hline
\end{tabular}

Devido à complexidade dos cálculos envolvidos na morfologia matemática, o tempo de processamento $(40,30$ s) foi muito superior quando comparado com os outros métodos (aproximadamente $1,5 \mathrm{~s}$ ), inviabilizando sua aplicação em dispositivos móveis.

Pode ser observado que na maioria dos métodos as imagens WTH41 apresentaram os melhores resultados de correlação, provavelmente por esse tipo de correção equilibrar a imagem de forma mais homogênea em comparação com os outros métodos utilizados pois, o WTH leva em consideração as regiões da imagem de forma discreta.

Os tempos de processamento para a obtenção dos valores de dimensão fractal, entropia, energia, variância e homogeneidade são praticamente os mesmos. Porém, os descritores de textura apresentam um pouco menos de esforço computacional e altos valores de coeficiente de correlação, sendo os método mais adequados para implementação no dispositivo móvel.

Dentre os descritores de textura a variância se mostra inviável pois requer a aplicação de dois processos de correção de iluminação, onerando o pré- 
processamento digital. O uso do método da energia é interessante pela correção por Sobel, porém, no ajuste linear, o coeficiente angular baixo pode induzir a grandes erros para pequenas variações, inviabilizando o uso deste método. Os métodos baseados na entropia e homogeneidade se mostram os mais adequados para analisar o sistema em estudo, entretanto, a entropia foi selecionada para ser implementada devido ao menor esforço computacional para seu cálculo.

Nos próximos itens serão apresentados os resultados relacionados às alterações nas imagens, com respeito a sua iluminação, tamanho, aumento e resolução para avaliar a influência desses parâmetros nos valores de entropia das imagens.

\subsubsection{Comportamento dos valores da entropia em função da alteração da luminosidade das imagens}

Como forma de verificar o comportamento da entropia com a alteração da luminosidade natural das imagens, porém, sem alteração da textura, as imagens tiveram os valores de gama ajustados e as imagens resultantes são apresentadas na figura 55. O valor de gama igual a 100 representa a imagem sem modificação. Para esta análise foram tomadas cinco imagens $0 \% A I A$ OR, e para cada uma delas o gama foi modificado conforme ilustrado na figura 55. Desta forma, os valores da entropia foram calculados a partir das imagens contendo essas alterações nos valores de gama. 
a)

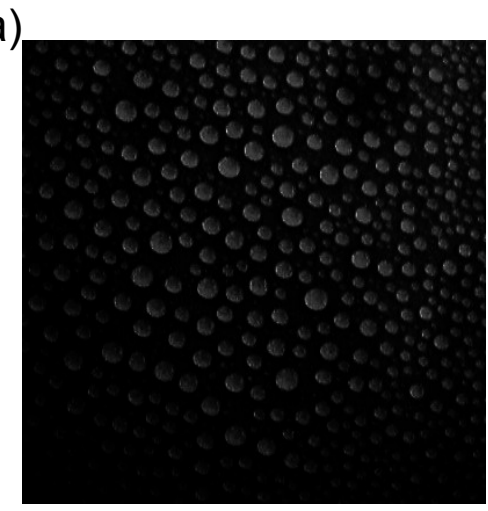

d)

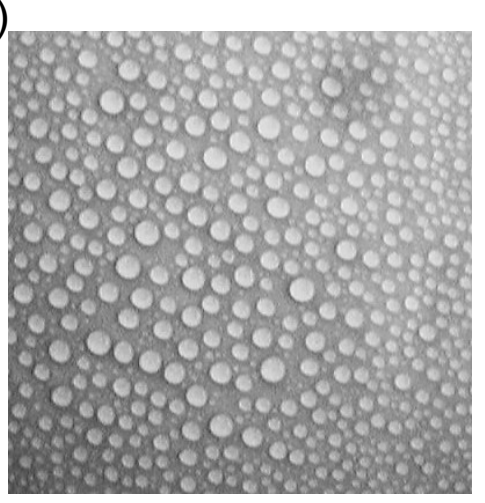

b)

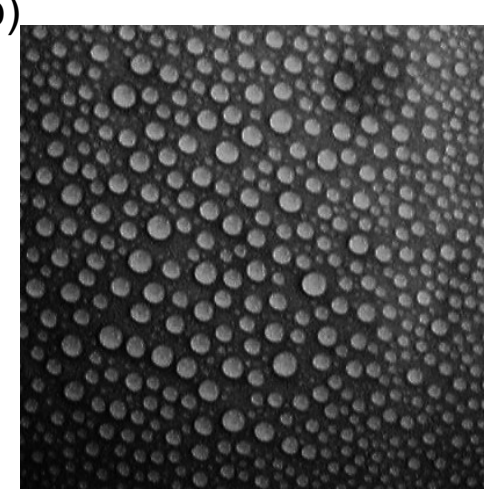

e)

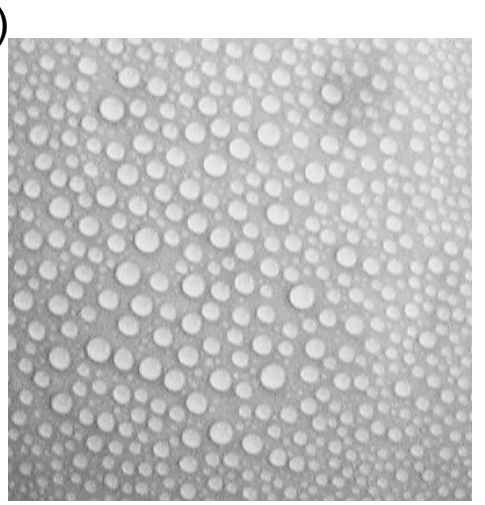

c)

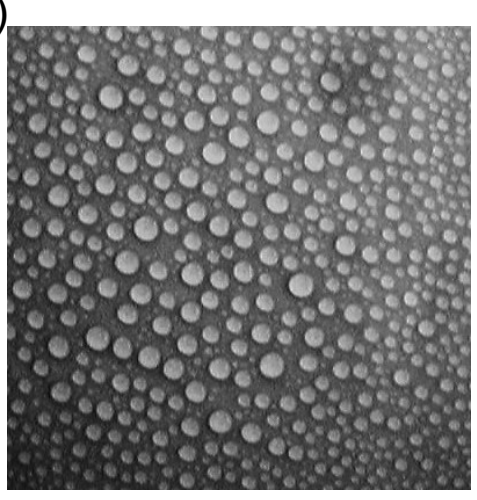

f)

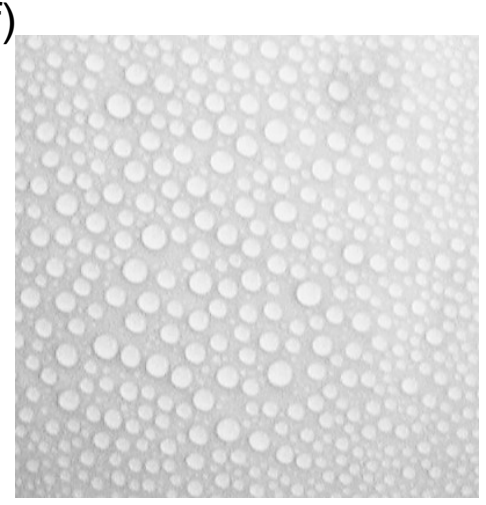

Figura 55. Imagem 0\%AIA OR com ajuste de gama nas seguintes condições: a) 10, b)30, c)50, d) 100 , e) 150 e f) 300 .

A figura 56 apresenta os valores de entropia para as imagens com alteração do gama. Neste caso, pode ser observado o menor desvio para as imagens WTH41 em relação aos outros tipos de imagem. Nesta análise, o desvio é de aproximadamente $7 \%$, resultado que confirma a entropia como sendo o método que pode ser implementado independente das condições de iluminação do ambiente. 


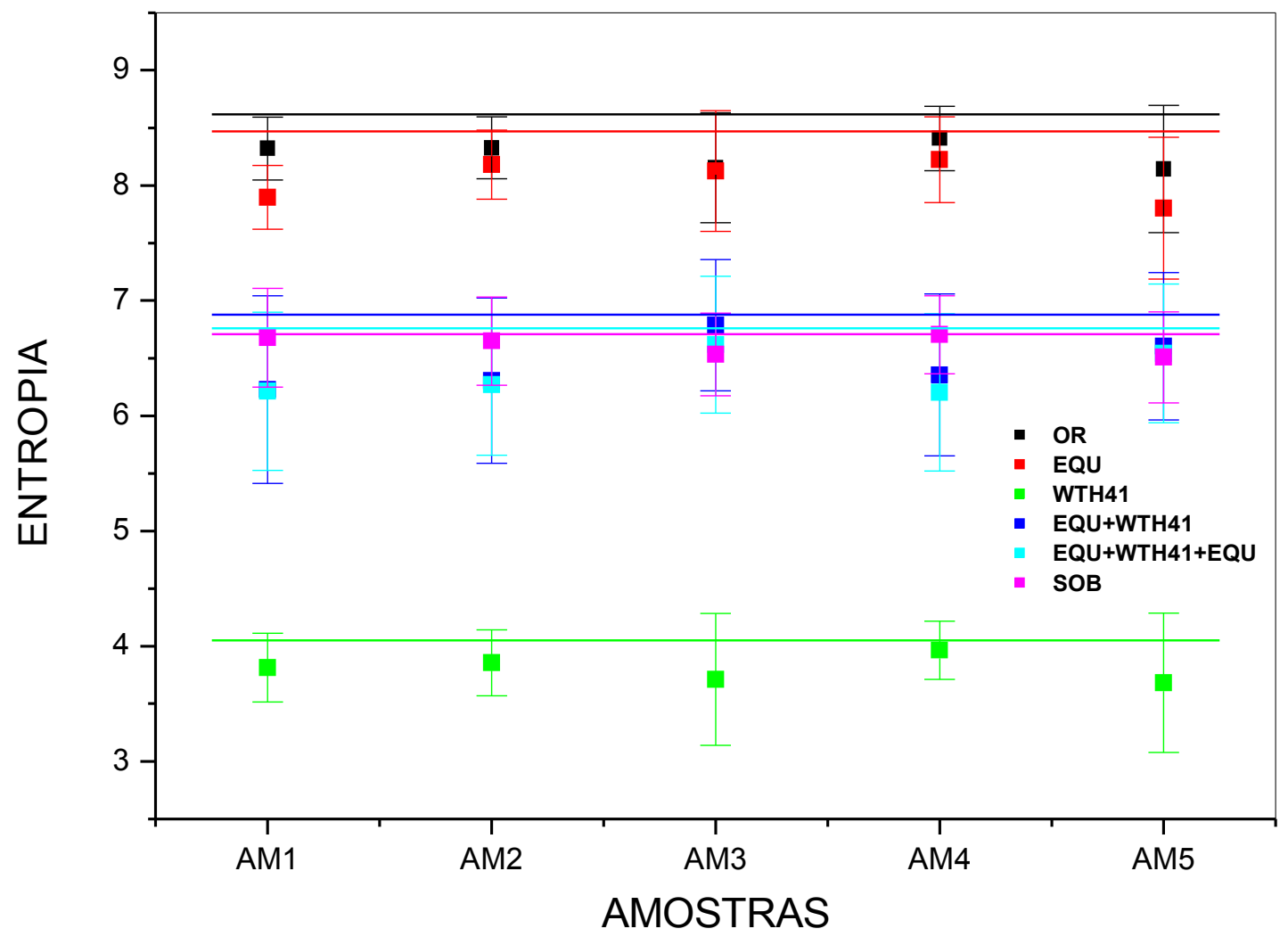

Figura 56. Entropia em função de imagens $0 \%$ AIA OR contendo alterações nos valores de gama.

\subsubsection{Resultados de entropia para diferentes resoluções, escalas e tamanhos de imagens}

A resolução, o escala e o tamanho das imagens foram outros parâmetros analisados com relação à determinação dos descritores. Para isso, foi selecionada uma imagem OAIA\% OR de $1800 \times 1800$ pixels cujo tamanho foi gradativamente reduzido sem alteração da cena analisada. A figura 57 mostra uma imagem a) $200 \times 200$, b) $600 \times 600$ e c) $1000 \times 1000$ para ilustrar o efeito desta variação. 
a)

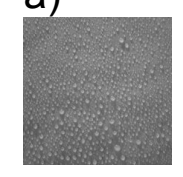

b)

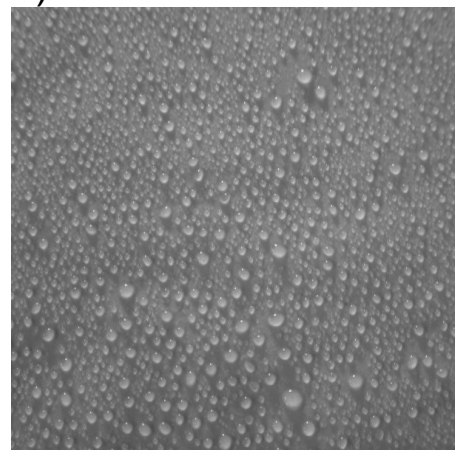

c)

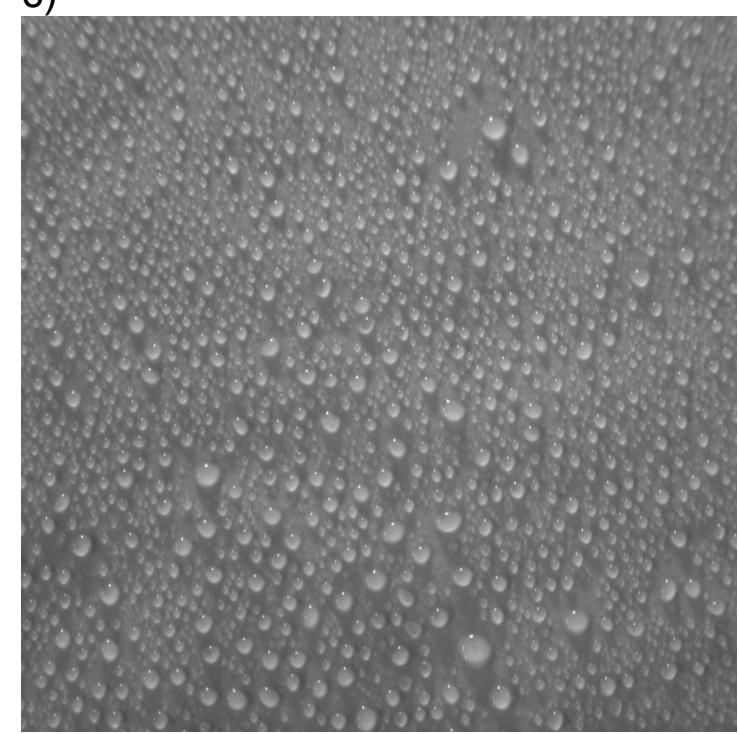

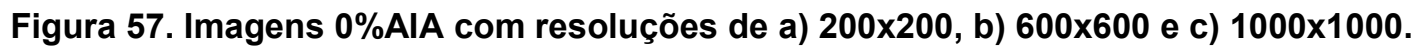

Pode ser observado o gradativo aumento na nitidez da imagem a medida em que se aumenta a quantidade de pixels na cena. Isso aumenta a discretização da imagem, o que influência o cálculo da entropia, como discutido na sequência.

Para a avaliação da influência do tamanho da imagem nos valores da entropia, uma imagem OAIA\% OR de 1800 × 1800 pixels foi recortada em diversas imagens cujos tamanhos variaram de 200×200 até 1800×1800 pixels. A figura 58 mostra as imagens 0\%AIA OR recortadas em a) $200 \times 200$, b) $600 \times 600$ e c) $1000 \times 1000$.

Este procedimento permitiu analisar o tamanho da imagem ideal para ser aplicada ao método, procurando reduzir o tempo de processamento. Pode ser observado na figura 60 que os valores de entropia apresentam pouca variação em função do tamanho da imagem. Porém, o uso de imagens com tamanho muito 
reduzido podem interferir nos valores de entropia para imagens de AIA superiores, pois podem não contemplar regiões representativas da textura.

a)

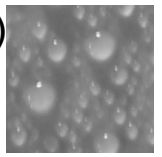

b)

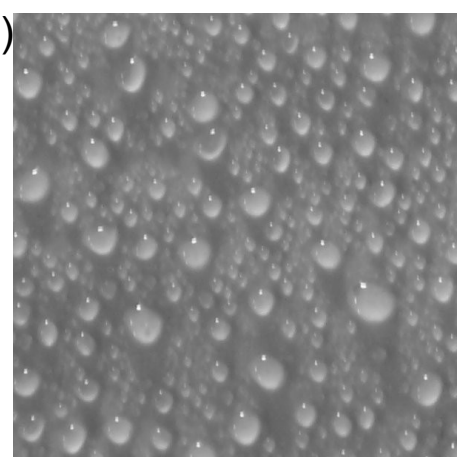

c)

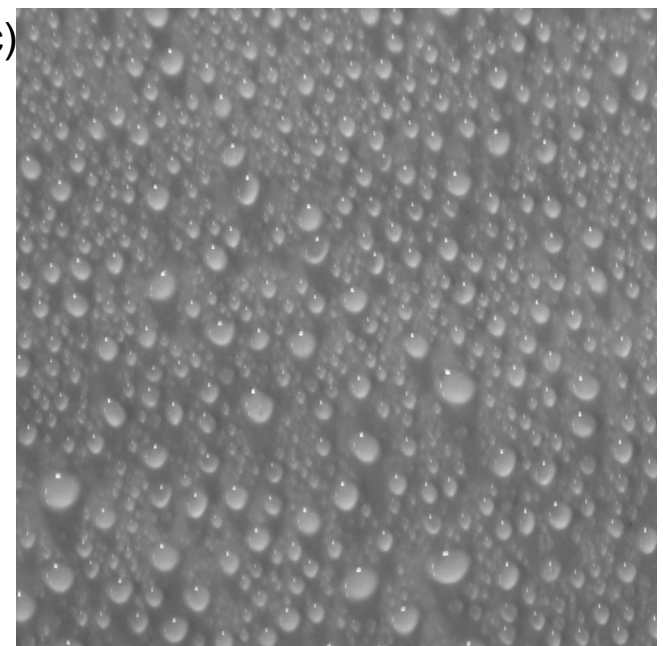

Figura 58. Imagens 0\%AIA OR com tamanho de a) $200 \times 200$, b) $600 \times 600$ e c) $1000 \times 1000$.

A figura 59 mostra as imagens obtidas a partir da escala das imagens apresentadas na figura 58.

a)

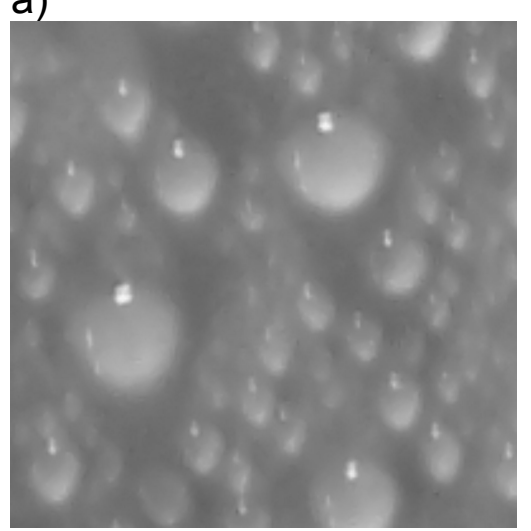

b)

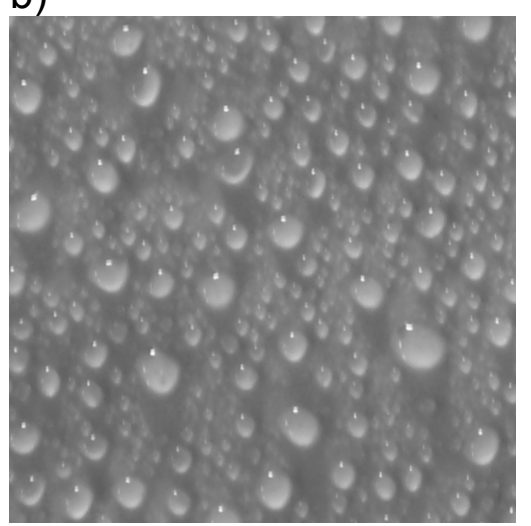

c)

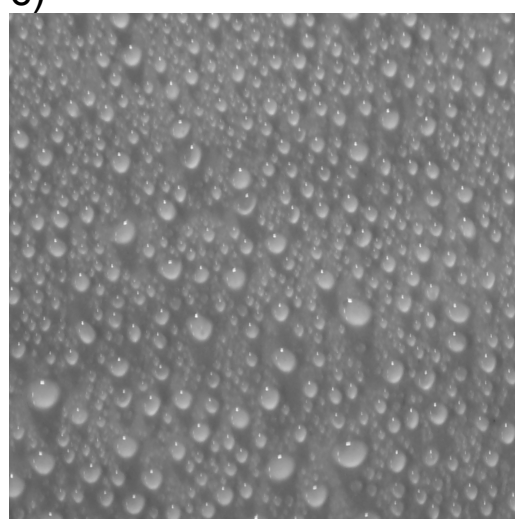

Figura 59. Imagens 0\%AIA OR com tamanho de 1800x1800 aumentadas a partir de imagens de

a) $200 \times 200$, b) $600 \times 600$ e c) $1000 \times 1000$. 
Pode ser observado o efeito de aproximação ou afastamento da cena de interesse. Da mesma forma que descrito anteriormente, na discussão sobre a influência sobre o tamanho da imagem, diferentes distâncias de tomada da cena pelo operador influência os valores da entropia, porque áreas representativas da textura podem ficar suprimidas. Além disso, pode haver o efeito da interpolação gerada pela câmera fotográfica digital. Essa inferência pode ser observada a partir dos valores crescentes de entropia em função do aumento das imagens, na figura 60 , que será discutida a seguir.

A figura 60 mostra o comportamento da entropia em função da resolução, do tamanho e da escala das imagens 0\%AIA OR.

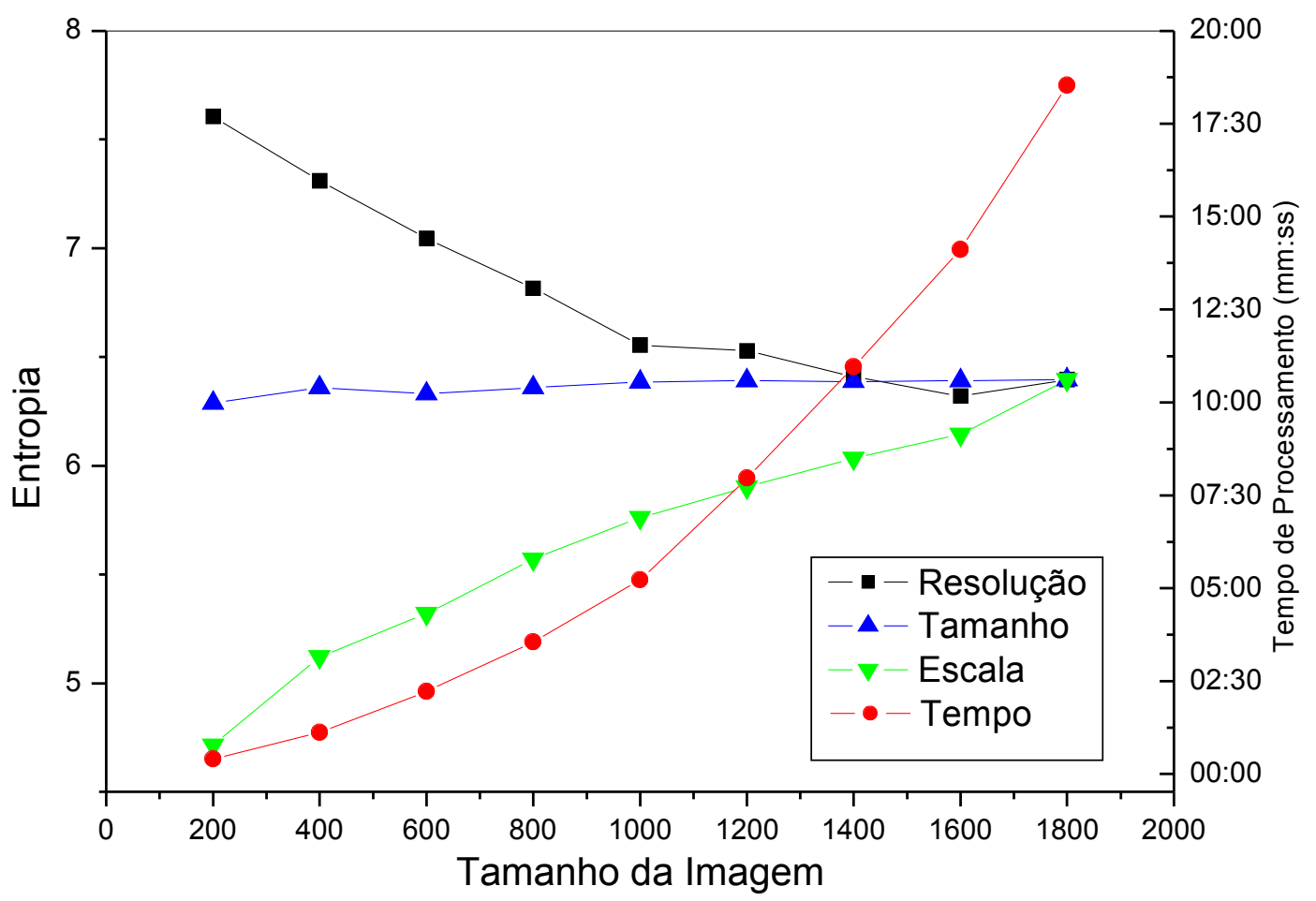

Figura 60. Entropia e tempo de processamento em função da resolução, do tamanho e da escala para diferentes tamanhos de imagens. 
De acordo com Gonzalez ${ }^{8}$, a normalização da GLCM em função do tamanho da imagem não deve modificar os valores dos descritores de textura. Porém, nota-se uma gradual redução do valor da entropia com o aumento do resolução da imagem, estabilizado-se para imagens acima de $1000 \times 1000$ pixels. Isso pode ter sido causado pelos arredondamentos na interpolação após a redução no tamanho da imagem, interferindo na obtenção da GLCM.

Observando o comportamento dos valores da entropia em função do tamanho das imagem, nota-se que praticamente não houve alterações desse parâmetro, obtendo-se uma correlação de 0,92 entre os pares e um coeficiente angular de 6,7 x $10^{-5}$ em um ajuste linear.

\subsubsection{Modelo para Classificação da Hidrofobicidade}

A partir dos resultados foi possível obter funções entre as texturas geradas e o grau de molhamento da superfície. De acordo com a figura 34 e o guia STRI não seria possível determinar a HC das superfícies através do ângulo de molhamento. Porém, através da figura 35 pode ser observada a gradativa evolução da textura, e conseqüentemente aumento do molhamento da superfície. Assim, poderia-se propor a classificação da hidrofobicidade com a utilização dos modelos apresentados nas equações 45, 46, 47 e 50. Porém, de forma a reduzir o tempo de processamento, principalmente em dispositivos móveis, a determinação da entropia se mostra mais eficiente na implementação do método proposto, como discutido no item 99 
Desta forma, o método para a classificação da hidrofobicidade deverá ser realizado da seguinte forma:

1)Início;

2)Obtenção da imagem em escala de cinza;

3)Aplicação do filtro WTH41;

4)Obtenção da GLCM;

5)Cálculo da entropia;

6)Cálculo do AIA baseado na eq. 47;

7)Fim.

Assim, um algoritmo baseado neste fluxograma foi implementado em um dispositivo portátil baseado no sistema operacional Windows Mobile ${ }^{\circledR}$ para a classificação da hidrofobicidade dos isoladores elétricos.

\subsubsection{Aplicativo embarcado em dispositivo móvel para determinação da} hidrofobicidade

A figura 61 mostra o emulador de um smartphone utilizando o sistema operacional Windows Mobile ${ }^{\circledR}$ 6. Os testes da aplicação, relacionados ao código, velocidade de processamento e resultados obtidos a partir do algoritmo proposto foram inicialmente simulados com essa ferramenta. Baseados nestas simulações o aplicativo foi testado em um aparelho real, no caso um TREO750 ${ }^{\circledR}$ da Palm ${ }^{\circledR}$. 


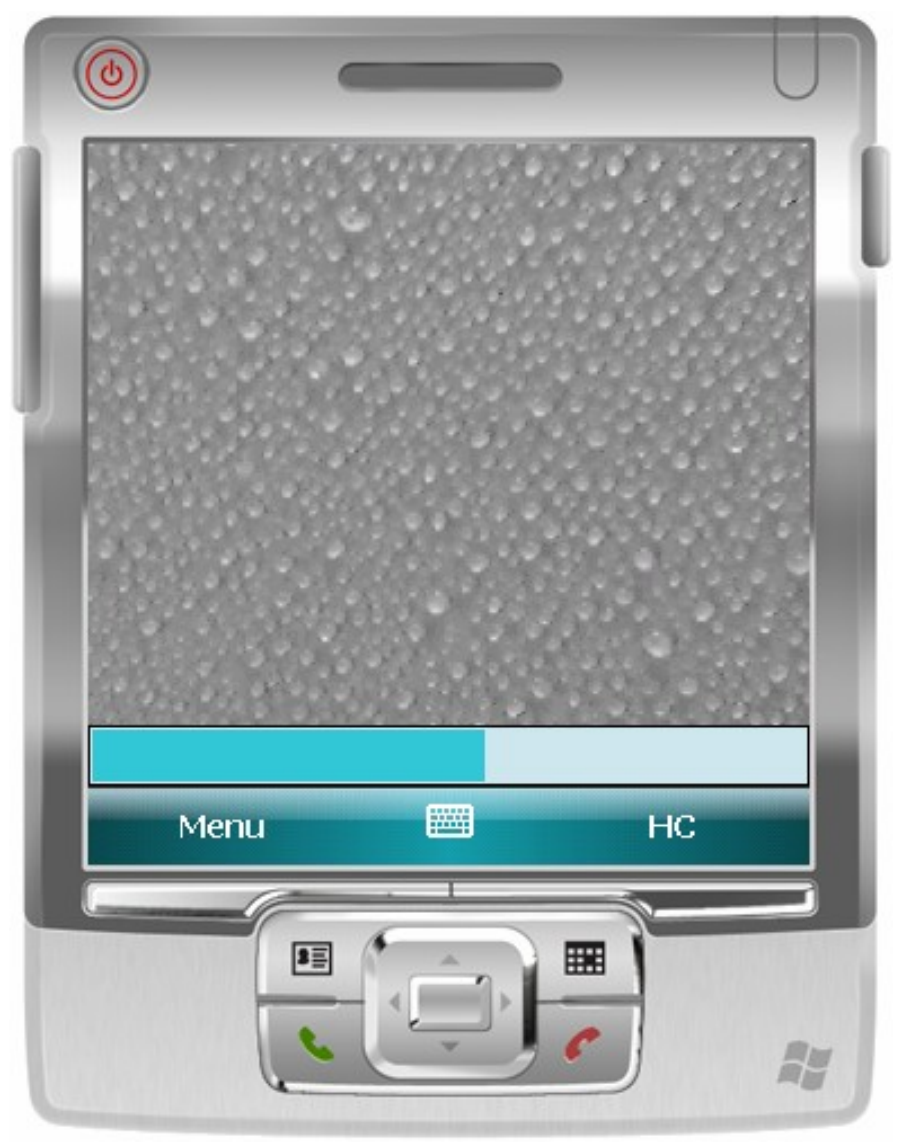

Figura 61. Emulador do smartphone em operação durante a análise de uma imagem.

Neste aplicativo foram colocadas as seguintes funcionalidades:

-Abertura de uma imagem gravada;

- Captura de uma imagem pela câmera fotográfica do aparelho;

•Aplicação do filtro WTH41 na imagem;

-Análise da imagem utilizando o modelo baseado na entropia;

-Envio de e-mail com os resultados da análise e a imagem anexada;

•Exibição da HC baseada na equação 47. 
Desta forma a hidrofobicidade de isoladores elétricos poliméricos pode ser classificada a partir de imagens obtidas em campo, sem a avaliação subjetiva do operador de manutenção das linhas de transmissão, em aproximadamente um minuto. 


\section{Capítulo 5- CONCLUSÕES}

Um método não destrutivo foi desenvolvido para classificar a hidrofobicidade (HC) de superfícies de isoladores poliméricos. A partir deste método foi criado um aplicativo em microcomputador para a determinação da $\mathrm{HC}$ em isoladores elétricos utilizando o processamento digital de imagem com a aplicação das ferramentas computacionais de morfologia matemática, dimensão fractal e descritores de textura.

Diversos ajustes nas imagens como, equalização de histograma (EQU), filtro White top-hat (WTH) e detecção de borda por Sobel (SOB) foram realizados para minimizar as diferenças de iluminação nas imagens e obter resultados da HC mais precisos, reduzindo a dispersão dos valores. O estudo destes recursos permitiram ainda avaliar tempo do processamento computacional. Dentre esses ajustes, o filtro White Top-Hat foi o mais eficiente pois em geral, os resultados das ferramentas aplicadas com esse ajuste apresentaram os menores desvios.

Não pôde ser observada uma tendência matemática a partir dos resultados obtidos por morfologia matemática. Isso foi causado devido à falta de uniformidade 
das gotas sobre a superfície, afetando de forma significativa o ajuste do elemento estruturante ao objeto de interesse na imagem. Porém, pôde ser obtida uma relação linear entre a derivada do volume da abertura em função das imagens de AIA para o elemento estruturante de tamanho $3 \times 3$. Neste caso, o melhor resultado foi obtido para as imagens EQU, com um coeficiente de correlação de 0,998. O maior impedimento no uso deste método é o alto tempo de processamento, aproximadamente 40 s.

Os valores de dimensão fractal obtidos através do método de box-counting mostraram uma tendência à convergência bastante significativa, apresentando uma pequena dispersão, tornando este método confiável. Apesar disso, os resultados obtidos para as imagens com a aplicação do filtro WTH41 apresentaram uma tendência exponencial e um coeficiente de correlação $(0,740)$ baixo inviabilizando o uso deste método. Outro impedimento observado foi a limitação no tamanho das matrizes geradas utilizando este método uma vez que há necessidade de alocação de muita memória RAM durante o processamento.

A análise das imagens utilizando os descritores de textura, através do método baseado na entropia e homogeneidade, apresentaram uma dispersão reduzida nos resultados, credibilizando estes descritores. Além disso, os resultados obtidos através destes descritores também apresentaram um comportamento linear, podendo ser facilmente implementados. Porém, o cálculo da entropia requer menos esforço computacional do que da homogeneidade, sendo selecionado neste estudo.

A modificação no gama das imagens simulou alterações em suas iluminações. Observou-se que os valores de entropia sofreram pouca variação sob a 
modificação da iluminação, indicando que esse descritor é apropriado para uso em campo.

Observou-se uma pequena variação da entropia em função do tamanho de imagens 0\%AIA OR recortadas. Para imagens de diferentes resoluções, ou seja, de mesma cena e alteração no tamanho, os valores de entropia decresceram para imagens com resolução até $1000 \times 1000$ permanecendo constante após este valor, porém o aumento do tamanho da imagem reflete diretamente no esforço computacional, não sendo interessante para a implementação em dispositivos móveis. A análise das imagens com diferentes escalas mostrou que os valores de entropia são diretamente proporcionais a ela, isso pode ser decorrente da interpolação gerada pelo sistema fotográfico, reduzindo a discretização e a dispersão dos valores da matriz de co-ocorrência (GLCM), diminuindo os valores de entropia.

Foi elaborado um aplicativo que captura as imagens a partir da câmera de um smartphone TREO750, aplica o filtro WTH41 e calcula a entropia da imagem, fornecendo rapidamente (40 s) ao operador o resultado da classificação da hidrofobicidade do isolador elétrico.

A partir deste trabalho será possível evitar a subjetividade da classificação da HC em isoladores elétricos poliméricos agilizando a manutenção das redes elétricas de alta potência. 


\section{SUGESTÕES PARA TRABALHOS FUTUROS}

O uso do processamento de imagens na análise de materiais poliméricos ainda é bastante incipiente. No caso de isoladores poliméricos, muitos outros estudos podem ser realizados de forma a continuar as pesquisas nesta linha.

Alguns estudos poderiam ser originados a partir deste trabalho, como por exemplo:

-avaliar o comportamento de outros descritores de textura, considerando que neste trabalho foram usados quatro dos catorze descritores sugeridos por Haralick; -avaliar os valores de dimensão fractal, entropia, energia, variância e homogeneidade para as diversas imagens AIA como função de variações no gama, tamanho, escala e resolução das imagens;

- viabilizar a implementação do descrito de textura homogeneidade no dispositivo embarcado;

-realizar a implementação do aplicativo em outros tipos de dispositivos móveis (PDA, Pocket PC, Palm, etc), ou ainda, construir um dispositivo dedicado para esta finalidade, visando o aumento na performance da avaliação;

- obter as imagens das texturas utilizando luz polarizada, visando a redução no gradiente de iluminação;

-avaliar a hidrofobicidade em campo utilizando um material de sacrifício;

-avaliar o efeito da degradação em função da posição de exposição em relação ao isolador (base, meio ou topo). 


\section{REFERÊNCIAS BIBLIOGRÁFICAS}

1 HACKAM, R. Outdoor high voltage composite polymeric insulators. Trans. On Dielectric and Electric, v. 6, n. 5, p.557-585, 1999.

2 KIKUCHI, T.;NISHIMURA, S.; NAGAO, M.; IZUMI, K.; KUBOTA, Y.; SAKATA, M. Survey on the Use on Non-Ceramic Composite Insulator, Trans. On Dielectric and Electric Insulation, v. 6, n. 5, p.548-556, 1999.

3 SHERIF, E. M. Performance and aging of HVAC and HVDC overhead line insulators. Ahalmes Institute of Technology, Suécia, 1987.

4 GORUR, R. S.; CHANG, J. W.; AMBURLEY, O. G. Surface hydrophobicity of polymers used for outdoor insulation. IEEE Trans. on Power Delivery, v. 5, n.4, p.1923-1933, 1990.

5 ERMELER, K. and PFEIFER, W. About the correlation between the hidrophobicity and impulse withstand voltage characteristics of insulation materials surfaces under humidity conditions. In: ANNUAL REPORT CONFERENCE ON ELECTRICAL INSULATION AND DIELECTRIC PHENOMENA. Proceedings... IEEE, 2001.

6 WANKOWICZ, J. G.;GUBANSKI, S. M.; LAMPE, W. D. Loss and recovery of hydrophobicity on RTV coating surfaces. IEEE Trans. on Dielectrics and Electrical Insulation. v. 1, n. 4, p. 604-614, 1994.

7 IEC 60507 Ed. 2.0 b:1991, Artificial pollution tests on high-voltage insulators to be used on A.C. systems.

8 GONZALEZ, R.C. and WOODS, R.E., Digital Image Processing, $2^{\mathrm{a}}$ ed., New Jersey: Addison-Wesley, 1992, 793 p.

9 SOILLE, P., Morfological Image Analysis : principles and applications, $2^{\text {a }}$ ed., Berlin: Springer, 2003, 391 p.

10 SARAIVA, D. B., Isolantes e dielétricos, in Materiais Elétricos, Rio de 


\section{REFERÊNCIAS BIBLIOGRÁFICAS}

Janeiro: Guanabara Koogan, 1988, p. 98-107.

11 Santa Terezinha, Transmissão e Isoladores Elétricos - Porcelana: catálogo, São Paulo, 10 p, 2007.

12 Saint-Gobain, Transmissão e Isoladores Elétricos - Vidro: catálogo, São Paulo, 13 p, 2007.

13 Balestro, Isoladores Poliméricos para Alta Tensão: catálogo, São Paulo, 4 p, 2007.

14 Weathering 101, Q-Panel Lab products: catálogo, 2000.

15 MONTENEGRO, I. N. S; FILGUEIRA, A. R. M; ALMEIDA NETO , J. N. de, Corrosão Atmosférica no Estado do Ceará, In: II CONGRESSO DE INOVAÇÃO TECNOLÓGICA EM ENERGIA ELÉTRICA, Anais... 2003, p.61.

16 INONE , P. C.; PIAZZA, F.; TOMIOKA, J.; SALES, J. M. M., Caracterização de Isoladores Poliméricos Envelhecidos Artificialmente, In: II CONGRESSO DE INOVAÇÃO TECNOLÓGICA EM ENERGIA ELÉTRICA, Anais... 2003, p. 520.

$17 \mathrm{JIZ}, \mathrm{Z}$. and GUAN, Z; The discharge along hydrophobic and hydrophilic surfaces. In: INTERNATIONAL SYMPOSIUM ON ELECTRICAL INSULATION. Conference Report..., IEEE, 2002.

18 STRI, Classificação da Hidrofobicidade em Isoladores Elétricos - STRI Guide 92/1: catálogo, Suécia, 9 p, 1992.

19 ALLAN, D.; BLUNDELL, M.; BOYD, K.; HINDE, D. New techniques for monitoring the insulation quality of in-service high voltage apparatus, IEEE Transactions on Electrical Insulation, v. 27, n. 3, p.578-585, 1992.

20 BERG, M.; THOTTAPPILLI, R.; SCUKA, V.; A digital image processing method for estimating the level of hydrophobicity of high voltage polymeric 


\section{REFERÊNCIAS BIBLIOGRÁFICAS}

insulating materials, In: CONFERENCE ON ELECTRICAL INSULATION AND DIELECTRIC PHENOMENA, Proceedings..., IEEE, 1999.

21 TOROTO, T.; NAGAO, M.; KOSAKI, M. Image analisys of hidrophobicity of polymer insulators by observing at microscopic area, In: CONFERENCE ON ELECTRICAL INSULATION AND DIELECTRIC PHENOMENA, Proceedings..., p.226-229, IEEE, 2000.

22 SANKOWSKI, D.; STRZECHA, K.; JEZEWSKI, S. Computerized device with CCD camera for measurement of surfaces tension and wetting angle in solidliquid systems, In: INSTRUMENTATION AND MEASUREMENT TECHNOLOGY CONFERENCE, Proceedings..., 2001. IMTC 2001.

23 KARADY, G. G.; AMATH, F.; SUNDARAJAN, R. Dynamic modeling of AC flashover characteristics, In: HIGH VOLTAGE ENGINEERING SYMPOSIUM, Conference Publication..., n.467, IEEE, 1999.

24 REY, J. P.; JANDRELL, I. R.; REYNDERS, S. M. Review of aging recovery of silicon rubber insulation for outdoor use, IEEE Trans. on Dielectric and Electrical Insulation, v. 6, n. 5, p.620-631, 1999.

25 LYMAN, W. J.; ROSENBLATT D. H.; REEHL, W. J., Handbook of Chemical Property Estimation: Environmental Behavior of Organic Compounds, American Chemical Society, Washington: Mcgraw-Hill, 1990, $960 \mathrm{p}$.

26 HANSCH, C., QUINLAN, J.E.; LAWRENCE, G. L. The Linear Free-Energy Relationships between Partition Coefficients and the Aqueous Solubility of Organic Liquids, J. Org. Chem., v. 33, p. 347-50, 1968.

27 VEITH, G.D., MACEK, K.J.; PETROCELLI, S.R.; CARROLL, J. An Evaluation of Using Partition Coefficients and Water Solubility to Estimate 


\section{REFERÊNCIAS BIBLIOGRÁFICAS}

Bioconcentration factors for Organic Chemicals in Fish, J. Fish. Res. Board Can., 1980.

28 WU, S. Polymer Interface and Adhesion, New York: Marcel Dekker-Inc., 1982, $630 \mathrm{p}$.

29 TOKORO, T.; NAGAO, M.; KOSAKI, M. Image Analysis of Hidrophobicity of silicone rubber insulator, In: ANNUAL REPORT CONFERENCE ON ELECTRICAL INSULATIONS AND DIELECTRIC PHENOMENA (CEIDP), Proceedings..., IEEE, Piscataway, NJ, USA, v.2, pp. 763 - 766, 1999.

30 TOKORO, T.; YANAGIHARA, S.; KOSAKII, M. Diagnosis of Hydrophobic Condition of Silicone Rubber using Dielectric Measurement and Image Analysis, In: ANNUAL REPORT CONFERENCE ON ELECTRICAL INSULATION AND DIELECTRIC PHENOMENA,Proceedings..., IEEE 2005.

31 TOKORO, T.; IWASAKI, T. and KOSAKI, M., Diagnosis of hydrophobic condition of polymer materials using dielectric measurement and image analysis, In: ANNUAL REPORT CONFERENCE ON ELECTRICAL INSULATION AND DIELECTRIC PHENOMENA,Proceedings..., IEEE 2004.

32 ZHENYU LI, Xidong LIANG, Yuanxiang ZHOU, Jing TANG, Jifeng CUI, Yaxin LID, Influence of temperature on the hydrophobicity of silicone rubber, In: ANNUAL REPORT CONFERENCE ON ELECTRICAL INSULATION AND DIELECTRIC PHENOMENA,Proceedings..., IEEE 2004.

33 ALTAFIM, R. A. C.; SANTANA, A. M.; MURAKAMI, C. R.; BASSO, H. C.; CHIERICE, G. O.; NETO, S.C., Hydrophobicity of polyurethane resins, In: 2004 IEEE INTERNATIONAL CONFERENCE ON SOLID DIELECTRICS, Proceedings..., v. 1, 5-9 July 2004, p. 452-455.

34 SANTANA, A. M., Desenvolvimento de sistema para medição de 


\section{REFERÊNCIAS BIBLIOGRÁFICAS}

hidrofobicidade em materiais poliméricos. 2004, 78 f. Dissertação (Mestrado em Engenharia Elétrica) - EESC, Universidade de São Paulo, São Carlos, 2004.

35 BERG, M. Estimation of hidrophobicity of insulating surfaces by studying sessile water drops, Acta Universitatis Upsalienis, Uppsala Dissertations from the faculty of Science and Tecnology 33, Uppsala Sweden, 2001. ISBN 91-554-5060-1.

36 BERG, M.; THOTTAPPILLIL, R.; SCUKA, V. Hidrophobicity estimation of HV polymeric Insulating Materials - Development of a digital image processing method, IEEE Trans. on Dielectric and Electrical Insulation, v. 8, n. 6., p. 1098-2007, 2001.

37 TOKORO, T.; INOKI, T.; WADA, E. Diagnosis of Degradation Condition of Silicone Rubber Using Hydrophobic Surface Anaysis, In: 2008 INTERNATIONAL SYMPOSIUM ON ELECTRICAL INSULATING MATERIALS (ISEIM2008) IEEE, Proceedings... Mie, Japan, p.89, 2008.

38 HARALICK, R. M.; SHANMUGAM, K.; DINSTEIN, I., Textural Features for Image Classification, IEEE Trans. On System, Man, and Cyb., v. 3 SMC-3, n.6, p.610-621, 1973.

39 RUSS, J.C., The Image Processing Handbook, $5^{\text {th }}$ ed. CRC: New York, 2006, 832 p.

40 Weeks, Jr, A.R., Fundamentals of Electronic Image Processing, New York: Wiley-IEEE Press, 1996, 576 p.

41 WOLF, G., Usage of Global Information and Priori Knowledge for Object Isolation, In: $8^{\text {TH }}$. INT. CONGR. STEROL., Proceedings... Irvine, CA, pp 56, 1991. 


\section{REFERÊNCIAS BIBLIOGRÁFICAS}

$42 \mathrm{FACOH}$, Jaques. Processamento e análise de imagens, Cordoba: Universidad Nacional de Cordoba, 1993, 198p.

43 PRODANOVA, D.; HEEROMAC, J.; MARANIA E., Automatic morphometry of synaptic boutons of cultured cells using granulometric analysis of digital images, Journal of Neuroscience Methods, v. 151, n. 2, pp. 168-177, 2006.

44 Merriam - Webster Dictionary, http://www . merriam - webster . com / dictionary / recursion, acesso em 04 de julho de 2008.

45 Merriam - Webster Dictionary, http:// www . merriam - webster . com / dictionary / iteration, acesso em 04 de julho de 2008.

46 Recursive Algorithm, http:// www.cs.odu.edu / toida/ nerzic/ content/ recursive_alg/ rec_alg.html, acesso em 29 de julho de 2006.

47 SOILLE, P., TALBOT, T., Directional Morphological Filtering, IEEE Transactions on Pattern Analysis and Machine Intelligence, v. 23, n. 11, p. 1313-1329, 2001.

48 SARKAR N. e CHAUDHURI, B.B., An Efficient Diferential Box-Couting Approach to Compute Fractal Dimension of Image, IEEE Trans. on Systems, Man and Cybernetics, vol 24, n.1, pp 115-120, 1994.

49 SHANNON, C. E., A Mathematical Theory of Communication, The Bell System Technical Journal, v. 27, p. 379-423, 1948.

50 STOWE, K., Introduction to statistical mechanics and thermodynamics, New York: Wiley \& Sons, 1983, 560p.

51 TUPIN, F., TIGELLE, M., MAÎTRE, H., Definition of a spatial entropy and its use for texture discrimination, In: International Conference on Image Processing ICIP 2000 Vancouver, Proceedings... p. 725-728, sept.2000. 


\section{REFERÊNCIAS BIBLIOGRÁFICAS}

52 CHEN, W. S.; YUAN, S. Y.; HSIAO, H. K. and HSIEH C. M., Algorithms to estimating fractal dimension of textured images, In: ICASSP 2001, Proceeding... May, 2001.

53 MANDELBROT, B., Fractal geometry of nature, San Francisco: Freeman, 1982, $468 p$.

54 BARNSLEY, M. F., Fractal everywhere, $2^{\text {nd }}$ ed., Morgan Kaufmann, 1993, $531 \mathrm{p}$.

55 STEVENS, R. T., Fractal programming in C, M\&T Books, 1989, 958 p.

56 PEITGEN, H. O. and RICHER, P. H., The beauty of fractals: Images of Complex Dynamical Systems, New York: Springer, 1986, 211 p.

57 PARKER, T. S. and CHUA, L. O., Practical numerical algorithms for chaotic systems, New York: Springer, 1989, 348 p.

58 FLEISCHMANN, M. et al, Fractals in natural sciences, Priceton: Princeton University Press, 1990, 200p.

59 FISHER, Y. et al, Fractal Image Compression Using Iterated Transforms, in James A.Strorer, ed. Image and Text Compression, pp 35-61. Kluwer Academic Publishers, Boston, MA, 1992.

60 PENTLAND, A. P., Shading into texture, Artificial Intell., vol 29, 1986, p. $147-170$.

61 PELEG, S. et al, Multiple Resolution Texture Analysis and Classification, IEEE Trans. Patt. Anal. Mach. Intell., vol PAMI 6,, p. 5181984.

62 RIGAUT, J. P., .Automated Image Segmentation by Mathematical Morphology and Fractal Geometry, J. Microsc., pp 21-30, 1988.

63 MECHOLSKY, J. J. et al, Quantitative Analysis of Brittle Fracture Surfaces Using Fractal Geometry, J. Am. Ceram. Soc., p. 60, 1989. 


\section{REFERÊNCIAS BIBLIOGRÁFICAS}

64 FAHMY,Y. et al, Application of Fractal Geometry Measurements to the Evaluation of Fracture Toughness of Brittle Intermetallics, J. Mater. Res., n. 6, v.9, p. 1856-186, 1991.

65 SRINIVASAN, S. et al, "Fractal Analysis of Erosion Surfaces, J. Mater. Res., p. 2616-2619, 1990.

66 UNDERWOOD, E. E., Fractals in Fractography, Mater. Sci. Eng. p. 1, 1986.

67 AVNIR, D. e PFEIFER, P., Fractal Dimension in Chemistry: An Intensive Characteristic of Surface Irregularity, Nouv. J. Chim, v. 7, p 71-72, 1983.

68 ORFORD, J e WHALLEY, W., The Use of Fractal Dimension to Characterize Irregular-Shaped Particle, Sedimetology, v. 30, p. 665-668, 1983.

$69 \mathrm{KAYE}$, B.H., Image analysis procedures for characterizing the fractal dimension of fine particles, In: PART. TECHNOL. CONF., Proceedings... 1986.

70 PROENÇA, C. B., Investigação Para a Detecção de Automática de Falhas em Tecidos Têxteis, 1997, Tese (Doutorado em Engenharia Mecânica) - Departamento de Engenharia Mecânica, Pontifícia Universidade Católica do Rio de Janeiro, Rio de Janeiro, 1997.

$71 \mathrm{CONCl}$, A. e PROENÇA, C. B., A Box Counting Approach for Color Segmentation, In: INTERNATIONAL CONFERENCE ON IMAGE PROCESSES - ICIP'97, Proceedings... Santa Barbara, CA, 1997.

72 Departamento de Física da UFJF, O método dos mínimos quadrados, www.fisica.ufjf.br/disciplinas/labfis2/apendice.pdr, acesso em 08 de novembro de 2006.

73 CAMPOS, C. F. J., Um algoritmo para o cálculo da dimensão fractal de imagens, 1996, Dissertação (Mestrado em Engenharia Mecânica) - 


\section{REFERÊNCIAS BIBLIOGRÁFICAS}

Departamento de Engenharia Mecânica, Pontifícia Universidade Católica do Rio de Janeiro, 1996.

74 PELEG, S. et al, Multiple resolution texture analysis and classification, IEEE Trans. Patt. Anal. Mach. Intell. vol PAMI 6 pp 518, 1984.

75 PENTLAND, A. P., Fractal-Based Description of Natural Scenes, IEEE Trans. Pattern Analysis Mach. Intell., vol PAMI-6, n. 6, p. 661-674, 1984.

76 GANGEPAIN, J. e ROQUES-CARMES, C., Fractal Approach to Two Dimensional and Three Dimensional Surfaces Roughness, Wear, v. 109, p. 119-126, 1986.

77 KELLER, J. et al, Texture Description and Segmentation Through Fractal Geometry, Comput. Vision Graphics and Image Processing, v. 45, p. 150160, 1989. 